\title{
Organizational Cynicism: on the nature, antecedents, and consequences of employee cynicism toward the employing organization
}

Citation for published version (APA):

Naus, A. J. A. M. (2007). Organizational Cynicism: on the nature, antecedents, and consequences of employee cynicism toward the employing organization. [Doctoral Thesis, Maastricht University]. Maastricht University Press. https://doi.org/10.26481/dis.20071012an

Document status and date:

Published: 01/01/2007

DOI:

10.26481/dis.20071012an

Document Version:

Publisher's PDF, also known as Version of record

Please check the document version of this publication:

- A submitted manuscript is the version of the article upon submission and before peer-review. There can be important differences between the submitted version and the official published version of record.

People interested in the research are advised to contact the author for the final version of the publication, or visit the DOI to the publisher's website.

- The final author version and the galley proof are versions of the publication after peer review.

- The final published version features the final layout of the paper including the volume, issue and page numbers.

Link to publication

\footnotetext{
General rights rights.

- You may freely distribute the URL identifying the publication in the public portal. please follow below link for the End User Agreement:

www.umlib.nl/taverne-license

Take down policy

If you believe that this document breaches copyright please contact us at:

repository@maastrichtuniversity.nl

providing details and we will investigate your claim.
}

Copyright and moral rights for the publications made accessible in the public portal are retained by the authors and/or other copyright owners and it is a condition of accessing publications that users recognise and abide by the legal requirements associated with these

- Users may download and print one copy of any publication from the public portal for the purpose of private study or research.

- You may not further distribute the material or use it for any profit-making activity or commercial gain

If the publication is distributed under the terms of Article 25fa of the Dutch Copyright Act, indicated by the "Taverne" license above, 


\section{ORGANIZATIONAL CYNICISM ON THE NATURE, ANTECEDENTS, AND CONSEQUENCES OF EMPLOYEE CYNICISM TOWARD THE EMPLOYING ORGANIZATION}

\section{PROEFSCHRIFT}

ter verkrijging van de graad van doctor aan de Universiteit Maastricht

op gezag van de Rector Magnificus Prof. Mr. G.P.M.F. Mols

volgens het besluit van het College van Decanen

in het openbaar te verdedigen op

vrijdag 12 oktober 2007 om 14.00 uur door

Alphons Johannes Aloysius Maria Naus 
Promotor:

Prof. dr. R. A. Roe

Copromotor:

Dr. A. van Iterson

Beoordelingscommissie:

Prof. dr. M.A. Carree (voorzitter)

Prof. dr. J.C. de Ruyter

Prof. dr. W.B. Schaufeli (Universiteit Utrecht)

Prof. dr. C.P.M. Wilderom (Universiteit Twente) 
Cyn-ic:

An idealist whose rose-colored glasses have been removed, snapped in two, and stomped into the ground, immediately improving his vision.

From: The Cynic's Sanctuary

(http://www.i-cynic.com) 


\section{Acknowledgements}

This dissertation could not have been completed without the invaluable help and support of others and this is the appropriate place to give them the credits they deserve.

First of all I would like to thank Rob for having been my supervisor and promotor. Rob, let's not beat around the bush, I know I can be very stubborn and sometimes working with me must have been an ordeal, I guess. However, I want you to know that I learned an awful lot from you. No doubt you will ask me "so what have you learned?" Well, as you know it always takes time to realize what it is exactly that has somehow been learned. It's more like an education, and I want to thank you very much for having been my academic educator!

Next, I am very grateful to Ad. If it were not for you, I could not have even started my $\mathrm{PhD}$ research! At the time when Christophe had left the department, and we were in a vacuum without a full professor, you were the paterfamilias in charge (it's the age, Ad, they don't ask you whether you like these things...) and you were the one who opened up the opportunity for me to do what I so much wanted to do: become a researcher. Thank you very much Ad, I am for ever indebted to you.

More members of the department should be mentioned. First of all there is Sara. Dear Sara, I hope that having been my roommate for almost four years has not taken too much of a toll on you. I feel that we have developed a very special relationship that I wish to cherish for the years to come. I don't have to elaborate on this, we both know! Adela, Eva, and Kitty, you are the spiders in the web. It has always been a pleasure to come over to your office and have a chat about anything (from the latest gossip to a sore back...) that might come up. Woody, Anneloes, Omar, Walter, Jan, Jasper, Stefanie, Jacqueline, Mary, Martin, Boris, Mark, John, Peter B. (2x), Boris, Anita, Ursula, Mieke, and all the others, being with you has been a true source of inspiration.

Finally, there is my family. Dear mother, I know you are extremely proud of what I have accomplished, and sometimes your pride is more than I can handle. But on the other hand, it would be wrong to deny you the right to have motherly feelings, I guess. Therefore, you have my consent, but please keep in mind that a $\mathrm{PhD}$ does not make me a better person. And to the rest of my family, whether you are up there (my dad and my brother Jan) or still with us (Tjeu, Han and Mieke), I hope that somehow you understand what I have been doing all these years. 
Last but most certainly not least, a few words to the ones that have to put up with me on a daily basis. Dear Leen, Luca, and Sara, who and where would I be without you? Need I say more? Thanks so much for your support and patience with me. I will work less and spend more time with you in the future. That's a promise! 


\section{Table of contents}

Chapter 1

\section{Introduction}

1. Organizations and cynicism $\quad 1$

2. Research objectives 3

3. Outline of the dissertation 4

References $\quad 7$

Chapter 2

\section{Literature review}

Abstract 11

1. Introduction $\quad 12$

2. Cynicism in organizations $\quad 12$

3. Conceptualizations of organizational cynicism 25

4. Antecedents of organizational cynicism 26

5. Consequences of organizational cynicism 27

6. Methods, measurement and incidence of organizational cynicism 28

7. Discussion 31

References $\quad 33$

Chapter 3

Value incongruence, job autonomy, and organization-based self-esteem: A self-based perspective on organizational cynicism

$\begin{array}{ll}\text { Abstract } & 37\end{array}$

1. Introduction 38

2. Theory and hypotheses $\quad 39$

2.1 Organizational cynicism and value incongruence $\quad 40$

2.2 Organizational cynicism and job autonomy 41

2.3 The mediating role of organization-based self-esteem $\quad 42$

3. Method 44

3.1 Sample and procedure $\quad 44$

3.2 Measures 45

4. Results $\quad 47$

5. Discussion $\quad 54$

References $\quad 59$ 


\section{Chapter 4}

Organizational cynicism: Extending the exit, voice, loyalty, and neglect model of employees' responses to adverse conditions in the workplace

Abstract

1. Introduction

2. The exit, voice, loyalty, and neglect (EVLN) model 66

2.1 The development of the EVLN model 66

2.2 The EVLN model in organizational research 66

2.3 Conceptualizations of exit, voice, loyalty, and neglect 68

2.4 Expanding the EVLN model with organizational cynicism $\quad 70$

3. Predicting exit, voice, loyalty, neglect, and cynicism 71

$\begin{array}{ll}3.1 \text { Hypotheses } & 72\end{array}$

4. Method 76

4.1 Sample and procedure $\quad 76$

4.2 Measures: dependent variables $\quad 77$

$\begin{array}{ll}\text { 4.3 Measures: independent variables } & 78\end{array}$

5. Results 79

5.1 Factor analysis of the exit, voice, loyalty, neglect, and cynicism 79

5.2 Regression results $\quad 85$

6. Discussion $\quad 87$

References $\quad 90$

Appendix: exit, voice, loyalty, neglect, and cynicism items 95

\section{Chapter 5}

Effects on work outcomes of employees' exit, voice, loyalty, neglect, and cynicism responses to adverse circumstances in the workplace

Abstract

1. Introduction 98

2. Exit, voice, loyalty, neglect, cynicism, and work outcomes 99

2.1 Associations between responses and outcomes: hypotheses 101

3. Method 106

3.1 Sample and procedure $\quad 106$

$\begin{array}{ll}3.2 \text { Measures: work outcomes } & 107\end{array}$

4. Results 108

4.1 Factor analysis of the exit, voice, loyalty, neglect, and cynicism 108 
items

4.2 Descriptive statistics and correlational analyses $\quad 110$

4.3 Using outcome patterns to differentiate EVLNC 115

4.4 The added value of cynicism to the EVLN model 118

5. Discussion 119

$\begin{array}{ll}\text { References } & 123\end{array}$

Chapter 6

Discussion

$\begin{array}{lr}\text { 1. Introduction } & 128\end{array}$

2. Research questions and answers 128

3. Theoretical and methodological strengths and limitations 131

4. Practical implications and considerations 132

5. Future research directions 133

References $\quad 135$

Summary 138

Samenvatting 141

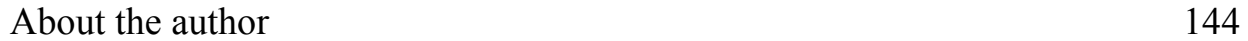




\section{CHAPTER 1}

\section{Introduction}

\section{Organizations and cynicism}

The time when people were largely self-supporting, without organizations to take care of their wants and needs, seems long gone. Especially in the Western world, people no longer provide for their own food, housing, footwear and clothing, health care, education, and other vital and less vital products and services. Over time, more and more of these activities have been taken over by specialized organizations and, not surprisingly, these organizations have become central to our lives. Crossing our path from the cradle to the grave, they satisfy an almost infinite variety of human needs. It is obvious, then, that organizational effectiveness and the motivation and engagement of the persons working to accomplish that effectiveness are of paramount importance.

The question what an organization is and how its effective operation can be ensured has no easy answer. Managerial texts tend to present us with idealized pictures of what organizations should be like and how they should operate. For instance, Daft (2001) defines organizations as goal directed social entities, designed as deliberately structured and coordinated activity systems, and linked to the external environment. Daft argues that the most essential element of organizations is people, working together in a coordinated fashion to meet shared goals. Those organizations that succeed in motivating their employees to accomplish these common goals will likely be effective, those that do not will suffer and eventually cease to exist. On the other end of the spectrum, Morgan argues that 'although we are usually encouraged to think about organizations as rational enterprises pursuing goals that aspire to satisfy the interests of all, there is much evidence to suggest that this view is more an ideology than a reality. Organizations are often used as instruments of domination that further the selfish interests of elites at the expense of others, and there is an element of domination in all organizations' (Morgan, 1998, p. 261). 
Both views can be considered on their own merits. Goals are often clearly stated and employees are often highly motivated to meet those goals, because meeting goals provides them with satisfaction and opportunities for personal growth and development. On the other hand, working can be a stressful experience and officially stated organizational goals can be perceived as ambiguous to the extent that employees become suspicious about the organization's real intent and motives for decisions and practices. Such perceptions may have an impact on employees' motivation and satisfaction, when they start questioning the sincerity and integrity of their organization. In the long run, this may even jeopardize organizational effectiveness and survival. In the past, there used to be a strong emphasis on the positive side of work in organizational research. A large number of studies describe aspects of employee behavior presumed to be beneficial to the organization, such as, among others, job satisfaction (e.g. Cramer, 1995; Judge, 2001), affective organizational commitment (Meyer \& Allen, 1991; Meyer, Irving, \& Allen, 1998; Meyer, Paunonen, Gellatly, Goffin, \& Jackson, 1989; Williams \& Hazer, 1986), and organizational citizenship behavior (Diefendorff, Brown, Kamin, \& Lord, 2002; Moorman, Blakely, \& Niehoff, 1998; Niehoff \& Moorman, 1993). More recently, however, the research focus has somewhat shifted to include constructs that describe less favorable aspects of employee behavior. Examples are work and occupational stress (Cooper, 2001; Ganster \& Schaubroeck, 1991; Gil-Monte, Valcarcel, \& Zornoza, 1993; Kahn, Wolfe, Quinn, \& Snoek, 1981), burnout (Demerouti, Bakker, Nachreiner, \& Schaufeli, 2001; Maslach \& Leiter, 1997; Maslach, Schaufeli, \& Leiter, 2001), and a set of behaviors, including incivility, bullying, and violence in the workplace, subsumed as counterproductive work behavior (Fox \& Spector, 2005).

This dissertation is about one of those less favorable aspects of work and employee behavior: Cynicism toward the employing organization, in the organizational sciences referred to as organizational cynicism (OC). Organizational cynicism is defined as 'a negative attitude toward one's employing organization, comprising three dimensions: (1) a belief that the organization lacks integrity; (2) negative affect toward the organization; and (3) tendencies to disparaging and critical behaviors toward the organization that are consistent with these beliefs and affect' (Dean, Brandes, \& Dharwadkar, 1998, p. 345).

$\mathrm{OC}$ is a somewhat controversial issue. It frequently brings about confusion, irritation, or even antagonism, among those who fail to acknowledge cynicism as something that may develop in the context of work. On the other hand, there is also a great deal of recognition and understanding for those who 
are cynical at work. A few examples will serve to illustrate this apparent paradox. In an article entitled Don't blame cynicism on 'bad apples', BusinessWeek Online cites professor John Wanous from Ohio State University, who studied employee cynicism about organizational change. Wanous found out that 'The pet theory we heard from plant managers was that a rotten core of employees with bad attitudes caused workplace cynicism... But that's not what we found. It wasn't bad apples that caused problems at the company. The problem was that management spoiled the fruit' (Gill, 2000). The popular comic strip Dilbert, sometimes referred to as the icon of workers' cynicism, poses another example of cynicism in the work environment. Dilbert is a pathetic figure, spending all his working life in his cubicle, where he has to endure a never ending series of organizational fads, whims and follies. Dilbert may present us with an abject perspective on organizations and work, but the fact that the strip was syndicated to more than 2000 newspapers in 65 countries leaves little doubt that many workers recognize his situation and probably also identify with it. It seems, therefore, that cynicism is a widely known issue.

Apart from being controversial, cynicism is also an elusive concept, because so far a universal definition across the social sciences is lacking. As will be discussed in the literature review in chapter 2 , the term has made its way in the organization sciences as an occupational attitude toward clients, and as an attitude toward the organization or certain parts of it. The latter form, named organizational cynicism, is the topic of this dissertation.

\section{Research objectives}

Only a limited number of scientific studies has investigated the incidence of organizational cynicism. Available estimates based on studies in the United States suggest that around $50 \%$ of the workforce is cynical toward the employing organization (Kanter \& Mirvis, 1989, 1991; Reichers, Wanous, \& Austin, 1997). At the same time, cynicism has been associated with a host of negative outcomes, such as apathy, resignation, alienation, hopelessness, distrust of others, suspicion, contempt, disillusionment, and scorn, as well as poor performance, interpersonal conflict, absenteeism, job turnover, and burnout (Andersson, 1996; Andersson \& Bateman, 1997; Dean et al., 1998). If cynicism is indeed widespread, and given its potentially serious consequences for the employee and for the organization, it is remarkable why so relatively little scientific effort has been devoted to studying it. Maybe management researcher Lynn Andersson was right when she argued that 'unlike other work attitudes such as job satisfaction and organizational commitment, cynicism is 
generally viewed as negative and is therefore a sensitive topic to managers and organizations. Because of this sensitivity, negative attitudes as well as the organizational practices that foster them have been relatively neglected in management research' (Andersson, 1996, p. 1401).

In this dissertation we accept the challenge to investigate the nature, antecedents, and consequences of organizational cynicism. The negative consequences for the employee, especially health-related problems and burnout (Maslach et al., 2001), indicate that cynicism is not an enjoyable state. For employees to become cynical, there must be something important at stake. In the literature it is suggested that cynicism has to be understood as a form of selfdefense, to cope with and make sense out of puzzling or disappointing events (Reichers et al., 1997). However, apart from Andersson (1996) who couched cynicism in psychological contract theory, and Cole, Bruch and Vogel (2006) who postulated emotions as primary antecedent of cynicism, little theoretical progress has been made thus far. The first aim of this dissertation is to combine multiple perspectives on cynicism, such as self-consistency theory (Korman, 1970, 1976, 2001) and person-organization fit (Kristof, 1996), to arrive at a theoretically based model. The second aim is to investigate antecedents and consequences of cynicism. To this end, cynicism is seen as an employee's response to adverse organizational circumstances and compared with other responses, i.e. exit, voice, loyalty, and neglect (Farrell, 1983; Hirschman, 1970; Rusbult, Farrell, Rogers, \& Mainous III, 1988; Rusbult, Johnson, \& Morrow, 1986; Rusbult \& Zembrodt, 1983; Rusbult, Zembrodt, \& Gunn, 1982). With regard to antecedents, an important question is whether cynicism is rooted in the personality, or whether it is indeed a response developed in reaction to adverse conditions in the work environment. A crucial issue regarding the organizational consequences of cynicism is how these consequences compare to those associated with other responses to adverse circumstances, in particular exit, voice, loyalty, and neglect.

\section{Outline of the dissertation}

In this dissertation we address the following research questions: What is organizational cynicism, why would employees turn cynical toward their employing organization, what is it that makes them cynical, and what are the consequences of their cynicism? The structure of the dissertation is presented in Figure 1. 
Chapter 1: Introduction

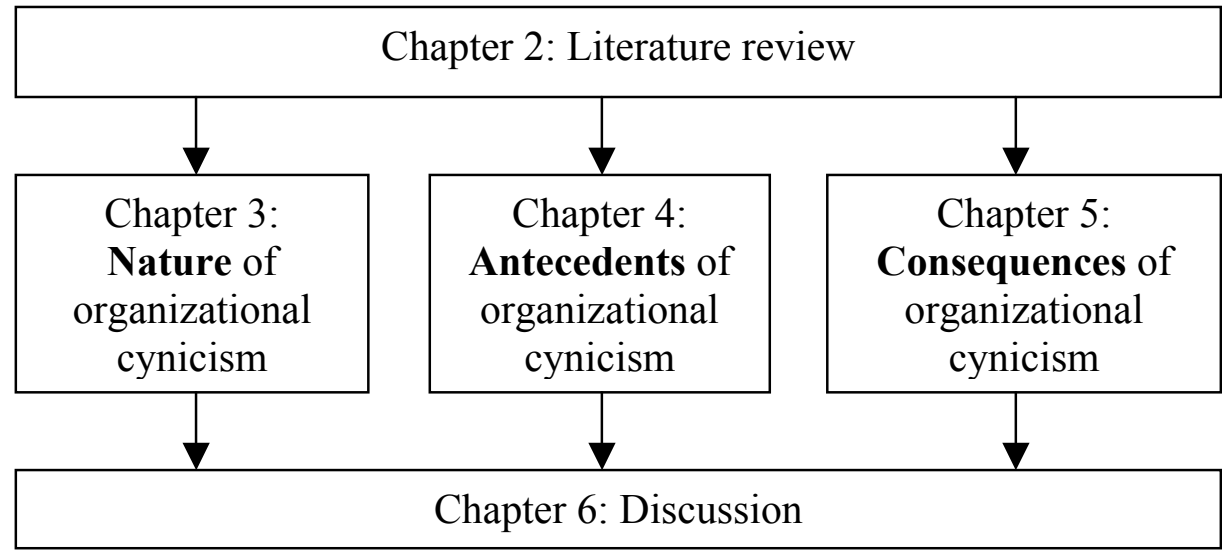

Figure 1. Structure of the dissertation.

The first question will be answered in chapter 2, which presents an overview of the extant literature on employee cynicism. In the work environment, organizational cynicism is identified as a distant employee attitude toward the employing organization.

The question why employees turn cynical is addressed in chapter 3, in which a self-based perspective on cynicism is developed and empirically tested on a sample of 174 employees from various organizations. Taking as point of departure the conceptualization of cynicism as a self-defensive attitude, and based on Korman's $(1970,1976,2001)$ self-consistency theory, a model is developed in which autonomy and incongruence between key personal and organizational values serve as antecedents of cynicism. At the core of the model is organization-based self-esteem (OBSE), described as the self-perceived value employees have of themselves as members of the organization (Pierce, Gardner, Cummings, \& Dunham, 1989). It is hypothesized, and supported, that the relationships between value incongruence and organizational cynicism, and between autonomy and organizational cynicism, will be mediated by OBSE operating as a 'central processing unit'.

In chapter 4 organizational cynicism is considered in a broad perspective, as it is conceptualized as an employee's behavioral reaction to adverse circumstances in the work environment. Clearly, cynicism is not the only conceivable reaction, and therefore it is embedded in the existing exit, voice, loyalty, and neglect model of employee's responses. Data provided by 
159 employees of a large Dutch trade union, experiencing organizational change at the time of the research, will be used to assess the fit of the postulated 5 -factor model with the data. The second aim of this study is to identify antecedents to predict each of the responses. Thus, we seek to understand what it is that makes employees cynical. The situational variables role conflict and autonomy, the personality variables assertiveness and rigidity, and selected interactions between these variables, will be used as antecedents of exit, voice, loyalty, neglect, and cynicism.

In chapter 5 the third empirical study in this dissertation serves two primary aims. First, to replicate the previous study, in order to gain additional support for the inclusion of cynicism in the response model. Data provided by 576 hospital employees will be fitted to the postulated 5-factor model. A second aim of this study is to identify consequences of cynicism and its alternatives, by relating all five responses to a number of resultant employee attitudes, behaviors and experiences. Responses will be related to affective organizational commitment, organizational citizenship behaviors, and in-role behavior in relation to the organization, to job involvement and service orientation related to the job, and to organization-based self-esteem and stress related to the individual employee.

In chapter 6, the major findings are summarized, methodological, theoretical and practical implications as well as limitations are discussed, and suggestions for future research are made. 


\section{References}

Andersson, L. M. (1996). Employee cynicism: An examination using a contract violation framework. Human Relations, 49(11), 1395-1418.

Andersson, L. M., \& Bateman, T. S. (1997). Cynicism in the workplace: some causes and effects. Journal of Organizational Behavior, 18(5), 449-469.

Cole, M. S., Bruch, H., \& Vogel, B. (2006). Emotion as mediators of the relations between perceived supervisor support and psychological hardiness on employee cynicism. Journal of Organizational Behavior, 27, 463-484.

Cooper, C. (2001). Managerial, occupational and organizational stress research. Aldershot, UK: Ashgate.

Cramer, D. (1995). Life and job satisfaction: A two-wave panel study. Journal of Psychology, 129(3), 261-267.

Daft, R. L. (2001). Organization theory and design. Cincinatti: Thomson Learning.

Dean, J. W., Brandes, P., \& Dharwadkar, R. (1998). Organizational cynicism. Academy of Management Review, 23(2), 341-352.

Demerouti, E., Bakker, A. B., Nachreiner, F., \& Schaufeli, W. B. (2001). The job demands-resources model of burnout. Journal of Applied Psychology, $86,499-512$.

Diefendorff, J. M., Brown, D. J., Kamin, A. M., \& Lord, R. G. (2002). Examining the roles of job involvement and work centrality in predicting organizational citizenship behaviors and job performance. Journal of Organizational Behavior, 23(1), 93-108.

Farrell, D. (1983). Exit, voice, loyalty, and neglect as responses to job dissatisfaction: A multidimensional scaling study. Academy of Management Journal, 26(4), 596-607.

Fox, S., \& Spector, P. E. (Eds.). (2005). Counterproductive work behavior: Investigations of actors and targets. Washington, D.C.: American Psychological Association. 
Ganster, D. C., \& Schaubroeck, J. (1991). Work stress and employee health. Journal of Management, 17(2), 235-271.

Gil-Monte, P. R., Valcarcel, P., \& Zornoza, A. (1993). Role stress: Burnout antecedent in nursing professionals. European Work \& Organizational Psychologist, 3(3), 217-227.

Gill, J. (2000). Don't blame cynicism on 'bad apples'. Retrieved December 28, 2006, from http://www.businessweek.com/careers/content/oct2000/ca20001011_406.htm

Hirschman, A. O. (1970). Exit, voice and loyalty. Responses to decline in firms, organizations, and states. Cambridge, Massachusetts: Harvard University Press.

Judge, T. A. (2001). Dispositional affect and job satisfaction: A review and theoretical extension. Organizational Behavior \& Human Decision Processes, 86(1), 67-98.

Kahn, R. L., Wolfe, D. M., Quinn, R. P., \& Snoek, J. D. (1981). Organizational stress: Studies in role conflict and role ambiguity (Reprint Edition (orig, 1964) ed.). Malabar, Florida: Robert E. Krieger Publishing Company.

Kanter, D. L., \& Mirvis, P. H. (1989). The cynical Americans: Living and working in an age of discontent and disillusionment. San Francisco: JosseyBass.

Kanter, D. L., \& Mirvis, P. H. (1991). Cynicism: The new American malaise. Business \& Society Review, Spring 91(77), 57-61.

Korman, A. K. (1970). Toward an hypothesis of work behavior. Journal of Applied Psychology, 54(1), 31-41.

Korman, A. K. (1976). Hypothesis of work behavior revisited and an extension. Academy of Management Review, 1(1), 50-63.

Korman, A. K. (2001). Self-enhancement and self-protection: Toward a theory of work motivation. In M. Erez, U. Kleinbeck \& H. Thierry (Eds.), Work motivation in the context of a globalizing economy. Mahwah, NJ: Lawrence Erlbaum Associates, Inc. 
Kristof, A. L. (1996). Person-organization fit: An integrative review of its conceptualizations, measurement, and Personnel Psychology, 49(1), 1-49.

Maslach, C., \& Leiter, M. P. (1997). The truth about burnout. San Francisco: Jossey-Bass.

Maslach, C., Schaufeli, W. B., \& Leiter, M. P. (2001). Job burnout. Annual Review of Psychology, 52(1), 397-422.

Meyer, J. P., \& Allen, N. J. (1991). A three-component conceptualization of organizational commitment. Human Resource Management Review, 1(1), 61-89.

Meyer, J. P., Irving, P. G., \& Allen, N. J. (1998). Examination of the combined effects of work values and early work experiences on organizational commitment. Journal of Organizational Behavior, 19(1), 29-52.

Meyer, J. P., Paunonen, S. V., Gellatly, I. R., Goffin, R. D., \& Jackson, D. N. (1989). Organizational commitment and job performance: It's the nature of the commitment that counts. Journal of Applied Psychology, 74(1), 152156.

Moorman, R. H., Blakely, G. L., \& Niehoff, B. P. (1998). Does perceived organizational support mediate the relationship between procedural justice and organizational citizenship behavior? Academy of Management Journal, 41(3), 351-357.

Morgan, G. (1998). Images of organization. Thousand Oaks: Sage Publications.

Niehoff, B. P., \& Moorman, R. H. (1993). Justice as a mediator of the relationship between methods of monitoring and organizational citizenship behavior. Academy of Management Journal, 36(3), 527-556.

Pierce, J. L., Gardner, D. G., Cummings, L. L., \& Dunham, R. B. (1989). Organization-based self-esteem: Construct definition, measurement, and validation. Academy of Management Journal, 32(3), 622-648.

Reichers, A. E., Wanous, J. P., \& Austin, J. T. (1997). Understanding and managing cynicism about organizational change. Academy of Management Executive, 11(1), 48-59. 
Rusbult, C. E., Farrell, D., Rogers, G., \& Mainous III, A. G. (1988). Impact of exchange variables on exit, voice, loyalty, and neglect: An integrative model of responses to declining job satisfaction. Academy of Management Journal, 31(3), 599-627.

Rusbult, C. E., Johnson, D. J., \& Morrow, G. D. (1986). Determinants and consequences of exit, voice, loyalty, and neglect: Responses to dissatisfaction in adult romantic involvements. Human Relations, 39(1), 4564.

Rusbult, C. E., \& Zembrodt, I. M. (1983). Responses to dissatisfaction in romantic involvements: A multidimensional scaling analysis. Journal of Experimental Social Psychology, 19, 274-293.

Rusbult, C. E., Zembrodt, I. M., \& Gunn, L. K. (1982). Exit, voice, loyalty, and neglect: Responses to dissatisfaction in romantic involvements. Journal of Personality and Social Psychology, 43(6), 1230-1242.

Williams, L. J., \& Hazer, J. T. (1986). Antecedents and consequences of satisfaction and commitment in turnover models: A reanalysis using latent variable structural equation models. Journal of Applied Psychology, 71(2), 219-231. 


\section{CHAPTER 2}

\section{Literature review}

\section{Abstract}

We reviewed 29 conceptual and empirical articles on employee cynicism toward the employing organization. Cynicism is conceptualized as a selfdefensive attitude that allows for change, rather than a stable disposition or a fixed personality trait. Its main antecedent is unmet expectations about honesty, fairness, and justice in the workplace, and the experience of not being treated with respect by the employing organization. Consequences of cynicism include various forms of psychological disengagement and detachment from the organization, and alienation and reduced self-esteem at the personal level. Work performance, however, seems to be less affected. It is shown that cynicism is a widespread form of employee conduct. 


\section{Introduction}

In the introductory chapter we discussed the high incidence and the potentially serious consequences of organizational cynicism as reasons for studying this phenomenon. Another reason we brought forward was the lagging behind of theoretical advancement in understanding the process whereby cynicism originates and develops. In addition, we also discussed a few examples demonstrating the controversy surrounding cynicism in the workplace. In this chapter, we will review and discuss the extant scientific literature on cynicism in the work environment. To facilitate the interpretation of research findings regarding the nature, antecedents, and consequences of organizational cynism, the following practical case serves to introduce the literature review.

A few years ago, the CEO of a large Dutch bank received a salary increase of about 65 per cent. A bank spokesman told the media that the CEO was being underpaid according to international standards, and therefore his pay raise was a legitimate means to make him catch up with his peers. At about the same time, the bank's employees were urged by their top management not to demand a salary increase, because the Dutch economy was recovering from a decline and the bank's competitiveness had to be secured and maintained at all cost. Soon after the news about the CEO's pay raise got out, employees at headquarters reacted in a manner described by one news agency as follows: 'To boost the 'meagre' salary of their CEO, merciful employees at headquarters of [bank X] have installed offertory boxes in the restrooms to collect donations for him, because he appears to be grossly underpaid.' Various perspectives on this event emerged afterwards in heated discussions on internet discussion forums. Some saw it as an inappropriate action by jealous employees who were ignorant about what it takes to attract and retain top executives, others regarded it as a legitimate expression of employees to vent their feelings of anger, frustration and disillusionment. The discussion of cynicism in the previous chapter suggests that this action might also be interpreted as an overt form of employee or organizational cynicism. To see if this interpretation is corroborated by research, we will review the extant literature on cynicism in the workplace, with a focus on the nature, antecedents, and consequences of organizational cynicism.

\section{Cynicism in organizations}

In the organization sciences, two major lines of research into workrelated cynicism have appeared. One has concentrated on the development and 
function of cynicism during the work career, particularly in occupational socialization processes. In their first work encounters, students and starting professionals frequently experience a series of unmet expectations and unexpected events, causing what is aptly referred to by Blau (1974) as a 'reality shock.' Starting with a healthy dose of idealism to help people, or to make the world a better place, newcomers in areas such as medicine and social services quickly learn that the work environment can be quite different from what they thought it would be like. Alongside appreciation and gratitude, they also meet resistance, negligence, or even hostility from clients or help recipients. As a reaction to this experience, workers may get less involved and adopt a distant, cynical attitude toward their clients. Studies in this line of research, referred to as occupational cynicism, have primarily focused on the helping professions, in particular health care (Becker \& Geer, 1958; Peiró, González-Romá, Valcárcel, \& Ramos, 1992), social work (Blau, 1974; Meyerson, 1990), and the police (Niederhoffer, 1967; O'Connell, Holzman, \& Armandi, 1986). Occupational cynicism is mainly directed at clients and may generalize to the general public. It may also extend to the employing organization when employees put the blame for their inability to serve their clients on management, policies or practices, or a lack of resources. It is recognized that this cynical attitude, eventually resulting in what Becker and Geer (1958) have described as a state of 'informed idealism', may help employees to cope with the stress emanating from taxing demands by help recipients. Blau (1974) goes even further by claiming that cynicism may increase a service provider's proficiency, because by becoming less involved with clients, contacts cease to be a threatening and unpleasant experience. Thus, the service provider creates a psychological latitude that helps to become increasingly conversant with procedures and to acquire the skills necessary to serve clients more effectively. In the same vein, police officers learn to withstand the taxing demands of their jobs without completely losing their initial enthusiasm and idealism (Niederhoffer, 1967), and the same holds for other occupational areas, such as medicine and education. The transition from 'naive' idealism to cynicism, and from cynicism back again to 'informed' idealism, seems to reflect a learning process which potentially benefits the organization and the person alike.

A second line of research has focused on cynicism among employees responding to certain adverse organizational circumstances. Similar to occupational cynicism, unmet or frustrated expectations as well as unexpected organizational characteristics or events are the key element. This form of cynicism, referred to as employee cynicism or organizational cynicism (OC), is the topic of this dissertation. It is targeted at the organization at large, or specific 
organizational elements, such as management, policies, or practices. To identify publications on this type of cynicism eligible for review, we searched the EBSCO and PsychINFO databases for articles in peer reviewed journals, with the word 'cynicism' in the title line. This search yielded 57 and 62 items respectively, with considerable overlap between both databases. Next, each item's title was inspected and, if in doubt, also the abstract or the original publication, to verify that the article indeed discussed employee cynicism directed at the organization and not any other form of cynicism. In most cases the title provided sufficient information to decide whether the article would qualify for the review. Thus, 26 publications with a clear focus on organizational cynicism were selected. Next, a new search was conducted in both databases with the term 'cynical' in the title line. Interestingly, the majority of publications matching this criterion either focus on occupational forms of cynicism, primarily among the police, or on health related aspects of cynicism, with a clear emphasis on antecedents and consequences of cynical hostility ${ }^{1}$. However, no new publications on organizational cynicism were identified. In addition, we also used Google to search the internet, using 'organizational cynicism' and 'cynicism about organizational change' as search keys. This search resulted in three additional items. Thus, 29 publications were selected for review. For each publication, we assessed the conceptualization, antecedents, and consequences of cynicism, as well as its measurement and the research setting. The results are presented in Table 1. This table was inspired by Dean, Brandes and Dharwadkar (1998), who reviewed the literature on cynicism from several disciplines, but differs in important respects. Whereas Dean and colleagues used a variety of attributes (facets) to make comparisons between various forms of cynicism, including employee and organizational cynicism, and between organizational cynicism and 'competing' constructs, such as organizational commitment, trust, job satisfaction, and alienation, the emphasis in the present study is exclusively on employee and organizational cynicism.

\footnotetext{
${ }^{1}$ In personality psychology, cynicism is inferred from items taken from the Minnesota Multiphasic Personality Inventory (MMPI). One of the subscales of the full MMPI is Cook \& Medley's (1954) cynical hostility scale.
} 


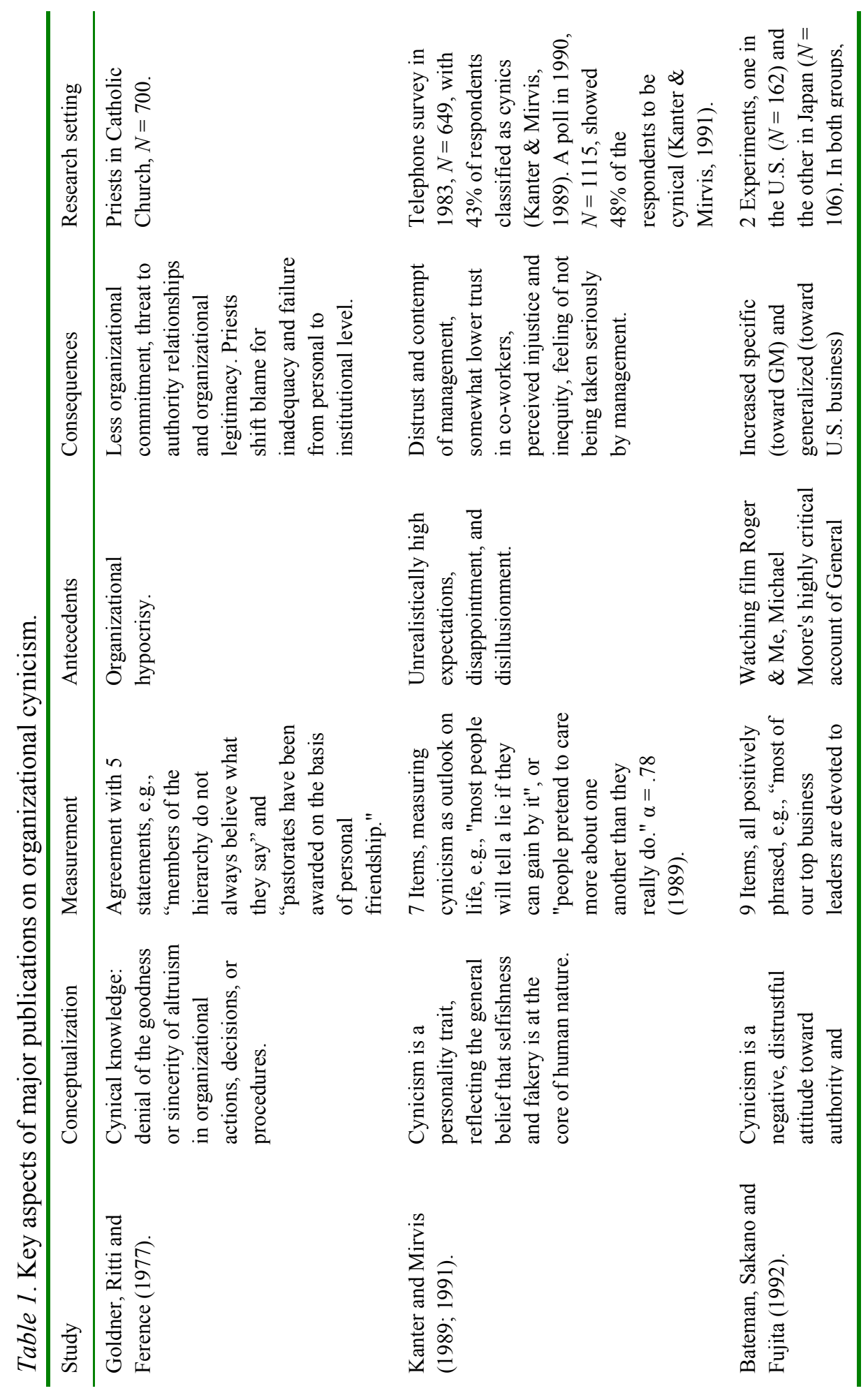




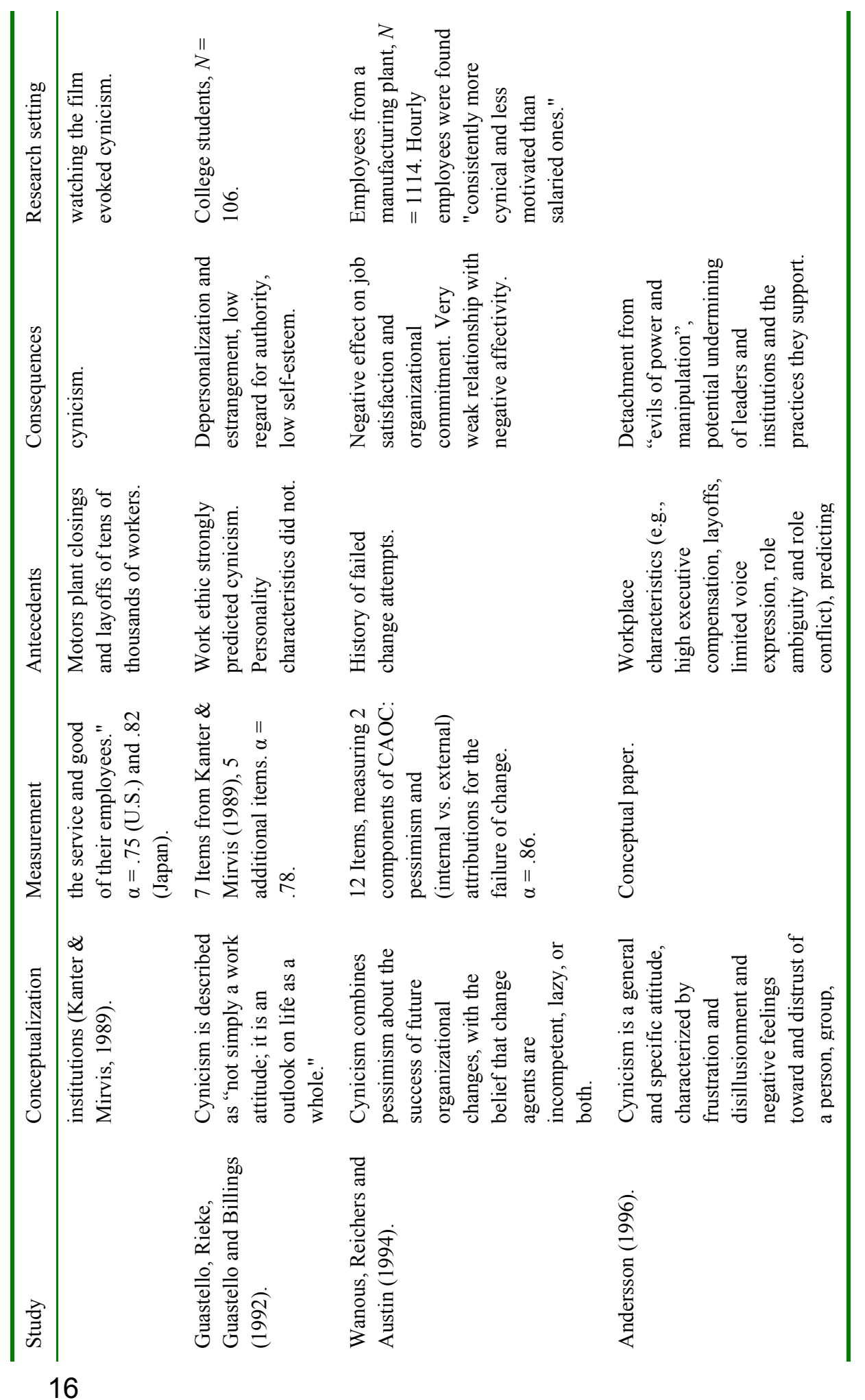




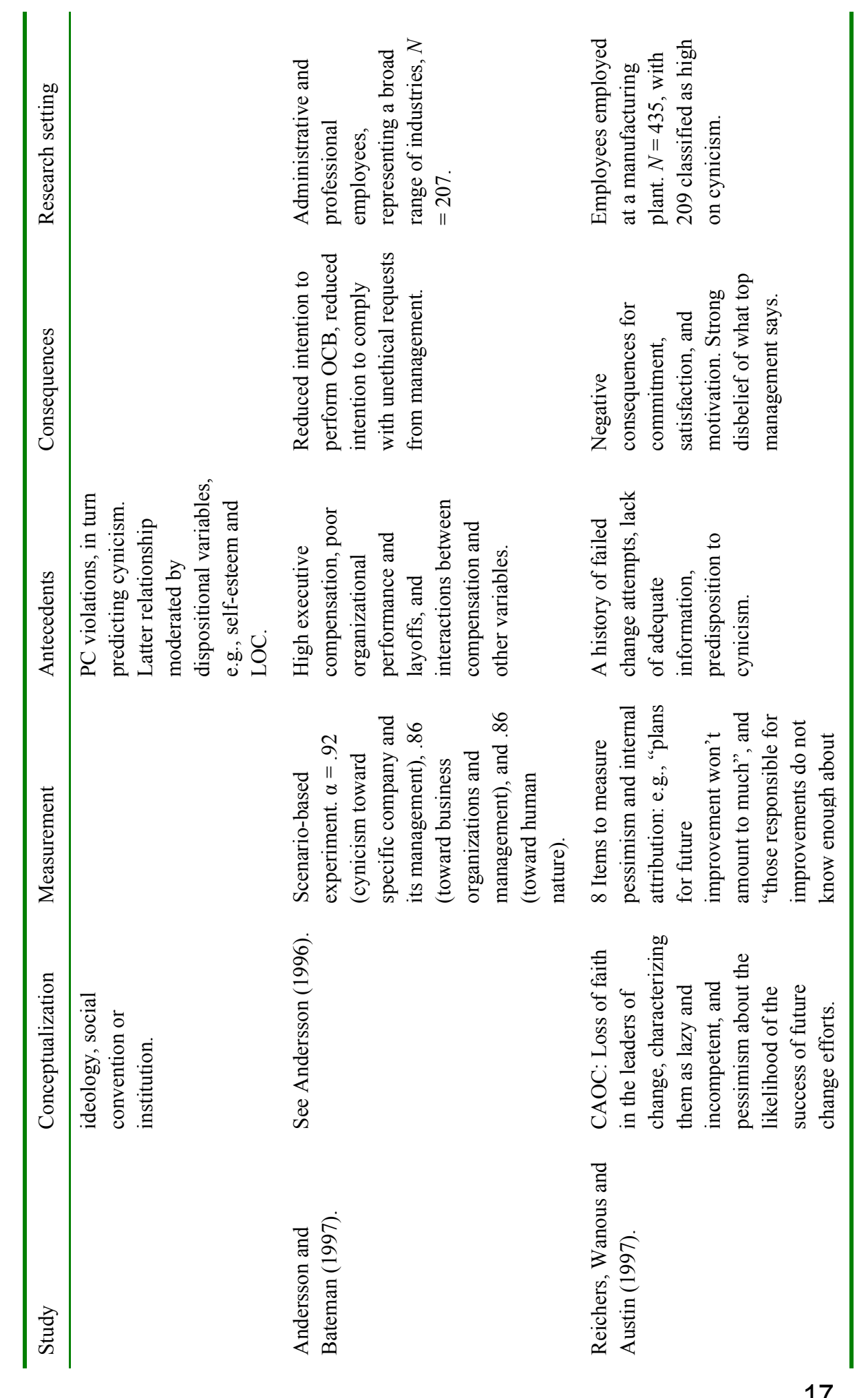




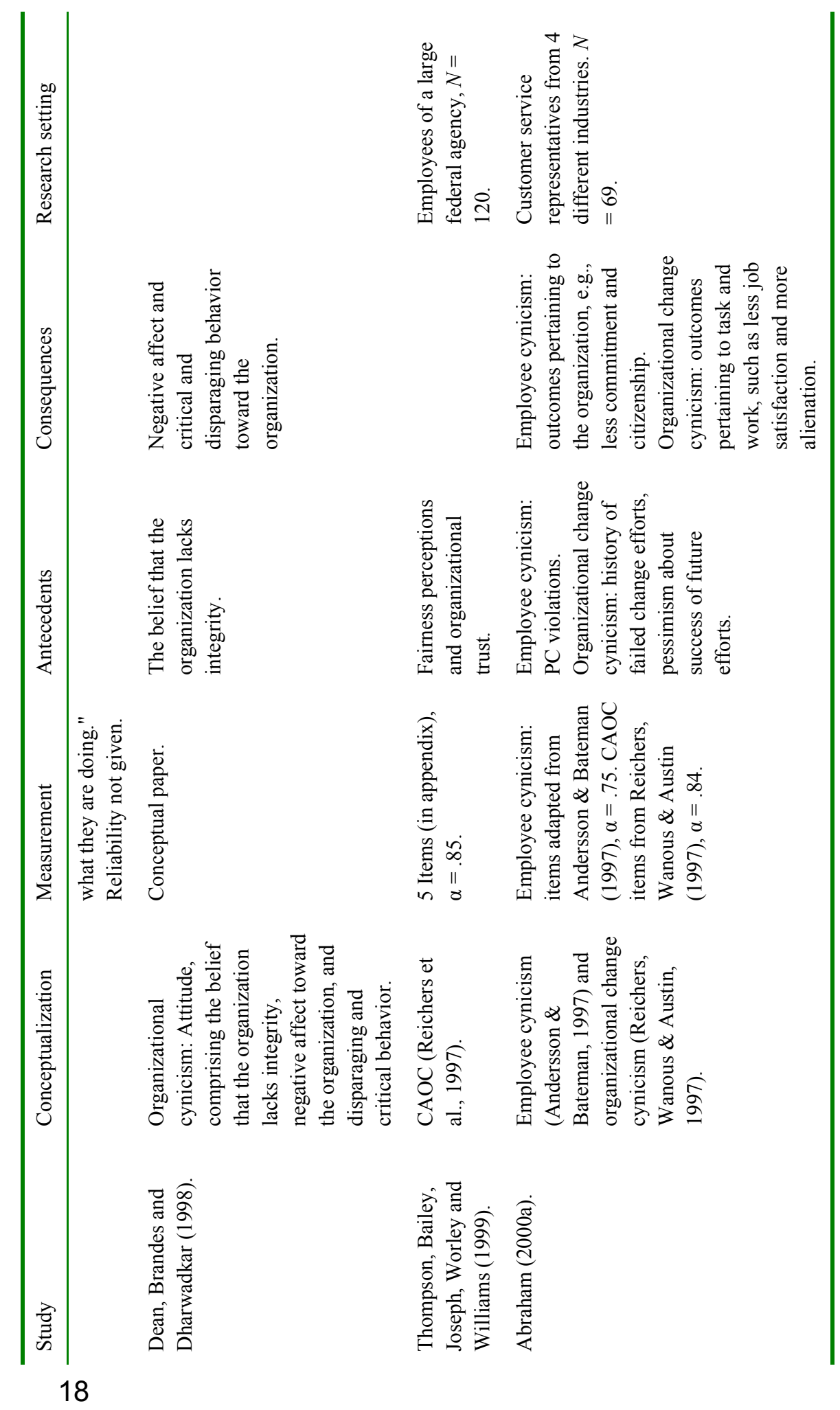




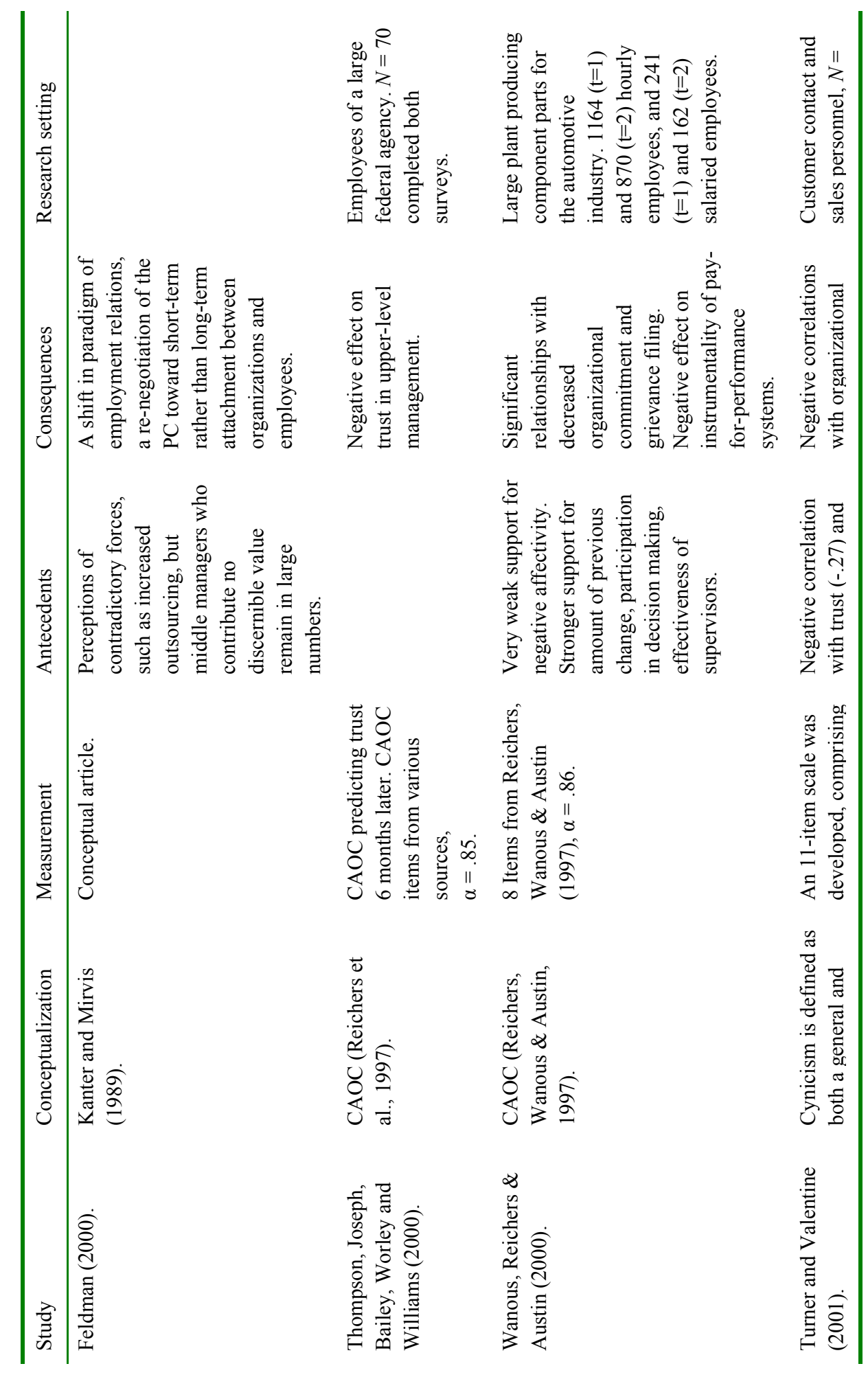




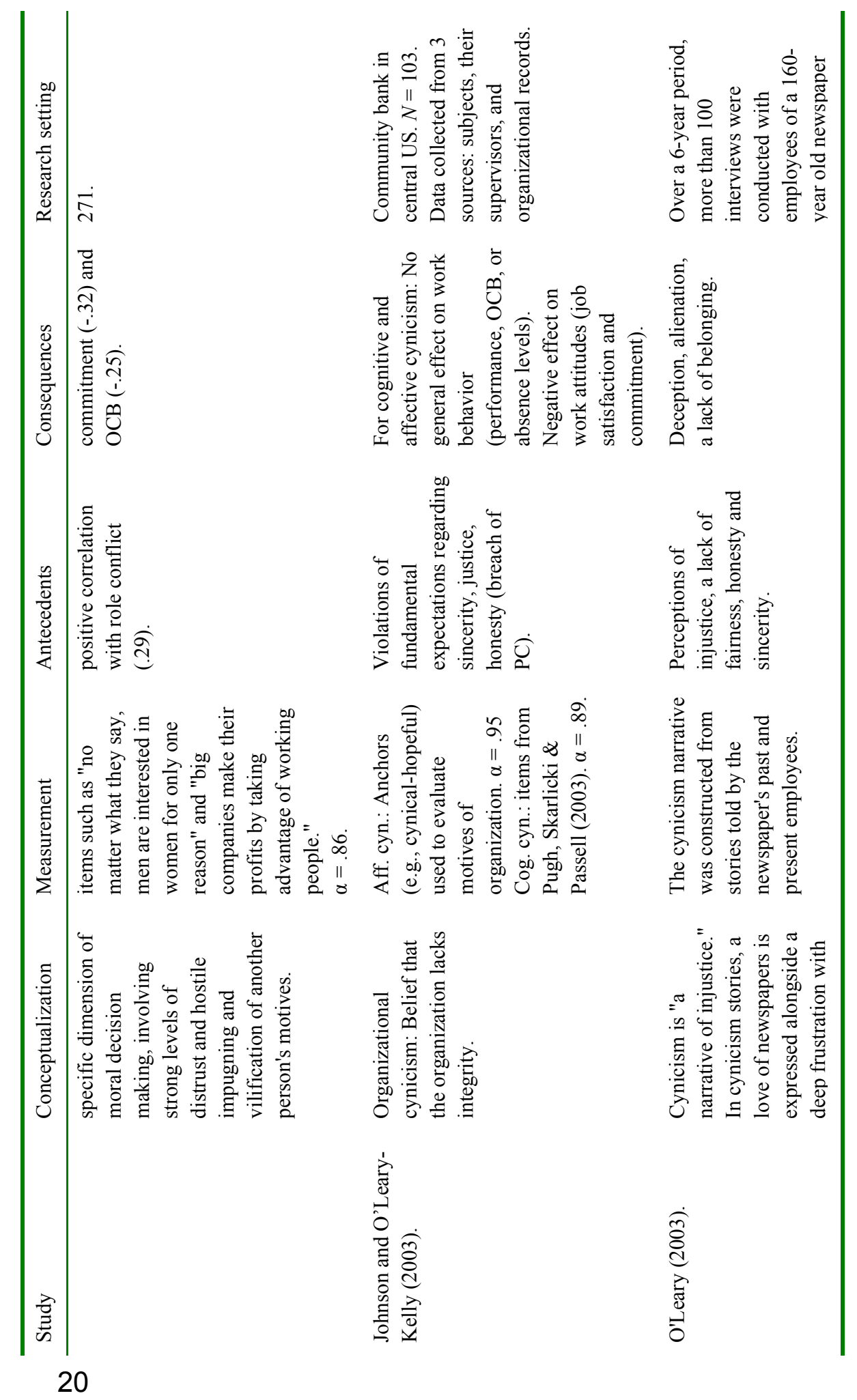




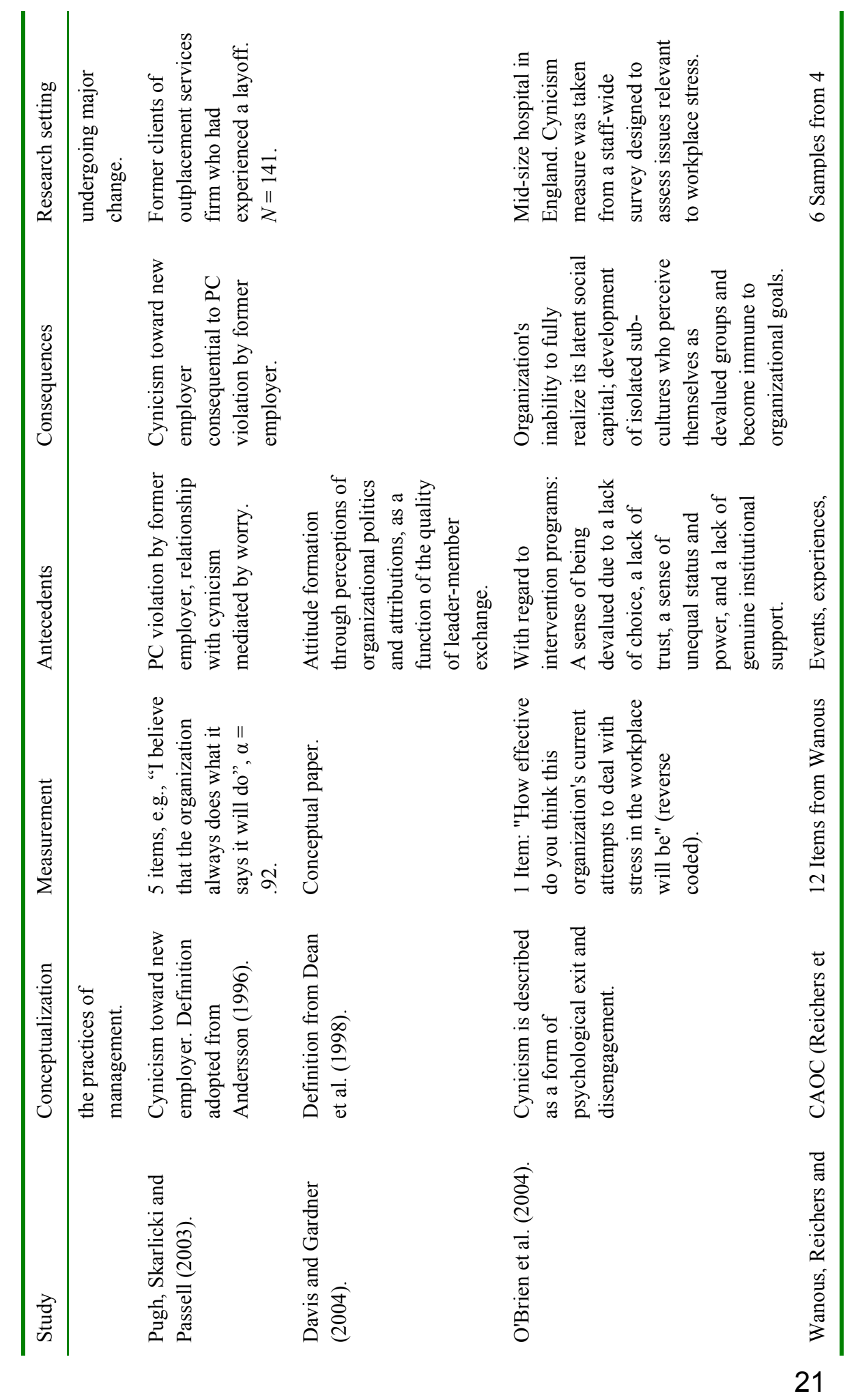




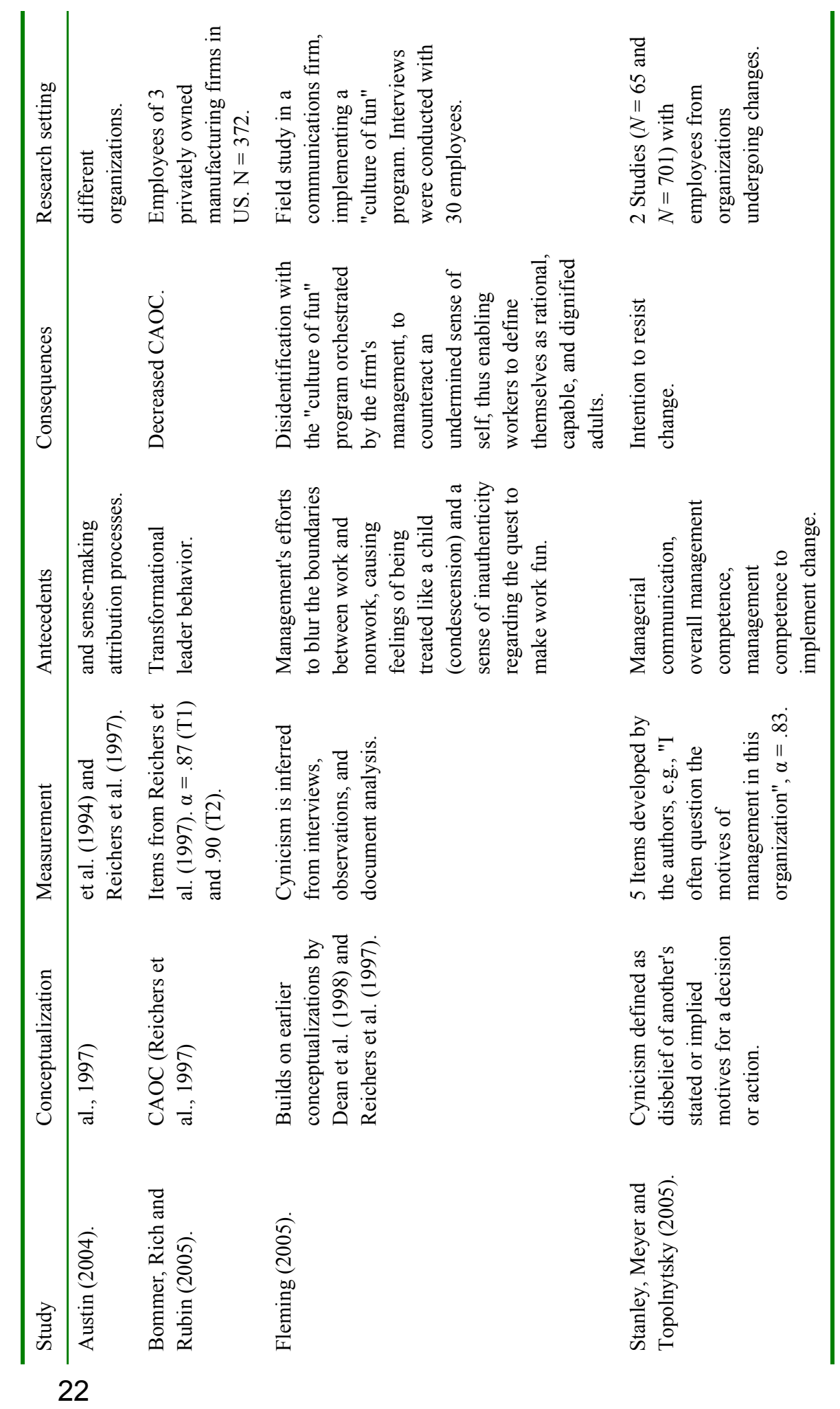




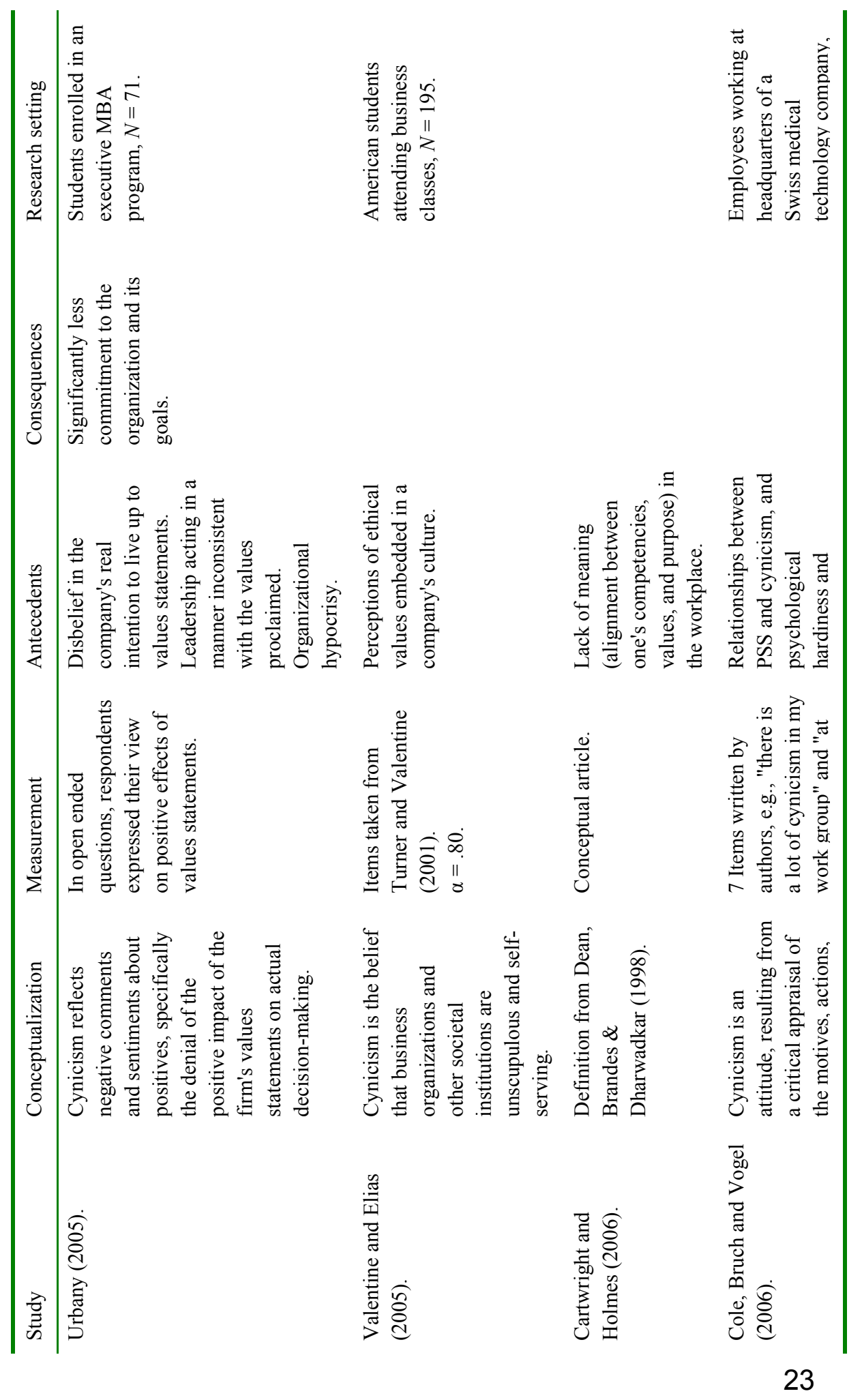




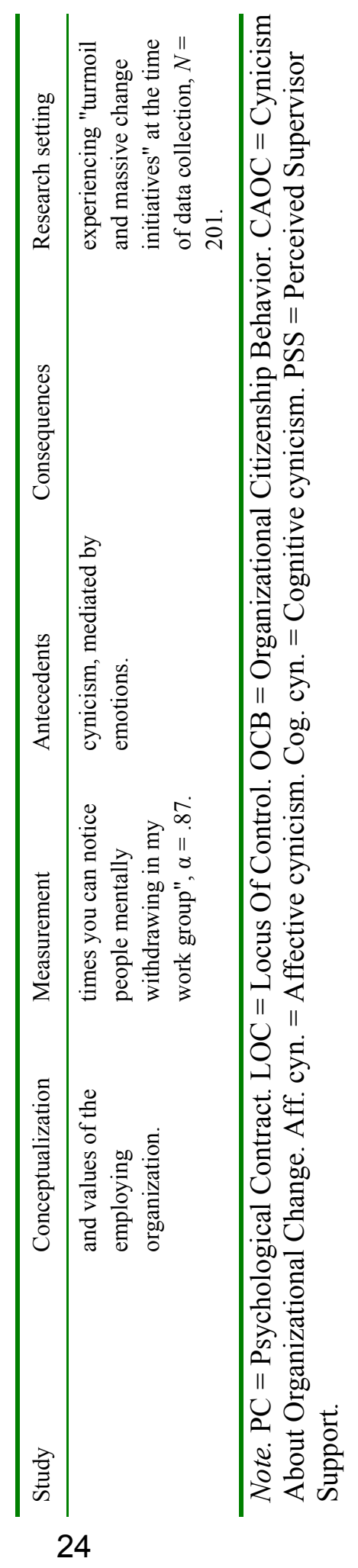




\section{Conceptualizations of organizational cynicism}

Dean et al. (1998) conceive of organizational cynicism as an attitude, thereby adopting a 3-dimensional cognitive, affective, and behavioral structure of the cynicism construct. These dimensions are represented in the various conceptualizations of cynicism presented in Table 1. The cognitive dimension, referred to by Dean et al. (1998) as 'cynicism being thought and experienced through cognition' (p. 346) is expressed as denial of the sincerity of the organization (Goldner et al., 1977; Urbany, 2005), as the belief that selfishness and fakery is at the core of human nature (Kanter \& Mirvis, 1989, 1991; Mirvis \& Kanter, 1991), or that organizations are unscrupulous and self-serving (Valentine \& Elias, 2005) and fall short of integrity (Dean et al., 1998; Johnson \& O'Leary-Kelly, 2003) or, alternatively, as the disbelief of stated motives (Stanley et al., 2005). The affective dimension of cynicism 'being felt' is represented in emotionally flavored conceptualizations, such as frustration and disillusionment (Andersson, 1996; Andersson \& Bateman, 1997; O'Leary, 2003), or pessimism (Reichers et al., 1997; Wanous et al., 1994). Finally, the behavioral dimension of employees overtly or covertly 'acting out' their cynicism is key to conceptualizations such as hostile impugning and vilification of motives (Turner \& Valentine, 2001), alienation and psychological exit and disengagement (O'Brien et al., 2004), a loss of faith in leaders of change (Reichers et al., 1997; Wanous et al., 2000, 2004), or as distrust of a person, group, ideology, social convention or institution (Andersson, 1996; Andersson \& Bateman, 1997; Bateman et al., 1992; Turner \& Valentine, 2001).

Dean et al. (1998) have synthesized these dimensions into their definition of organizational cynicism as (1) a belief that the organization lacks integrity; (2) negative affect toward the organization; and (3) tendencies to disparaging and critical behaviors toward the organization that are consistent with these beliefs and affect.' Although this definition seems to capture all facets of cynicism, a potential problem may be its lack of specificity. For instance, O'Leary (2003) describes the cynicism of newspaper employees who are deeply frustrated with the practices of management, yet at the same time love the product they make. This example makes clear that negative affect may not be targeted at the entire organization, but rather at specific parts of it. In the same vein, disparaging behavior may not be overtly expressed at all times, but only at specific occasions.

The conceptualization of cynicism as an attitude not only structures and brings together the various facets of the cynicism construct, but it also has an important implication with regard to the permanency or malleability of 
cynicism. Reseachers who regarded cynicism as a personality trait or a stable disposition (Guastello et al., 1992; Kanter \& Mirvis, 1989; Mirvis \& Kanter, 1991; Reichers et al., 1997) found little evidence in support of their view. Most reseachers nowadays tend to regard cynicism as an attitude (e.g., Andersson, 1996; Andersson \& Bateman, 1997; Cole et al., 2006; Dean et al., 1998), that is as 'a psychological tendency to evaluate a particular entity with some degree of favor or disfavor' (Eagly \& Chaiken, 1993). The word 'tendency' implies that attitudes can change and be changed over time as a result of disconfirming experiences, whereas cynicism as a disposition or personality trait puts employees in a lasting or even permanent state of distrust.

\section{Antecedents of organizational cynicism}

Attitudes, it is argued, derive from cognitive learning processes that occur when people gain information about the attitude object and thereby form beliefs about this object. According to the definition by Dean et al. (1998), the key element of organizational cynicism is the employee's belief that the organization lacks integrity. The Oxford English Dictionary Online defines integrity as 'Soundness of moral principle; the character of uncorrupted virtue, especially in relation to truth and fair dealing; uprightness, honesty, and sincerity.' In other words, beliefs about the organization due to perceptions or experiences of untruthful or unfair dealing, a lack of uprightness, dishonesty, or insincerity, constitute primary precursors of organizational cynicism. Table 1 contains an extensive selection of organizational characteristics, practices, and events that may be perceived or experienced as such, for instance unmet or broken promises leading to perceptions of psychological contract violation or breach (Abraham, 2000; Andersson, 1996; Johnson \& O'Leary-Kelly, 2003; Pugh et al., 2003), organizational politics in which power play and self-serving behavior may go at the expense of uprightness (Davis \& Gardner, 2004), the feeling of being disregarded by the organization and not being treated with respect and dignity (Fleming \& Spicer, 2003; O'Brien et al., 2004), the absence of meaning in work (Cartwright \& Holmes, 2006), a lack of sincere participation in decision making processes and the absence of genuine support by management (Fleming, 2005; O'Brien et al., 2004; Wanous et al., 2000), the deficient quality of leader-member exchange (Bommer et al., 2005; Cole et al., 2006; Davis \& Gardner, 2004), a history of failed change attempts (Reichers et al., 1997; Wanous et al., 1994, 2000, 2004), managerial incompetence (Stanley et al., 2005) in combination with lofty salaries (Andersson \& Bateman, 1997), institutionalized organizational hypocrisy (Feldman, 2000; Fleming, 2005; 
Goldner et al., 1977; Urbany, 2005; Valentine \& Elias, 2005), and everyday workplace events and practices such as high executive compensation, restructurings, downsizings and layoffs (Abraham, 2000; Andersson, 1996; Andersson \& Bateman, 1997; Bateman et al., 1992). These experiences result in unmet expectations of meaningfulness, and an unmet need for self-fulfillment and growth, bringing about disappointment and disillusionment. Clearly, for cynicism to develop, the exchange relationship between employee and employing organization must be out of balance. This is probably what Cartwright and Holmes (2006) have in mind when they state that 'As organizations have expected more from their workforce and have provided little in return other than simply a job or employability, it is perhaps not surprising that employee cynicism and mistrust have increased' (p. 199).

However, not all employees are similarly affected by the same circumstances. Situational characteristics of the organization interact with the dispositional characteristics of the employee in the development of cynicism. Although little empirical evidence has been found for cynicism as a personality trait, or for cynicism caused by employees' negative affectivity, research evidence does indicate that certain personal characteristics may be conducive to cynicism. For instance, Guastello et al. (1992) argue that 'a cynical outlook on work and life is not caused by special personality characteristics. Cynicism appears to affect a wide range of people' (p. 45-46). On the other hand, they also found a strong correlation of .79 between cynicism and work ethic, described as the private belief that work is good in itself. People with a strong work ethic or similar values tend to work hard and they will likely expect their employing organization to treat them with respect and dignity, and to reciprocate and do justice to their contribution. The organization's failure to meet their expectations is likely to result in disappointment and disillusionment, making them susceptible to cynicism. On the other hand, people who care less or not at all about dishonesty or lack of sincerity, or who have learned over time to cope with it, will probably not become cynical as a consequence of their experiences.

\section{Consequences of organizational cynicism}

In the previous section we signalled agreement among researchers concerning the antecedents of cynicism toward the organization. Table 1 shows that a strong consensus also exists with regard to the consequences of organizational cynicism. Most frequently mentioned are affective and behavioral consequences, such as a decrease in organizational commitment, 
motivation and job satisfaction (Abraham, 2000; Goldner et al., 1977; Johnson \& O'Leary-Kelly, 2003; Reichers et al., 1997; Turner \& Valentine, 2001; Urbany, 2005; Wanous et al., 1994, 2000), an increase in suspicion, distrust and contempt of the organization (Kanter \& Mirvis, 1989, 1991; Reichers et al., 1997; Thompson et al., 2000), and other forms of psychological disengagement and detachment (Andersson, 1996; Feldman, 2000; Fleming, 2005; Guastello et al., 1992; O'Brien et al., 2004; O'Leary, 2003). Two studies showed that cynicism is associated with a decrease in self-esteem (Fleming, 2005; Guastello et al., 1992), and another study revealed that even the new employer may experience the cynicism among employees, resulting from maltreatment by their former employer (Pugh et al., 2003). In reaction to perceptions of psychological contract breach and violations, these consequences may be attributed to a reassessment of the psychological contract by the employee. Broken promises and the feeling of not being treated with dignity and respect evoke distrust, reciprocation wariness (Eisenberger, Cotterell, \& Marvel, 1987; Levinson, 1965; Lynch, Eisenberger, \& Armeli, 1999), and a loss of commitment. Such responses can be expected to have inhibiting and disruptive effects on interpersonal relationships (Cotterell, Eisenberger, \& Speicher, 1992). Other researchers, looking beyond these immediate effects, point at the undermining of the authority of leaders and their institutions (Andersson, 1996; Feldman, 2000; Goldner et al., 1977), and the underutilization of human capital (O'Brien et al., 2004). One of the main coordinating mechanisms in organizations is the system of interdependent authority relationships and allocation of responsibilities. If this system is no longer respected or even taken seriously by a significant part of the workforce, the long-term consequences of organizational cynicism can be dramatic, as the organization literally starts to disintegrate. Indeed, in the long run the effectiveness and viability of the organization may be at stake.

\section{Methods, measurement, and incidence of organizational cynicism}

In comparison with established constructs in the field of organizational behavior, such as job satisfaction or employee commitment, the number of studies into organizational cynicism is relatively low. Nevertheless, the studies discussed in this review display considerable variety in research designs. Most quantitative studies employed a cross-sectional design, measuring self-reported cynicism as a point-in-time phenomenon. A limitation to the samples used in these studies may be that managers appear to be somewhat under-represented, 
thus introducing a potential bias toward 'common' workers' cynicism. In addition, we identified experimental studies conducted by Bateman et al. (1992) and Andersson and Bateman (1997), longitudinal designs employed by Wanous et al. (2000) and Bommer et al. (2005), and a study by Johnson and O'LearyKelly (2003) in which data were obtained from 3 different sources. Especially these studies provide rigorous hypotheses tests. We also detected a number of efforts to establish construct validity by discussing the differences between cynicism and related constructs (Dean et al., 1998), and by conducting confirmatory factor analyses to assess the dimensionality of the cynicism construct (e.g., Andersson \& Bateman, 1997; Cole et al., 2006). With Cronbach's alphas between .78 and .92, the measures generally display good internal consistency. The qualitative studies, although more inferential in nature, also provide valuable insights into various aspects of employee or organizational cynicism, including its development over time.

Following the previous discussion of the nature, antecedents, and consequences of organizational cynicism, we find it instructive to also assess its incidence, to answer the question how big a 'problem' it really is. In a nationwide survey, Kanter and Mirvis (1989) found 43\% of the American employees to be highly cynical toward the employing organization. In a followup study, the same authors learned that the percentage had risen to $48 \%$ (Kanter \& Mirvis, 1991). A study by Reichers, Wanous and Austin (1997) yielded identical findings, and it is argued that the figure may be even higher at present due to corporate scandals and ongoing restructurings and downsizings (Bommer et al., 2005). Kanter and Mirvis (1989) categorized the workforce into the Upbeat (41\%), the Wary (16\%), and the Cynics (43\%). This may be intuitively appealing, yet it is also a simplification of reality akin to stereotyping, because it suggests that people must be in either of these mutually exclusive categories, and within the categories no distinction is made with regard to the degree of being upbeat, wary, or cynical. Moreover, the criterion to allocate respondents to either of these categories is not clearly explained. To obtain more information about the incidence of cynicism among workers, we used the empirical data of 8 studies, discussed in Table 1. We standardized the cynicism variable used in each particular study to calculate the probability that cynicism would be higher than the midpoint of the scale on which it was measured. Obviously, one underlying assumption is that the cynicism variable approximates a normal distribution. Another assumption is that cynicism 'starts' from the scale's midpoint onward. In keeping with the conceptualization of cynicism as an attitude that may vary in strength from person to person and from occasion to 
occasion, we prefer to regard scores in this area as being reflective of a tendency or an inclination toward cynicism. Table 2 presents the results of this analysis.

Table 2. Incidence of organizational cynicism.

\begin{tabular}{lllll}
\hline Study & Scale & $M$ & $S D$ & $P>$ Midpoint \\
\hline 1. Bommer et al. (2005) & 7-point & T1:3.83 & T1: 1.35 & T1: 44.9\% \\
& & T2: 3.91 & T2: 1.43 & T2: $47.4 \%$ \\
2. Cole et al. (2006) & 7-point & 3.83 & .98 & $43.1 \%$ \\
3. Johnson and O'Leary- & Aff. cyn. 9-p. & 3.68 & 1.56 & $19.8 \%$ \\
Kelly (2003) & Cog. cyn. 7-p. & 3.42 & 1.36 & $33.4 \%$ \\
4. Pugh et al. (2003) & 5-point & 2.46 & .88 & $26.9 \%$ \\
5. Thompson et al. (1999) & 7-point & 4.23 & 1.29 & $57.0 \%$ \\
6. Thompson et al. (2000) & 7-point & 4.44 & 1.23 & $63.9 \%$ \\
7. Wanous et al. (1994) & 5-point & 3.00 & .74 & $50.0 \%$ \\
8. Wanous et al. (2000) & 5-point & 2.91 & .70 & $44.8 \%$ \\
\hline
\end{tabular}

Note. Aff. cyn. $=$ Affective cynicism. Cog. cyn. $=$ Cognitive cynicism. Midpoint $=3$ for 5 -point scale, 4 for 7-point scale, and 5 for 9-point scale.

It should be noted that all studies were conducted in the United States, with the exception of study 2, which was conducted in Switzerland. On the whole, the percentages in Table 2 appear to be in line with those reported by Kanter and Mirvis (1989), but they also show variability. For instance, the percentages for studies 3 and 4 are considerably lower. Although the bank employees in study 3 expressed strong perceptions of psychological contract breach $(M=5.00$ on 7-point scale), which has been previously identified as a primary antecedent of cynicism, they also expressed high levels of job satisfaction ( $M=5.10$ on 7-point scale) and commitment ( $M=5.02$ on 7-point scale). This could be due to the fact that unemployment in the region was very low and thereby the most cynical employees might have left the organization, taking advantage of the job opportunities on offer. The probability in study 4 is also low, because this form of cynicism was directed against the new employer, but caused by the former employer. On the other hand, studies 5 and 6 show very high cynicism levels. These studies were situated in governmental organizations, undergoing change processes. Although these results show quite some variability, they do seem to support Kanter and Mirvis' (1989; 1991) contention that a considerable portion of the American workforce tends to be 
cynical to some degree toward the employing organization. Much less is known about organizational cynicism in other parts of the world, but study 2 seems to suggest that the situation in Europe may be comparable to the United States.

\section{Discussion}

This literature review has highlighted a number of important aspects with regard to employee cynicism that may contribute to a better understanding of this form of employee conduct. It has been shown that cynicism is indeed a prevalent employee response to certain organizational circumstances. As regards the nature of cynicism, most researchers have conceptualized cynicism as an attitude, that is as a malleable state rather than a stable trait, with a cognitive, affective, and behavioral dimension. The cognitive dimension refers to employees who 'think and experience' (Dean et al., 1998) cynicism by gaining information about the organization through observation, perception, or experience and by forming beliefs about it. The affective dimension points at the emotional side of people 'feeling cynicism', who get angry, frustrated, and disillusioned when they believe that deeply-rooted expectations about honesty, fairness, justice, and the desire of being treated with respect and dignity are not met by the organization. Finally, although it is recognized in psychology that people's behavior may not always be consistent with their attitudes (Ajzen \& Fishbein, 1977), a number of behavioral expressions and consequences of employees acting out their cynical beliefs and affects about the organization were identified. These include various forms of psychological disengagement and detachment from the organization, and alienation and less self-esteem at the personal level. It is important to emphasize that cynicism is not by definition detrimental to the organization. For instance, Dean et al. (1998) argue that 'cynics may provide a necessary check on the temptation to place expediency over principle or the temptation to assume that self-interested or underhanded behavior will go undetected' (p. 347). However, if a significant portion of the workforce turns cynical, the organization may suffer. In the most extreme case, the psychological tissue of the organization may be dissolved by employee cynicism, as was indicated above.

On a concluding note, we refer to the practical case presented in the beginning of this chapter. Can the employees' installing of offertory boxes to donate for their boss be interpreted as cynicism in practice? We think research provides clues to suggest that this question can be answered in the affirmative. Although we will never know for sure what these employees thought and 
experienced, it should not be too hard to imagine that beliefs about self-serving behavior and the disbelief of stated motives in 'we are all in this together' rhetoric drove affective reactions such as anger, frustration, and disillusionment. In this case the behavioral expression of their emotions took the relatively harmless form of mockery. However, if the behavioral consequences become as serious as reciprocation wariness, or disengagement and detachment from the organization, widespread cynicism will ultimately jeopardize organizational coherence.

Given its prevalence and potentially serious consequences, the conclusion seems warranted that cynicism deserves a more prominent place on the research agenda. In chapter 3 a theoretical model of cynicism will be advanced and empirically tested. In chapters 4 and 5, the focus will be on antecedents and consequences of cynicism in relation to other employee responses to unfavorable organizational circumstances. 


\section{References}

Abraham, R. (2000). Organizational cynicism: Bases and consequences. Genetic, Social, and General Psychology Monographs, 126(3), 269-292.

Andersson, L. M. (1996). Employee cynicism: An examination using a contract violation framework. Human Relations, 49(11), 1395-1418.

Andersson, L. M., \& Bateman, T. S. (1997). Cynicism in the workplace: some causes and effects. Journal of Organizational Behavior, 18(5), 449-469.

Bateman, T. S., Sakano, T., \& Fujita, M. (1992). Roger, me, and my attitude: Film propaganda and cynicism toward corporate leadership. Journal of Applied Psychology, 77(5), 768-771.

Becker, H. S., \& Geer, B. (1958). The fate of idealism in medical school. American Sociological review, 18, 449-469.

Blau, P. M. (1974). On the nature of organizations. New York: John Wiley and Sons.

Bommer, W. H., Rich, G. A., \& Rubin, R. S. (2005). Changing attitudes about change: Longitudinal effects of transformational leader behavior on employee cynicism about organizational change. Journal of Organizational Behavior, 26(7), 733-753.

Cartwright, S., \& Holmes, N. (2006). The meaning of work: The challenge of regaining employee engagement and reducing cynicism. Human Resource Management Review, 16, 199-208.

Cole, M. S., Bruch, H., \& Vogel, B. (2006). Emotion as mediators of the relations between perceived supervisor support and psychological hardiness on employee cynicism. Journal of Organizational Behavior, 27, 463-484.

Cook, W. W., \& Medley, D. M. (1954). Proposed hostility and pharisaic-virtue scales for the MMPI. Journal of Applied Psychology, 38, 414-418.

Davis, W. D., \& Gardner, W. L. (2004). Perceptions of politics and organizational cynicism: An attributional and leader-member exchange perspective. Leadership Quarterly, 15(4), 439-465. 
Dean, J. W., Brandes, P., \& Dharwadkar, R. (1998). Organizational cynicism. Academy of Management Review, 23(2), 341-352.

Feldman, D. C. (2000). The Dilbert syndrome: How employee cynicism about ineffective management is changing the nature of careers in organizations. American Behavioral Scientist, 43(8), 1286-1300.

Fleming, P. (2005). Workers' playtime? Boundaries and cynicism in a 'Culture of Fun' program. The Journal of Applied Behavioral Science, 41(3), 285303.

Goldner, F. H., Ritti, R. R., \& Ference, T. P. (1977). The production of cynical knowledge in organizations. American Sociological Review, 42(4), 539-551.

Guastello, S. J., Rieke, M. L., Guastello, D. D., \& Billings, S. W. (1992). A study of cynicism, personality, and work values. The Journal of Psychology, 126(1), 37-48.

Johnson, J. L., \& O'Leary-Kelly, A. M. (2003). The effects of psychological contract breach and organizational cynicism: Not all social exchange violations are created equal. Journal of Organizational Behavior, 24(5), 627-647.

Kanter, D. L., \& Mirvis, P. H. (1989). The cynical Americans: Living and working in an age of discontent and disillusionment. San Francisco: JosseyBass.

Kanter, D. L., \& Mirvis, P. H. (1991). Cynicism: The new American malaise. Business \& Society Review, Spring 91(77), 57-61.

Meyerson, D. E. (1990). Uncovering socially undesirable emotions. American Behavioral Scientist, 33(3), 296-307.

Mirvis, P. H., \& Kanter, D. L. (1991). Beyond demography: A psychographic profile of the workforce. Human Resource Management, 30(1), 45-68.

Niederhoffer, A. (1967). Behind the shield. Garden City, NY: Doubleday \& Company. 
O'Brien, A. T., Haslam, S. A., Jetten, J., Humphrey, L., O'Sullivan, L., \& Postmes, T. (2004). Cynicism and disengagement among devalued employee groups: The need to ASPIRe. Career Development International, 9(1), 28-44.

O'Connell, B. J., Holzman, H., \& Armandi, B. R. (1986). Police cynicism and the modes of adaptation. Journal of Police Science and Administration, 14(4), 307-313.

O'Leary, M. (2003). From paternalism to cynicism: Narratives of a newspaper company. Human Relations, 56(6), 685-704.

Peiró, J. M., González-Romá, V., Valcárcel, P., \& Ramos, J. (1992). The disenchantment of professionals in a new, implemented model of primary health care in Spain: A structural equations model. Work \& Stress, 6(3), 261-276.

Pugh, S. D., Skarlicki, D. P., \& Passell, B. S. (2003). After the fall: Layoff victims' trust and cynicism in re-employment. Journal of Occupational \& Organizational Psychology, 76(2), 201-212.

Reichers, A. E., Wanous, J. P., \& Austin, J. T. (1997). Understanding and managing cynicism about organizational change. Academy of Management Executive, 11(1), 48-59.

Stanley, D. J., Meyer, J. P., \& Topolnytsky, L. (2005). Employee cynicism and resistance to organizational change. Journal of Business \& Psychology, 19(4), 429-459.

Thompson, R. C., Bailey, L. L., Joseph, K. M., Worley, J. A., \& Williams, C. A. (1999). Organizational change: Effects of fairness perceptions on cynicism. In U. S. D. o. T. F. A. Administration (Ed.).

Thompson, R. C., Joseph, K. M., Bailey, L. L., Worley, J. A., \& Williams, C. A. (2000). Organizational change: An assessment of trust and cynicism. In U. S. D. o. T. F. A. Administration (Ed.).

Turner, J. H., \& Valentine, S. R. (2001). Cynicism as a fundamental dimension of moral decision-making: A scale development. Journal of Business Ethics, 34(2), 123-136. 
Urbany, J. E. (2005). Inspiration and cynicism in values statements. Journal of Business Ethics, 62, 169-182.

Valentine, S., \& Elias, R. Z. (2005). Perceived corporate ethical values and individual cynicism of working students. Psychological Reports, 97, 832834.

Wanous, J. P., Reichers, A. E., \& Austin, J. T. (1994). Organizational cynicism: An initial study. Paper presented at the Academy of Management Proceedings.

Wanous, J. P., Reichers, A. E., \& Austin, J. T. (2000). Cynicism about organizational change: Measurement, antecedents, and correlates. Group \& Organization Management, 25(2), 132-153.

Wanous, J. P., Reichers, A. E., \& Austin, J. T. (2004). Cynicism about organizational change: An attribution process perspective. Psychological Reports, 94(3), 1421-1434. 


\section{CHAPTER 3}

\section{Value incongruence, job autonomy, and organization-based self-esteem: a self- based perspective on organizational cynicism}

Fons Naus, Ad van Iterson \& Robert A. Roe. Accepted for publication in the European Journal of Work and Organizational Psychology.

\section{Abstract}

Combining the perspectives of person-environment fit and self-theory, a model was postulated in which both the incongruence between personal and perceived organizational values and job autonomy precede organizational cynicism, while organization-based self-esteem, as a psychological explanation for cynicism, was hypothesized to mediate both relationships. The model and corresponding hypotheses were tested on a sample of 174 Dutch workers. Polynomial regression results indicated that value incongruence and job autonomy add significantly to the prediction of organizational cynicism. Hierarchical regression analysis was used to test the hypothesized mediating effect of organization-based self-esteem. Results indicated that self-esteem partially mediates both relationships. These results support the conceptualization of organizational cynicism as a self-defensive response to problematic events and circumstances in the work environment. 


\section{Introduction}

Organizations thrive on the favorable work attitudes of their employees. Yet, in many organizations unfavorable attitudes among employees are a fact of life. A recent survey by US-based professional services firm Towers Perrin among more than 85,000 people, working for large and midsized companies in sixteen countries on four continents, revealed that the vast majority of the people surveyed were at best moderately engaged with their employing organization, and a quarter of them were even found to be actively disengaged (Towers Perrin, 2005). Numerous scientific studies have demonstrated the existence of negative attitudes originating from adverse working conditions, such as high work demands, time pressure, lack of control, emotional abuse and bullying in the workplace (e.g. Cooper, 2001; Dollard, Winefield, Winefield, \& de Jonge, 2000; Einarsen, Hoel, Zapf, \& Cooper, 2003; Fox \& Spector, 2005; Hom \& Kinicki, 2001). Other studies have shown employees' negative attitudinal and health responses to downsizing, outsourcing, and organizational restructuring (e.g. Allen, Freeman, Russell, Reizenstein, \& Rentz, 2001; Hellgren, Sverke, \& Isaksson, 1999; McElroy, Morrow, \& Rude, 2001; Nettersrom \& Hansen, 2000).

An emerging topic in this context is organizational cynicism (OC), which has been defined as 'a negative attitude toward one's employing organization, comprising three dimensions: (1) a belief that the organization lacks integrity; (2) negative affect toward the organization; and (3) tendencies to disparaging and critical behavior toward the organization that are consistent with these beliefs and affect' (Dean et al., 1998). Its core belief is that principles of honesty, fairness, and sincerity are sacrificed to further the self-interests of leadership, leading to actions based on hidden motives and deception (Abraham, 2000a). Empirical data on the incidence of organizational cynicism were provided by Kanter and Mirvis (1989), who found that $43 \%$ of American workers were highly cynical about their employing organization, and by Reichers, Wanous and Austin (1997) who classified 48\% of the employees who participated in their study as high on cynicism about organizational change. In addition, it is argued that organizational cynicism has only increased in recent years (Bommer et al., 2005). Research findings suggest that organizational cynicism is associated with a variety of undesirable outcomes. Literature reviews by Andersson (1996) and Dean et al. (1998) mention relationships with apathy, resignation, alienation, hopelessness, distrust of others, suspicion, contempt, disillusionment, and scorn, as well as poor performance, interpersonal conflict, absenteeism, job turnover, and burnout. Both the 
prevalence of cynicism and its purported negative effects on the individual and the organization warrant further investigation into its nature and origin. Although researchers have identified a host of personal and organizational factors that may be related to the emergence of cynicism, such as failed attempts to initiate organizational change, perceptions of self-interested managerial behavior and managerial incompetence, the combination of high executive compensation, poor organizational performance and mass layoffs, excessive stress, role overload, unmet personal and organizational expectations, inadequate social support, promotion beyond the level of competence, goal conflict, organizational complexity, cutbacks, threats of obsolescence (Andersson, 1996; Andersson \& Bateman, 1997), there is as yet little consensus on its antecedents. In this article we will look beyond the apparent diversity of these findings. More specifically, our aim is to develop and test a theoretically based general model of the antecedents of OC.

\section{Theory and hypotheses}

As a starting point for the development of our model we refer to Kanter and Mirvis' (1989) conceptualization of cynicism 'as a matter of selfpreservation' (p. 14) and to Reichers et al. (1997) and Abraham (2000a), who discuss cynicism as a form of self-defense that may help people make sense out of puzzling events, shielding them from frustration and disappointment. Both conceptualizations of cynicism are centered around the self-construct. Theories about the self are grounded in the assumption that human beings have a fundamental need to maintain or enhance their own unique individuality and personality by keeping positive self-images. These images are most significantly defined in terms of central values, traits, and competencies (Leonard, Beauvais, \& Scholl, 1999), and it is through our attitudes and behavior that we will try to satisfy this fundamental need (Snyder \& Williams, 1982). The centrality of the self construct was adopted by organizational scholars, such as Korman (1970, 1976, 2001), to account for the attitudes and behavior of employees. Korman's central hypothesis was that employees will be motivated to act and behave in a manner consistent with their self-images. From this it follows that organizations that enable their employees to live up to central values, traits, and competencies, thereby developing positive self-images, will likely foster positive attitudes and behavior. On the other hand, organizational characteristics and practices, such as a high degree of external control or forced compliance with organizational values that deviate from privately held key values, may inhibit employees from developing positive self-images. Cynicism 
about the organization may then be an effective form of self-defense or 'damage control', to prevent further erosion of the self-image (Pierce \& Gardner, 2004). In line with Kanter and Mirvis (1989), Reichers et al. (1997), and Abraham (2000a), we conceive of cynicism as a self-defensive attitude, aiming to preserve, defend, or live up to values, traits, and competencies, central to the self in situations of potential discrepancy.

\subsection{Organizational cynicism and value incongruence}

As the first predictor of cynicism we postulate value incongruence, defined as the lack of fit between employees' personal values and organizational values (Kristof, 1996). This is in line with Abraham (2000a), who states that cynicism toward the organization may result from workers' perceptions of a lack of congruence between their own personal values and those of the organization. The idea of a misfit between personal and organizational values is particularly appealing for the study of cynicism, since values are enduring beliefs about preferable conduct or end-states (Rokeach, 1973) that can influence a wide range of attitudes and behaviors (Roe \& Ester, 1999). At the personal level, values are the basis for privately held norms that control expressions of the self through opinions, attitudes, and behavior. At the organizational level, values are part and parcel of the organizational culture. They will thereby be embedded in the way the organization is managed (Chatman, 1989) and become reflected in rituals and practices. When personal and organizational values are discrepant, the employee's behavior will violate either of these values. Because organizational values tend to be dominant and have to be given priority over individual values whenever the employee is 'in role', the personal values are the ones most likely to be violated. However, in the literature it is argued that 'an individual's internalized values (i.e. the ideal self) function as personal standards of conduct. Therefore, any actions that are inconsistent with these values will result in feelings of guilt, shame, or self-depreciation...Because value-inconsistent behavior produces such negative feelings, individuals who fail to act, or are prevented from acting, in accordance with their values should exhibit lower levels of satisfaction' (Meglino \& Ravlin, 1998, p. 356). The development of cynicism by employees can then be understood as a selfdefensive attitudinal response (Kanter \& Mirvis, 1989; Meyerson, 1990) that aims to withstand or cope with the organizational values in an effort to satisfy the need for self-consistency. This line of thought places organizational cynicism within the more general framework of person-environment fit. It confirms the assumption that value congruence is an important aspect of P-E fit 
(Kristof, 1996; Ostroff, Shin, \& Kinicki, 2005) and postulates that a lack of fit will result in a specific attitudinal response, in this case cynicism vis-à-vis the organization.

As person-organization fit and value congruence are based on the notion of similarity between personal and organizational characteristics (Kristof, 1996), there is no compelling reason to expect that work attitudes will differ depending on whether the individual's value orientation is greater than or less than that of the organization. In either situation 'incongruence....is likely to result in frustration, difficulty in working effectively with others, lack of role clarity, and so forth' (Ostroff et al., 2005, p. 595-596). Hence, we propose the following hypothesis:

Hypothesis 1: Incongruence between employees' personal values and the perceived corresponding values of the organization, will be positively related to organizational cynicism.

\subsection{Organizational cynicism and job autonomy}

A second predictor in our model is job autonomy (job control, decision latitude). Job autonomy has been defined as 'the degree to which the job provides substantial freedom, independence, and discretion to the individual in scheduling the work and determining the procedures to be used in carrying it out' (Hackman \& Oldham, 1976). Self-theory postulates that traits and competencies, i.e. the skills, abilities, talents, and knowledge possessed by the individual, are major defining characteristics of the self (Leonard et al., 1999). As individuals will be motivated to maintain or enhance consistent and favorable views of themselves, it stands to reason that they will be motivated to behave not only in accordance with their personal values, but also in accordance with their most central and identity defining traits and competencies. Organizational or job characteristics that enable them to do so, such as autonomy, will likely result in positive outcomes, such as job satisfaction and commitment. On the other hand, organizational characteristics that inhibit selfexpressive behavior will potentially evoke opposition and resistance, leading to less favorable attitudes and behavior. One such outcome might be cynicism, especially when employees' striving to develop and demonstrate creativity and competence in their work is thwarted by structural features, such as strict rules and procedures, seemingly pointless paperwork, and tight organizational control. In short, a lack of autonomy might result in negative outcomes. Research has demonstrated that at the individual level employees who have 
more job autonomy show more positive affect, internal motivation, and selfconfidence (Hackman \& Oldham, 1976), more creativity (Oldham \& Cummings, 1996), less mental strain (Karasek, 1979), more internal motivation and satisfaction with different aspects of the work context (Oldham \& Hackman, 1981), and less emotional dissonance (Abraham, 2000b), compared with those who have little job autonomy. At the organizational level, autonomy is considered a prerequisite for competency-based effective organizations (Lawler III, 1994). In addition, a general finding from burnout research is that autonomy seems to act as a buffer, reducing the impact of stressors on strain and burnout. In a recent study by Bakker, Demerouti \& Euwema (2005) of the job demands - resources model of Demerouti, Bakker, Nachreiner and Schaufeli (2001), which is an extension of the job demands-control model by Karasek (1979), it was found that autonomy buffered the effects of job demands on various outcomes, including cynicism. The relationship between job autonomy and organizational cynicism is also referred to by Abraham (2000a), who argues that '...merely giving employees more control over decision making in planning the scope and nature of their jobs...may help to overcome employee and organizational change cynicisms' (p. 285). We therefore offer the following hypothesis:

Hypothesis 2: Job autonomy will be negatively related to organizational cynicism.

\subsection{The mediating role of organization-based self-esteem}

The third step in the development of our model is the introduction of a construct that is intended to provide a specific psychological explanation for the hypothesized effects of value incongruence and job autonomy on organizational cynicism. Earlier research has suggested that cynicism is a self-defensive response to threat (Kanter \& Mirvis, 1989; Meyerson, 1990; Reichers et al., 1997). We assume that incongruence between personal and organizational values and a lack of autonomy may pose such threats to the self, since they prevent the employee from acting in a self-expressive and self-consistent manner (Korman, 2001). More specifically, we propose that value incongruence and low autonomy threaten the employee's self-esteem. Various studies have demonstrated the importance of gaining and maintaining self-esteem in organizational settings (e.g. Judge, Locke, \& Durham, 1997). Researchers of self-esteem have noted that global measures have limited explanatory power when used to explain specific behaviors in organizational settings. Therefore, 
Pierce, Gardner, Cummings and Dunham (1989) introduced the organizationbased self-esteem (OBSE) construct, reflecting 'the self-perceived value individuals have of themselves as organization members acting within an organizational context' (p. 625). Over the years many studies have shown the significance of the OBSE construct. From the OBSE literature review by Pierce and Gardner (2004) OBSE appears to be related to a wide area of work attitudes, such as job satisfaction, organizational commitment, adaptation to organizational change, turnover intention, organizational citizenship behavior, organizational identification and ethical behavior intentions. Also, positive relationships between autonomy and OBSE, and between job control and OBSE are reported.

Although we are unaware of studies that have looked into the links between OBSE and either value incongruence or cynicism, we suggest such links do exist, and that OBSE can in fact provide a psychological explanation why incongruence between personal and organizational values makes employees respond in a cynical manner. Korman $(1970,1976,2001)$ has argued that self-esteem is central to the explanation of employee attitudes. Furthermore, it is claimed that OBSE is, to a large extent, a social construction, shaped by implicit or explicit messages transmitted by relevant actors in the organizational environment and received and interpreted by employees as self-referent social feedback on values, competencies, and traits, and on the social value of these key attributes of the self-image (Pierce \& Gardner, 2004). One such message might be a high degree of system-imposed behavior control, implicitly communicating the organizational belief that the employee is not competent or even willing to self-regulate. Also, being compelled to comply with organizational values or practices the employee cannot identify with may engender feelings of powerlessness, disappointment and frustration, and set in motion the process of self-defense or damage control, earlier referred to in this chapter. In the same vein, Erez and Early (1993) refer to the self as the central processing unit, transforming cues from the social environment into information relevant to one's self-image, thereby directing attitudes and behavior. Therefore, we suggest that self-esteem may not only be predictive of cynicism, but it may also operate as a central processing unit, mediating the value incongruence cynicism and job autonomy - cynicism relationships. This leads to the following hypotheses:

Hypothesis 3a: Organization-based self-esteem will be negatively associated with organizational cynicism. 
Hypothesis 3b: The relationship between incongruence between employees' personal values and the perceived corresponding values of the organization, and organizational cynicism, will be mediated by organization-based self-esteem.

Hypothesis 3c: The relationship between job autonomy and organizational cynicism will be mediated by organization-based self-esteem.

The hypothesized relationships are illustrated in Figure 1.

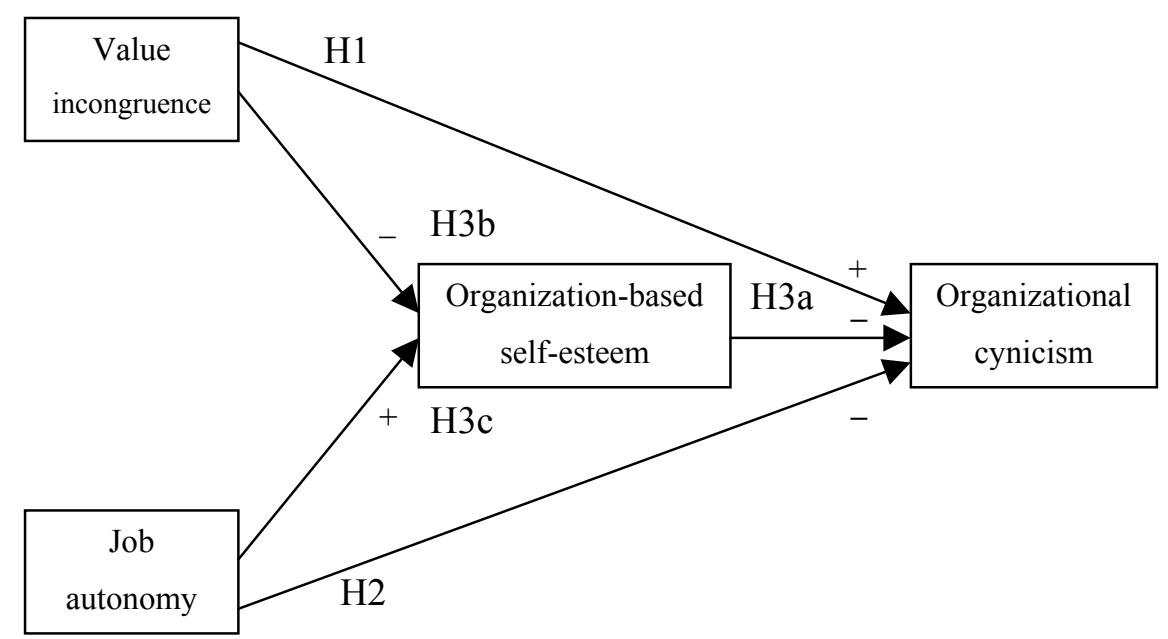

Figure 1. Research model.

\section{Method}

\subsection{Sample and procedure}

Participants in this study were 174 Dutch workers (100 female, 74 male). They were approached through a classified ad that was placed in 17 regional Dutch newspapers, covering the entire country, with a total circulation of about 1.2 million copies. The advertisement was placed in a neutral rubric 'miscellaneous announcements', and contained the following text: 'Nice job, boring job? If you want to participate in research on work experience, go to:...' with the URL of a website. On this website information was provided about the scientific nature of the research, the first author's affiliation, and relevant aspects of the research, such as the topic ('factors that affect work experience'), and the approximate time needed for completion of the survey (' 15 minutes at the maximum'). We also assured respondents anonymity and that there were no right or wrong answers, and they were offered to receive feedback on the results of the study. It is important to note that the term cynicism was avoided 
altogether, and special care was taken that the ad would not be placed anywhere near job advertisements, to avoid sample bias of dissatisfied workers looking for another job.

Respondents' ages ranged from 19 to 66 , with the average age 40.3 years $(S D=$ 10.5 years). Tenure in the present job ranged from 0 to 44 years, with an average of 8.6 years $(S D=9.7$ years). In total 105 respondents held a full-time job (41 female, 64 male) and 69 were part-time employed (59 female, 10 male). With regard to industry, health care $(n=34)$, education $(n=22)$ and the government sector $(n=16)$ were strongly represented.

\subsection{Measures}

Organizational cynicism. Organizational cynicism was measured with five items, taken and adapted from the measure previously used by Kanter and Mirvis (1989), reflecting particular beliefs about the integrity of the organization: 'My organization will tell a lie if it can gain by it,' 'My organization claims to have ethical standards, but does not stick to them when money is at stake,' 'My organization pretends to care more about social responsibility than it actually does,' 'My organization is not just out for itself (reverse-coded),' and 'My organization is honest and sincere by nature (reversecoded).' The items were measured on a 7-point Likert-type scale with endpoints strongly disagree (1) and strongly agree (7). To assess the homogeneity of the scale, an exploratory factor analysis was conducted. With all items loading on one factor, and all factor loadings being greater than .80 , we are confident that these items are indeed reflective of the same underlying construct. Responses were averaged into an index of organizational cynicism. We obtained a coefficient alpha of .90 .

Value incongruence. The following values were used to construct profiles of respondents' personal values and their perception of the corresponding values of their employing organization: achievement, helping and concern for others, fairness, and honesty (Meglino, Ravlin, \& Adkins, 1989). In analyses of 966 critical incident responses in over 40 organizations throughout the Unites States, these values emerged as the most salient values to employees across a broad spectrum of jobs and organizational environments (Judge \& Bretz Jr., 1992). For that reason, they were chosen in the present study. Following Dean et al. (1998) who noted that organizational cynicism primarily stems from the belief that the organization lacks integrity, integrity was added as a fifth value. In the questionnaire it was explained that integrity had to be interpreted as 'to practice what is being preached.' The values were 
measured using the following questions: 'How important is [value] to you?' and 'How important do you think [value] is to your organization?' The answers were measured on a 7-point Likert-type scale with endpoints not at all important (1) and very important (7).

To measure congruence between personal and organizational values, we employed indirect individual level measurement (Kristof, 1996, p. 14), i.e. we neither asked people to indicate directly whether they believe a good fit, or congruence, between them and the organization exists, nor did we strive for a purportedly objective assessment of organizational values. Instead, we asked respondents to separately indicate how important the values are to them personally and how important they think the values are to the organization. Accordingly, all measurements took place at the individual, perceptual level of analysis. Although this method is not without problems, its main advantage is that 'the perception of organizational characteristics may have a stronger influence on individual outcome variables such as stress, satisfaction, or commitment than would fit with the organization's actual characteristics' (Kristof, 1996, p. 14). The aim of this study was not to judge whether people make accurate observations, i.e. to measure objective congruence or fit, but rather to establish an individual level measure of actual fit between the person and the organization as a precursor of cynicism.

The measurement of (in)congruency, once profiles of personal and organizational values have been established, has raised some controversy among scholars. One of the most popular methods is to compare the profile of personal values with the profile of organizational values and to generate a single distance score, typically a simple difference score. Opponents of this method argue that difference scores suffer from problems such as conceptual ambiguity, discarded information, insensitivity to the sources of profile differences, overly restrictive constraints on coefficients in regression equations, unreliability, correlation with components and spurious correlation with other variables (e.g. Edwards, 1993; Edwards \& Parry, 1993; Johns, 1981). They prefer to include all variables and their interactions in the analysis. Edwards (1993; Edwards \& Parry, 1993) has strongly advocated the use of polynomial regression for predicting a dependent variable from potentially discrepant independent variables. Advocates of difference scores rebound that a difference between two entities represents something conceptually distinct from its components and that the researcher's primary concern should be whether the data fit a predetermined theory, rather than whether the data fit an empirical model (Tisak \& Smith, 1994a, 1994b). 
We believe both views have their merits. However, because the approach proposed by Edwards allows for a detailed analysis of the relationships between a set of independent variables and the dependent variable, and as it seems to prevail as a favored method of analysis in recent congruence studies in the organizational sciences (e.g. Finegan, 2000; Ostroff et al., 2005), it was decided to use this approach for hypothesis testing in the present study.

Organization-based self-esteem. Pierce et al. (1989) suggested ten items to measure the regard employees have for themselves as organization members. In the present study we used nine of them. Representative items were 'I count around here' and 'I am taken seriously.' One item ('I work efficiently around here') was dropped because it could not be translated meaningfully in Dutch. This need not be very problematic, because Pierce and Gardner (2004) argue that a more parsimonious instrument might be a viable option, given the consistently high coefficient alpha values obtained so far. Across the studies reviewed by them, the average alpha value was .88. In the present study we obtained a coefficient alpha of .89. All items were measured on a 7-point Likert-type scale with endpoints strongly disagree (1) and strongly agree (7).

Job autonomy. This variable was measured with six items, adapted from Karasek (1979). Representative items were 'To a large extent I have control over what happens in my job', and 'My job allows me to make decisions on my own.' All items loaded on the same factor with loadings between .61 and .82, and were measured on a 7-point Likert-type scale with endpoints strongly disagree (1) and strongly agree (7). Coefficient alpha was .79.

Control variables. We controlled for gender, age, tenure in the present job, part-time vs. full-time employment, and education. Education was coded as a dichotomous variable, with a category for lower to medium education (coded 0 ) and one for higher education (coded 1).

\section{Results}

Descriptive statistics and correlations are reported in Table 1 . Organizational cynicism (OC) correlates negatively with all perceived organizational values, and most strongly with integrity $(-.56, p<.001)$. This is in line with the definition of OC by Dean et al. (1998), and it attests to the construct validity of our measure of OC. 


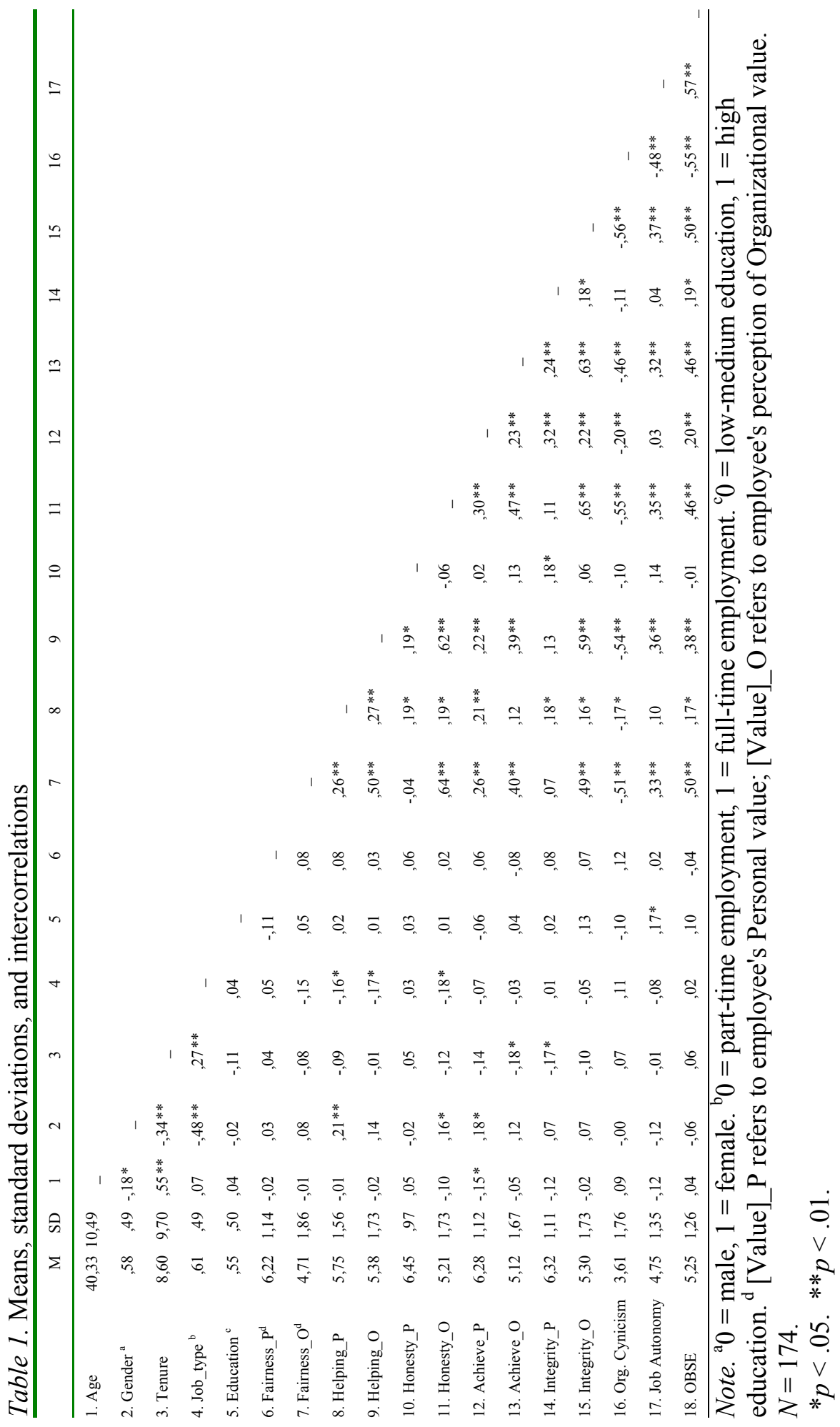


The control variables did not significantly explain unique variance in organizational cynicism $\left(R^{2}=.05, F(5,156)=1.72, p<.14\right)$. They were therefore not included in the analyses. Hypothesis 1 predicts a positive relationship between value incongruence and organizational cynicism. Prior to the analysis, all variables were centered around the mean, to avoid problems of multicollinearity. First, polynomial regression analysis was used to estimate the overall effect of all five values simultaneously. All linear, squared, and product terms for all values were entered, resulting in $R_{\text {adj }}^{2}=.49, p<.001$. This result indicates that a considerable portion of variance in organizational cynicism is indeed accounted for by values. Next, separate polynomial regression analyses were conducted for each value individually. The regression results are shown in Table 2. In the first step the linear terms for the personal and organizational value were entered (model 1), in the second step the squared terms and the product terms were entered additionally (model 2).

Model 2 was only interpreted when a significant portion of unique variance in cynicism was accounted for over and above model 1. In other words, a significant change in $R^{2}$ in the second step would be indicative of nonlinearity of congruence effects. This turned out to be the case for all variables, except for fairness. As for the interpretation of polynomial regression equations, it has to be noted that for decades (in)congruence between values has been captured in one single profile similarity index, such as a single difference score (for an overview, see Edwards, 1993), whereas the use of polynomial regression implies that both measures comprising the index are related to the outcome. Thus, the outcome is no longer a function of a single variable, such as a $D$ score, but instead becomes a function of two variables, and the effect of two predictors on one outcome can only be adequately represented in a threedimensional space. Moreover, coefficients from equations containing linear, squared and product terms are often difficult to interpret (Edwards \& Parry, 1993). To facilitate the interpretation of the results presented in Table 2, we therefore plotted the congruence effects in Figures 2a-2e. 


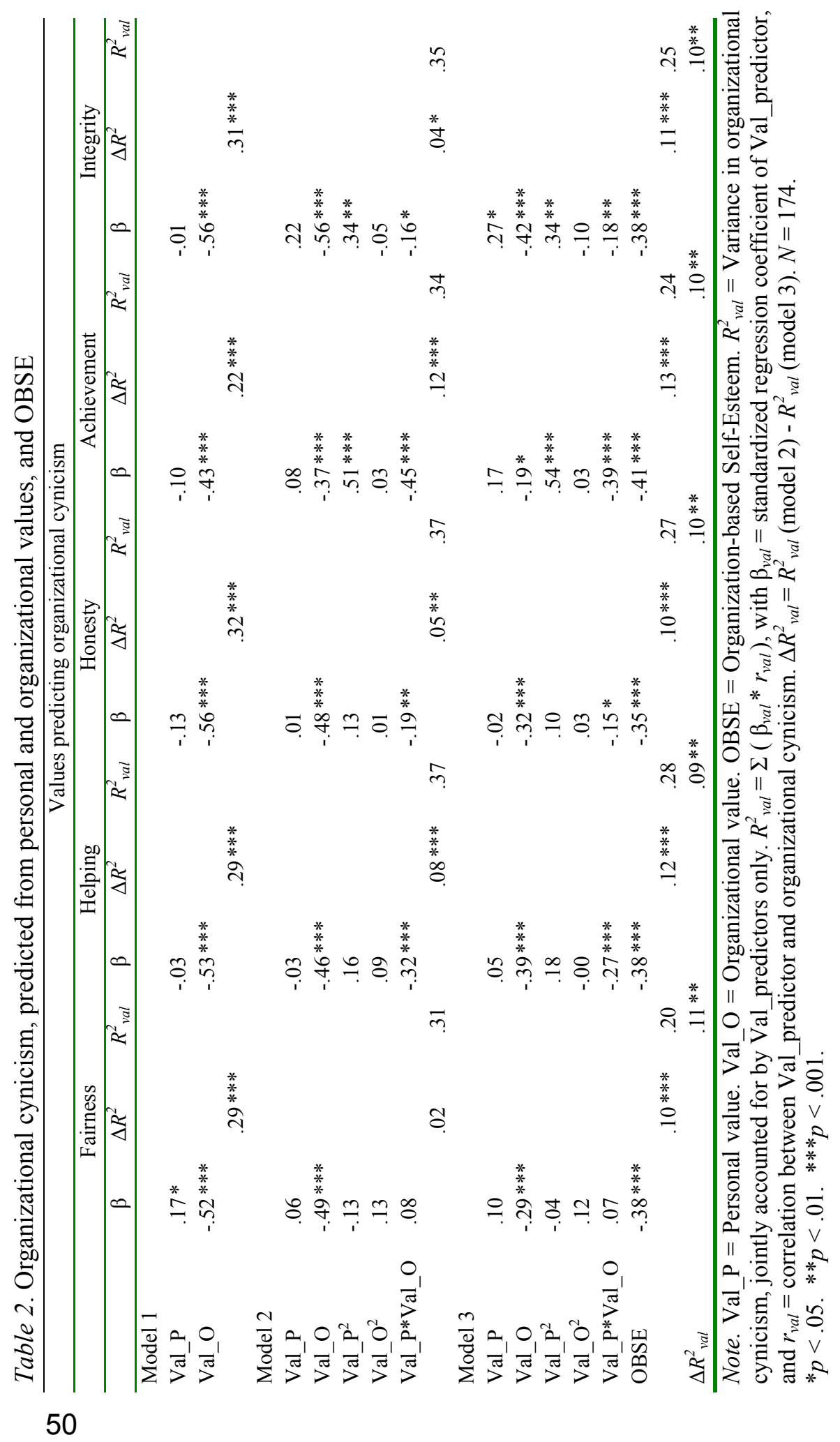




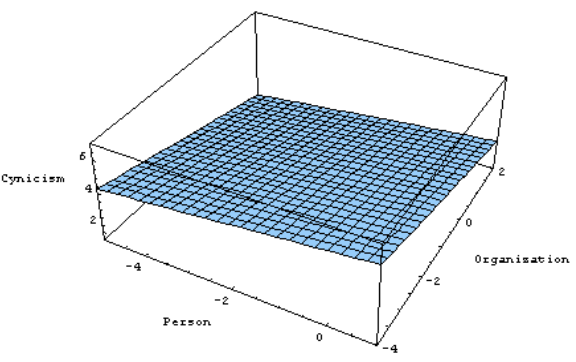

Figure 2a. Fitted surface graph showing relations between personal importance of fairness, its perceived organizational importance and organizational cynicism.

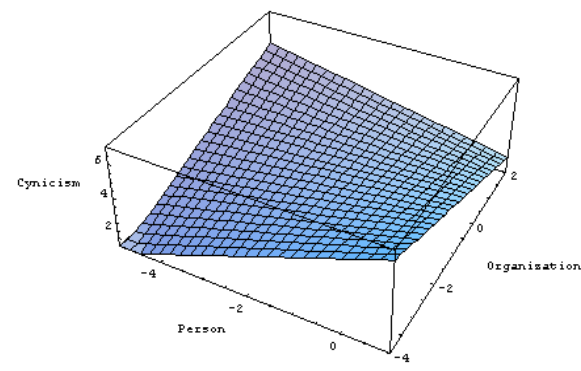

Figure 2c. Fitted surface graph showing relations between personal importance of honesty, its perceived organizational importance and organizational cynicism.

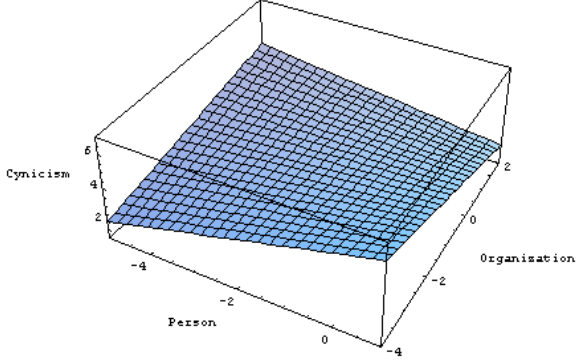

Figure 2b. Fitted surface graph showing relations between personal importance of helping and concern for others, its perceived organizational importance and organizational cynicism.

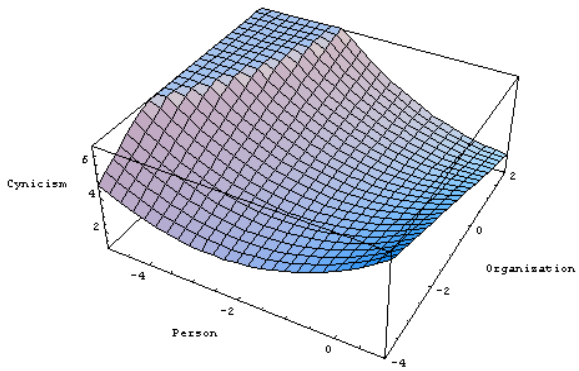

Figure $2 d$. Fitted surface graph showing relations between personal importance of achievement, its perceived organizational importance and organizational cynicism. 


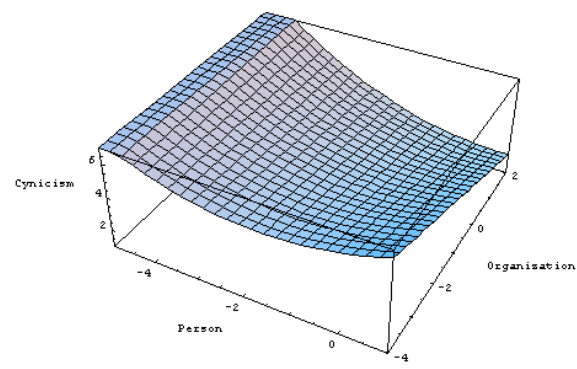

Figure 2e. Fitted surface graph showing relations between personal importance of integrity, its perceived organizational importance and organizational cynicism.

Table 3 gives an overview of theoretically expected vs. observed relationships between value (in)congruence and cynicism.

Table 3. Expected vs. observed relationships between value (in)congruence and organizational cynicism

\begin{tabular}{|c|c|c|c|c|c|c|c|c|}
\hline \multicolumn{9}{|c|}{ Value (in)congruence predicting organizational cynicism } \\
\hline $\begin{array}{l}\text { Val_P - } \\
\text { Val_O }\end{array}$ & \multicolumn{2}{|c|}{ High-High } & \multicolumn{2}{|c|}{ High-Low } & \multicolumn{2}{|c|}{ Low-High } & \multicolumn{2}{|c|}{ Low-Low } \\
\hline & Expected & Observed & Expected & Observed & Expected & Observed & Expected & Observed \\
\hline Fairness & Low & Low & High & High & High & Low & Low & Medium \\
\hline Helping & Low & Low & High & High & High & Medium & Low & Low \\
\hline Honesty & Low & Low & High & High & High & High & Low & Low \\
\hline Achievement & Low & Low & High & High & High & High & Low & Medium \\
\hline Integrity & Low & Low & High & High & High & High & Low & High \\
\hline
\end{tabular}

Note. Val_P $=$ Personal importance attributed to value. Val_O $=$ Perceived Organizational importance attributed to value. Incongruence between personal and organizational values respectively is represented in the High-Low and LowHigh columns, congruence in the High-High and Low-Low columns.

Hypothesis 1 predicts that incongruence in either direction is expected to result in relatively high cynicism, whereas congruence (high-high, or lowlow) is expected to result in relatively low cynicism. Only in two cases the results were not in line with our expectations: For the person low on fairness and the organization perceived as high on fairness cynicism was low instead of high, and for both the person and the organization scoring low on integrity cynicism was high instead of low. In three more cases the results were 
somewhat discrepant with our expectations. However, in fifteen cases the observed results were indeed in line with expectations. Taken together, these results are largely in support of hypothesis 1 .

Hypothesis 2 predicts a negative relationship between job autonomy and organizational cynicism. Table 1 shows that the direct association between both variables is rather strong and in the expected direction $(-.48, p<.001)$. This result is in support of hypothesis 2 .

Hypothesis 3a predicts a negative relationship between organizationbased self-esteem and organizational cynicism. Table 1 shows a negative correlation between OBSE and cynicism $(-.55, p<.001)$, supporting this hypothesis. Next, both mediation hypotheses were tested. Hypothesis $3 b$ predicts that OBSE will mediate the relationship between value incongruence and organizational cynicism. Whereas mediation of the relationship between a single predictor and an outcome can easily be assessed through inspection of the decrease in the regression coefficient when the mediating variable is included in the model, this assessment becomes less straightforward when the mediation pertains to the relationship between five predictors, jointly affecting a dependent variable, which is the case with the relationship between value incongruence and cynicism. To test this hypothesis, a comparison was made between variance in cynicism accounted for by all value congruence predictors in the model without OBSE (Table 2, model 2), and in the model with OBSE (Table 2, model $3)$. For OBSE to act as a mediator, the strength of the association between value incongruence and cynicism would have to decrease as a consequence of adding OBSE to the model (Baron \& Kenny, 1986; Frazier, Tix, \& Barron, 2004). For all 5 values, Table 2 shows a considerable drop in variance in cynicism accounted for by value predictors, after OBSE was added to the model. For fairness, it dropped from .31 to .20 , for helping and concern for others from .37 to .28 , for honesty from .37 to 27 , for achievement from .34 to .24 , and for integrity from .35 to .25 . This was taken as support for hypothesis $3 \mathrm{~b}$, because it attested to the role of OBSE, mediating the relationship between value incongruence and cynicism. Finally, hypothesis 3c predicts that OBSE will mediate the relationship between job autonomy and organizational cynicism. Table 4 shows that adding OBSE to the model not only accounts for a significant portion of unique variance in cynicism, but also for a considerable decrease in the strength of the relationship between job autonomy and cynicism, as indicated by a drop in the regression coefficient from -.48 to - .24 . This result is in support of hypothesis $3 \mathrm{c}$. 
Table 4. Organizational cynicism, predicted from job autonomy and OBSE

\begin{tabular}{lcc}
\hline & $\beta$ & $\Delta R^{2}$ \\
\hline Model 1 & & \\
Job autonomy & $-.48^{* * *}$ & \\
& & $.23 * * *$
\end{tabular}

Model 2

Job autonomy $\quad-.24 * *$

OBSE $\quad-.42 * * *$

Note. OBSE $=$ Organization-based self-esteem.

$N=174$.

${ }^{* *} p<.01 .{ }^{* * *} p<.001$.

Taken together, these results provide substantial support for hypotheses $3 \mathrm{~b}$ and $3 \mathrm{c}$, predicting that OBSE can serve as a psychological explanation for organizational cynicism in response to perceptions of incongruency between personal and organizational values, and to work situations in which the employee perceives a lack of freedom, independence, and discretion in the job.

\section{Discussion}

This study was undertaken to investigate potential antecedents of cynicism toward one's employing organization. Although many such antecedents have been identified in the literature, a coherent theoretical framework providing a specific psychological explanation for cynicism was lacking so far. Some important findings have emerged from our research. First, incongruence in either direction between employees' personal values and their perception of the values of their employing organization was shown to be a strong predictor of organizational cynicism, whereas congruence was shown to result in low cynicism. Although the congruency hypothesis received strong support, in a few cases the results were not in line with our expectations. In particular, this was the case for employees who indicated that their organization's integrity was neither very important to themselves, nor did they believe it was important to their organization, but who were nevertheless cynical. A methodological explanation might be that this result is due to measurement error. Although in the questionnaire it was explained that integrity was to be interpreted as 'to practice what is being preached', and although the scales generally appeared to provide valid and reliable measures of the 
underlying constructs, the possibility that one or more items may have been misinterpreted cannot be ruled out. A psychological explanation may be provided by cognitive dissonance theory. Over time, these respondents may have experienced their organization's lack of integrity, without being able to escape the situation or do something about it. One way to resolve their cognitive dissonance and cope with the situation may be to scale down the importance of integrity within the value hierachy, by telling themselves that 'there's more important things in life', although in reality they may still believe it's as important as ever. On the whole, the importance of values as a motivational force in the interaction between employees and their employing organization was confirmed (Meglino \& Ravlin, 1998). The same is true for Kristof's (1996) argument that the perception of organizational characteristics is likely to have a strong influence on individual outcome variables. Measuring values and value (in)congruence as an indicator of the (mis)fit between person and organization is the subject of an ongoing debate (Meglino \& Ravlin, 1998). In her review of conceptualizations, measurement, and implications of person-organization fit, Kristof (1996) discusses direct and indirect measures of fit. Direct measurement involves asking people explicitly whether they believe a good fit, or congruence, between them and the organization exists. Although direct measures may produce significant relationships with individual outcomes, these measures suffer from a number of substantial problems that may restrain the interpretation of research findings. These problems include the confounding of the constructs of the person and the organization, thereby preventing the estimation of their independent effects, and a consistency bias that could potentially inflate the strength of the relationships between variables, e.g., 'I think I fit well with my organization, so I must be satisfied with my job' (Kristof, 1996, p. 11). To measure value incongruence, we therefore opted for indirect individual level measurement (Kristof, 1996, p. 14). Second, whereas values have been proven to be a strong person-based predictor of cynicism, job autonomy turned out to be an equally strong situational predictor of cynicism. This is in line with a long series of earlier findings that job autonomy has a big impact on work attitudes. Third, and perhaps the most important strength of our study, was that the inclusion of a self-based construct provided a theoreticallybased psychological rationale for organizational cynicism. The fact that OBSE indeed partially mediated the effects of value incongruence and job autonomy on organizational cynicism, while adding to the explanatory power of the model as a whole, attests to the conceptualization of cynicism as a self-defensive 
attitude. Thus, we were able to empirically support Korman's ideas about selfconsistency under adverse conditions in the work environment.

Given that many organizations consistently emphasize their integrity, honesty, and concern for others, while not always living up to such claims in the eyes of their employees, these findings have important implications for management. They indicate that faith in the organization is seriously jeopardized when employees start questioning the integrity of their employing organization and perceive low autonomy in their jobs. Most importantly, under these circumstances they may even start questioning themselves as valuable employees, with potentially damaging consequences for their attachment to the organization.

As with any other study, the present research has several limitations that need to be addressed. First, the study was designed as a cross-sectional study in which self-reports were used as the sole source of data. Although the use of self-report surveys is common practice in the social sciences, this measuring instrument has raised severe concerns as a method for collecting data on independent as well as dependent variables (e.g. Avolio, Yammarino, \& Bass, 1991; Kline, Sulsky, \& Rever-Moriyama, 2000; Lindell \& Whitney, 2001; Podsakoff, MacKenzie, Lee, \& Podsakoff, 2003; Podsakoff \& Organ, 1986; Spector, 1994; Williams, Ronald Buckley, \& Cote, 1989). Essentially, the problem is that the variance in the data, and the relationships between variables, might potentially be as much attributable to the measurement method itself as to the actual constructs and relationships being measured. This might lead to erroneous conclusions about the validity of the model being tested. Although researchers seem unanimous in their criticism, Crampton and Wagner (1994) signalled widely conflicting conclusions about the effects of self-report methods on microorganizational percept-percept research. They concluded that perceptpercept inflation is neither dominant nor absent and that the effects of selfreport methods on research cannot be considered self-evident. In a similar vein, Doty and Glick (1998) found that common methods bias is indeed cause for concern, but it does not invalidate many research findings. Second, when both independent and dependent variables are measured at one point in time, causality can never be inferred. This is a limitation inherent in every crosssectional design and we believe Spector (1994) is rather modest in his observation that 'a cross-sectional study cannot provide much certainty about the causal connections among variables' (p. 389). In fact such a design cannot provide any certainty about causality at all, since cause-and-effect relationships between two variables can be reversed without affecting the strength of the 
relationship. Despite the fact that the process of mediation implies a causal chain, since the mediator is assumed to be caused by the predictor and to cause the outcome variable (Frazier et al., 2004), only an experimental or longitudinal design could accomodate this shortcoming. For that reason we have been reluctant to state our hypotheses in terms of causal relationships. Nevertheless, our finding of organization-based self-esteem as an intervening variable may be an important first step toward a more comprehensive self-based model of cynicism at work. Third, conceptual overlap exists between our cynicism measure and the values we measured. For example, one of the values measured was honesty, and one of the items measuring cynicism was 'my organization is honest and sincere by nature.' This overlap may have inflated the strength of the relationships between some of the variables in our study. Fourth, our sampling method may pose another limitation. Not everybody reads newspapers, and therefore the generalizability of our findings has to be assessed with due caution. Furthermore, an online questionnaire may be subject to potential restraints, such as limitations to internet access (Best \& Krueger, 2004). On the other hand, this method of gathering data has the advantage of reaching a broad sample of working people, covering a wide variety of jobs and organizations.

Given its importance for personal and organizational outcomes, future research into cynicism toward the employing organization seems warranted, and a wide agenda of research opportunities can be identified. First, having used the self as a central construct in the present study, we believe this is a promising route toward better understanding of cynicism and other work related attitudes and behaviors. Concepts such as self-worth, self-efficacy, and locus of control, although likely related to self-esteem, are conceptually different and may account for unique variance in outcome measures such as cynicism, thus adding to the explanatory power of the self as a central construct in organizational behavior. Second, a more focused approach to specific areas within the work domain may be warranted. For instance, the occupational cynicism associated with helping professions, such as police work, health care, education or social services work, is conceptually different from cynicism targeted at the organization at large. Third, another useful extension would be multi-level research, investigating the possibility of contamination of work groups or perhaps even larger organizational units with cynicism. Fourth, more research into the consequences of cynicism is needed. For instance, are cynical employees indeed less committed to their work than non-cynical employees? Fifth, in order to gain more insight into the central position of values in the consistency-seeking process, another measurement method may be warranted. 
Basically, there are two ways to measure values (Meglino \& Ravlin, 1998). In this study, we employed the so-called normative technique, requiring respondents to rate the extent to which they endorse a set of items or statements describing a value or set of values. We did so, because our aim was to make comparisons between the respondent's personal values and his or her perception of organizational values. The ipsative technique asks respondents to rank order a set of values or to choose one at the expense of another in a forced choice format (Chatman, 1989; O'Reilly III, Chatman, \& Caldwell, 1991). This method could give more insight into the dynamics of value hierarchies. Although values tend to be rather stable, it is conceivable that the ordering of values within the value hierarchy changes over time due to, for instance, life experience or important events in the work environment. This could have important implications for the development of cynicism. Finally, studying the process whereby cynicism develops over time and inferring causality requires longitudinal research. In this respect, one of the biggest challenges lying ahead is to convince organizations and their managers that it is in their best interest to help researchers investigate the causes and effects of cynicism toward the organization. 


\section{References}

Abraham, R. (2000a). Organizational cynicism: Bases and consequences. Genetic, Social, and General Psychology Monographs, 126(3), 269-292.

Abraham, R. (2000b). The role of job control as a moderator of emotional dissonance and emotional intelligence-outcome relationships. The Journal of Psychology, 134, 169-184.

Allen, T. D., Freeman, D. M., Russell, J. E., Reizenstein, R. C., \& Rentz, J. O. (2001). Survivor reactions to organizational downsizing: Does time ease the pain? Journal of Occupational and Organizational Psychology, 74(2), 145164.

Andersson, L. M. (1996). Employee cynicism: An examination using a contract violation framework. Human Relations, 49(11), 1395-1418.

Andersson, L. M., \& Bateman, T. S. (1997). Cynicism in the workplace: some causes and effects. Journal of Organizational Behavior, 18(5), 449-469.

Avolio, B. J., Yammarino, F. J., \& Bass, B. M. (1991). Identifying common methods variance with data collected from a single source: An unresolved sticky issue. Journal of Management, 17(3), 571-587.

Bakker, A. B., Demerouti, E., \& Euwema, M. C. (2005). Job resources buffer the impact of job demands on burnout. Journal of Occupational Health Psychology, 10(2), 170-180.

Baron, R. M., \& Kenny, D. A. (1986). The moderator-mediator variable distinction in social psychological research: Conceptual, strategic, and statistical considerations. Journal of Personality and Social Psychology, 51(6), 1173-1182.

Best, S. J., \& Krueger, B. S. (2004). Internet data collection: Sage Publications.

Bommer, W. H., Rich, G. A., \& Rubin, R. S. (2005). Changing attitudes about change: Longitudinal effects of transformational leader behavior on employee cynicism about organizational change. Journal of Organizational Behavior, 26(7), 733-753.

Chatman, J. A. (1989). Improving interactional organizational research: A model of person-organization fit. Academy of Management Review, 14(1), 333-349. 
Cooper, C. (2001). Managerial, occupational and organizational stress research. Aldershot, UK: Ashgate.

Crampton, S. M., \& Wagner III., J. A. (1994). Percept-percept inflation in microorganizational research: An investigation of prevalence and effect. Journal of Applied Psychology, 79(1), 67-76.

Dean, J. W., Brandes, P., \& Dharwadkar, R. (1998). Organizational cynicism. Academy of Management Review, 23(2), 341-352.

Demerouti, E., Bakker, A. B., Nachreiner, F., \& Schaufeli, W. B. (2001). The job demands-resources model of burnout. Journal of Applied Psychology, $86,499-512$.

Dollard, M. F., Winefield, H. R., Winefield, A. H., \& de Jonge, J. (2000). Psychosocial job strain and productivity in human service workers: A test of the demand--control--support model. Journal of Occupational \& Organizational Psychology, 73(4), 501-510.

Doty, D. H., \& Glick, W. H. (1998). Common methods bias: Does common methods variance really bias results? Organizational Research Methods, 1, 374-406.

Edwards, J. R. (1993). Problems with the use of profile similarity indices in the study of congruence in organizational research. Personnel Psychology, 46(3), 641-665.

Edwards, J. R., \& Parry, M. E. (1993). On the use of polynomial regression equations as an alternative to difference scores in organizational research. Academy of Management Journal, 36(6), 1577-1613.

Einarsen, S., Hoel, H., Zapf, D., \& Cooper, C. (Eds.). (2003). Bullying and emotional abuse in the workplace: International perspectives in research and practice. New York: Taylor \& Francis.

Erez, M., \& Earley, P. C. (1993). Culture, self-identity and work. New York: Oxford University Press.

Finegan, J. E. (2000). The impact of person and organizational values on organizational commitment. Journal of Occupational \& Organizational Psychology, 73(2), 149-169. 
Fox, S., \& Spector, P. E. (Eds.). (2005). Counterproductive work behavior: Investigations of actors and targets. Washington, D.C.: American Psychological Association.

Frazier, P. A., Tix, A. P., \& Barron, K. E. (2004). Testing moderator and mediator effects in counseling psychology research. Journal of Counseling Psychology, 51(1), 115-134.

Hackman, J. R., \& Oldham, G. R. (1976). Motivation through the design of work: Test of a theory. Organizational Behavior \& Human Performance, 16(2), 250-279.

Hellgren, J., Sverke, M., \& Isaksson, K. (1999). A two-dimensional approach to job insecurity: Consequences for employee attitudes and well-being. European Journal of Work \& Organizational Psychology, 8(2), 179-195.

Hom, P. W., \& Kinicki, A. J. (2001). Toward a greater understanding of how dissatisfaction drives employee turnover. Academy of Management Journal, 44(5), 975-987.

Johns, G. (1981). Difference score measure of organizational behavior variables: A critique. Organizational Behavior \& Human Performance, 27(3), 443-463.

Judge, T. A., \& Bretz Jr., R. D. (1992). Effects of work values on job choice decisions. Journal of Applied Psychology, 77(3), 261-271.

Judge, T. A., Locke, E. A., \& Durham, C. C. (1997). The dispositional causes of job satisfaction: A core evaluations approach. Research in Organizational Behavior, 19, 151-188.

Kanter, D. L., \& Mirvis, P. H. (1989). The cynical Americans: Living and working in an age of discontent and disillusionment. San Francisco: JosseyBass.

Karasek, R. A. (1979). Job demands, job decision latitude, and mental strain: Implications for job redesign. Administrative Science Quarterly, 24(2), 285308.

Kline, T. J., Sulsky, L. M., \& Rever-Moriyama, S. D. (2000). Common method variance and specification errors: A practical approach to detection. Journal of Psychology, 134(4), 401-421. 
Korman, A. K. (1970). Toward an hypothesis of work behavior. Journal of Applied Psychology, 54(1), 31-41.

Korman, A. K. (1976). Hypothesis of work behavior revisited and an extension. Academy of Management Review, 1(1), 50-63.

Korman, A. K. (2001). Self-enhancement and self-protection: Toward a theory of work motivation. In M. Erez, U. Kleinbeck \& H. Thierry (Eds.), Work motivation in the context of a globalizing economy. Mahwah, NJ: Lawrence Erlbaum Associates, Inc.

Kristof, A. L. (1996). Person-organization fit: An integrative review of its conceptualizations, measurement, and Personnel Psychology, 49(1), 1-49.

Lawler III, E. E. (1994). From job-based to competency-based organizations. Journal of Organizational Behavior, 15(1), 3-15.

Leonard, N. H., Beauvais, L. L., \& Scholl, R. W. (1999). Work motivation: The incorporation of self-concept-based processes. Human Relations, 52(8), 969-998.

Lindell, M. K., \& Whitney, D. J. (2001). Accounting for common method variance in cross-selectional research designs. Journal of Applied Psychology, 86(1), 114-121.

McElroy, J. C., Morrow, P. C., \& Rude, S. N. (2001). Turnover and organizational performance: A comparative analysis of the effects of voluntary, involuntary, and reduction-in-force turnover. Journal of Applied Psychology, 86, 1294-1299.

Meglino, B. M., \& Ravlin, E. C. (1998). Individual values in organizations: Concepts, controversies, and research. Journal of Management, 24(3), 351389.

Meglino, B. M., Ravlin, E. C., \& Adkins, C. L. (1989). A work values approach to corporate culture: A field test of the value congruence process and its relationship to individual outcomes. Journal of Applied Psychology, 74(3), 424-432.

Meyerson, D. E. (1990). Uncovering socially undesirable emotions. American Behavioral Scientist, 33(3), 296-307.

Nettersrom, B., \& Hansen, A. M. (2000). Outsourcing and stress: Physiological effects on bus drivers. Stress Medicine, 16, 149-160. 
O'Reilly III, C. A., Chatman, J., \& Caldwell, D. F. (1991). People and organizational culture: Assessing person-organization fit. Academy of Management Journal, 34(3), 487-516.

Oldham, G. R., \& Cummings, A. (1996). Employee creativity: Personal and contextual factors at work. Academy of Management Journal, 39(3), 607634.

Oldham, G. R., \& Hackman, J. R. (1981). Relationships between organizational structure and employee reactions: Comparing alternative frameworks. Administrative Science Quarterly, 26(1), 66-83.

Ostroff, C., Shin, Y., \& Kinicki, A. J. (2005). Multiple perspectives of congruence: Relationships between value congruence and employee attitudes. Journal of Organizational Behavior, 26, 591-623.

Pierce, J. L., \& Gardner, D. G. (2004). Self-esteem within the work and organizational context: A review of the organization-based self-esteem literature. Journal of Management, 30(5), 591-622.

Pierce, J. L., Gardner, D. G., Cummings, L. L., \& Dunham, R. B. (1989). Organization-based self-esteem: Construct definition, measurement, and validation. Academy of Management Journal, 32(3), 622-648.

Podsakoff, P. M., MacKenzie, S. B., Lee, J.-Y., \& Podsakoff, N. P. (2003). Common method biases in behavioral research: A critical review of the literature and recommended remedies. Journal of Applied Psychology, 88(5), 879-903.

Podsakoff, P. M., \& Organ, D. W. (1986). Self-reports in organizational research: Problems and prospects. Journal of Management, 12(4), 531-544.

Reichers, A. E., Wanous, J. P., \& Austin, J. T. (1997). Understanding and managing cynicism about organizational change. Academy of Management Executive, 11(1), 48-59.

Roe, R. A., \& Ester, P. (1999). Values and work: Empirical findings and theoretical perspective. Applied Psychology: An International Review, $48(1), 1-21$.

Rokeach, M. (1973). The nature of human values. New York: The Free Press.

Snyder, R. A., \& Williams, R. R. (1982). Self theory: An integrative theory of work motivation. Journal of Occupational Psychology, 55(4), 257-267. 
Spector, P. E. (1994). Using self-report questionnaires in OB research: A comment on the use of a controversial method. Journal of Organizational Behavior, 15(5), 385-392.

Tisak, J., \& Smith, C. S. (1994a). Defending and extending difference score methods. Journal of Management, 20(3), 675-682.

Tisak, J., \& Smith, C. S. (1994b). Rejoinder to Edwards's comments. Journal of Management, 20(3), 691-694.

Towers Perrin. (2005). Employee engagement levels threaten corporate performance. Retrieved June 27, 2006, from http://www.towersperrin.com/tp/jsp/hrservices_html.jsp?webc=203/global/s potlight/spotlight_gws.htm

Williams, L. J., Ronald Buckley, M., \& Cote, J. A. (1989). Lack of method variance in self-reported affect and perceptions at work: Reality or artifact? Journal of Applied Psychology, 74(3), 462-468. 


\section{CHAPTER 4}

\section{Organizational cynicism: Extending the exit, voice, loyalty, and neglect model of employees' responses to adverse conditions in the workplace}

Fons Naus, Ad van Iterson \& Robert A. Roe. A revised version of this chapter is accepted for publication in Human Relations.

\section{Abstract}

We propose to extend the exit, voice, loyalty, and neglect (EVLN) model of employees' responses to adverse organizational circumstances with the construct of organizational cynicism. Structural equation modeling was used to fit the data provided by 159 office employees of a large Dutch trade union, who were involved in a restructuring program at the time of the research, to the postulated 5-factor model. Results indicated that the model showed an acceptable fit, providing support for including organizational cynicism as a distinct response in the model. Multiple regression analysis was used for the differential prediction of the five responses, using two situational variables (role conflict and autonomy), two personality variables (assertiveness and rigidity), and selected interactions. The best predictions are obtained for exit, cynicism and loyalty. Loyalty is predicted by low role conflict and high autonomy, whereas cynicism and exit are about equally predicted by high role conflict, low autonomy, and low assertiveness. 


\section{Introduction}

The nature of the employment relationship is changing fundamentally. Sweeping trends like globalization and privatization, and the corresponding emphasis on competitive 'lean and mean' organizations with high levels of productivity, efficiency and control, have a pervasive influence on the contemporary workplace and on employees' work experiences. Organizations and employees have to find ways to respond to the new realities in the workplace such, that work continues to provide meaning and organizational success. One such sense-making response is employee cynicism toward the employing organization. However, cynicism is not the only way employees may respond. The exit, voice, loyalty, and neglect (EVLN) model proposes 4 alternative responses that employees may exhibit. The present study has two aims. First, we propose to incorporate organizational cynicism as a 5th response in the model. Thus, we seek to compare cynicism with alternative employee reactions. Second, building on earlier work (Rusbult et al., 1988; Rusbult et al., 1986; Withey \& Cooper, 1989) we aim to identify precursors of each of the five responses.

\section{The exit, voice, loyalty, and neglect (EVLN) model 2.1 The development of the EVLN model}

Albert Hirschman originally conceived of his seminal exit, voice, and loyalty (EVL) model to explain customers' and employees' responses to 'lapses from efficient, rational, law-abiding, virtuous, or otherwise functional organizational behavior' (1970, p. 1). Hirschman's account has made its way into various research areas, such as comparative politics, labor economics, marketing, political sciences, and social and even intimate relationships, to capture and structure the various ways in which actors may respond to sources of dissatisfaction (Dowding, John, Mergoupis, \& van Vugt, 2000). In the organizational literature it has acquired a position as a model that allows for and differentiates a variety of employees' responses to adverse conditions in the workplace (Farrell, 1983; Hagedoorn, van Yperen, van de Vliert, \& Buunk, 1999; Rusbult et al., 1988; Rusbult et al., 1986; Rusbult \& Zembrodt, 1983; Rusbult et al., 1982; Turnley \& Feldman, 1999; Withey \& Cooper, 1989).

\subsection{The EVLN model in organizational research}

Especially in the organizational sciences, Hirschman's model has served as a fruitful basis for research into organizational behavior. One of the main findings of a multi-dimensional scaling study by Rusbult et al. (1982) and Farrell (1983) was that Hirschman's EVL model needed to be extended with a 
fourth response termed 'neglect', and described as lax and disregardful behavior. A second outcome of the same study was the identification of the key dimensions 'active - passive' and 'constructive - destructive' as underlying descriptive attributes of the EVLN responses. Unfortunately, the use of these dimensions to account for covariance patterns among the constructs has produced rather inconsistent results. For example, the active - passive dimension did not adequately describe the pattern of responses in the second study by Rusbult \& Zembrodt (1983), in Farrell's (1983) study loyalty was classified as a destructive response, and in the study by Hagedoorn et al. (1999) the active - passive dimension distinguished between voice and loyalty, yet failed to make a distinction between exit and neglect. Taken together, these results indicate that the dimensions lack strong empirical support. For that reason, they will not be used in the analyses in the present study, although they will occasionally be referred to when results from earlier research are discussed.

The EVLN typology itself, however, has proven valuable for understanding antecedents and consequences of responses to unpleasant events in the workplace. Rusbult et al. (1988), using exchange theory, found that high job satisfaction and high levels of investment in one's job 'fairly consistently' promoted voice and loyalty, and inhibited exit and neglect (p. 615). The availability of high-quality alternatives to the current job was found to relate positively to exit and voice, negatively to loyalty, and was not significantly related to neglect behavior. Withey \& Cooper (1989) proposed a model based on the theory of reasoned action, in which 'people are depicted as implicitly weighing possible payoffs against likely costs, factoring in how positive they feel toward their current employer' (p. 523). As predictors of EVLN they used the direct and indirect costs associated with each response, its expected efficacy, and the attractiveness of the current workplace. They found that exiters were affected by all three predictors, neglecters were primarily affected by the costs and the efficacy of their responses, loyalists were primarily affected by the efficacy of their responses, and voicers were very difficult to predict. Turnley \& Feldman (1999) investigated the impact of psychological contract violation (PCV) on managers' exit, voice, loyalty and neglect behaviors. Positive relationships between PCV and exit, voice, and neglect, and a negative relationship between PCV and loyalty were found. Situational factors, such as the availability of attractive alternatives, only had an effect on managers' propensity to exit. Finally, Hagedoorn et al. (1999) found job satisfaction to promote considerate voice and loyalty, and to suppress exit, aggressive voice, and neglect. 


\subsection{Conceptualizations of exit, voice, loyalty, and neglect}

Hirschman initially described exit as 'some customers stop buying the firm's products or some members leave the organization: this is the exit option' (1970, p. 4). Its function was to signal discontent with a firm's performance. A conceptual broadening of the exit option was suggested by Rusbult et al. (1988), who conceived of the exit option not only as actually quitting the job or leaving the organization, but also as searching for a different job and thinking about quitting. In this view, it seems that exit is more a psychological state of disengagement or propensity to leave (turnover intent), that can vary in strength over time, than a dichotomous decision to actually leave or not. The psychological form of exit constituted a very important extension of the original exit option. Whereas actually leaving the organization may not always be a viable option, due to actual or perceived barriers to exit, leaving the organization in a psychological sense, i.e. as a form of disengagement, is something over which the employee has more control.

Voice was defined by Hirschman as 'any attempt at all to change an objectionable state of affairs, not only by petitioning to management or higher authorities, but also through protests including the mobilization of the public opinion' (1970, p. 30). As the original model accounts primarily for customers' dissatisfaction toward organizations, this conceptualization makes sense. Especially when customers have multiple options and when barriers to exit are low, they need not be concerned very much about the way they voice their grievances. However, when the model is employed to describe the organization - employee relationship, voice necessarily takes on a different meaning, defined by Rusbult et al. (1988) as 'actively and constructively trying to improve conditions' (p. 601), a form of voice also referred to as pro-social voice (Van Dyne, Ang, \& Botero, 2003). This can conceivably be accomplished by discussing problems with a supervisor or co-workers, taking action to solve problems, or suggesting solutions. However, the authors also mention seeking help from an outside agency like a union, and whistle blowing, as examples of voice behavior. Surely, these actions may be perceived by dissatisfied employees as constructive efforts to improve the situation, yet they will not be perceived as such by everyone. As a consequence, it can be questioned whether the voice construct is unidimensional. In an effort to resolve this issue, the category of voice responses was split up in considerate voice and aggressive voice (Hagedoorn et al., 1999). These opposing manifestations of voice admittedly bring conceptual clarity, but the descriptive elegance of the model 
suffers from having one construct with two different meanings. In the present study, voice is operationalized as pro-social voice.

As Hirschman set out to develop a theory of loyalty, he first somewhat loosely referred to it as '..that special attachment to an organization known as loyalty' (1970, p. 77). Later on he outlines the loyalist as 'the member who cares, who leaves no stone unturned before he resigns himself to the painful decision to withdraw or switch' (p. 83). According to Hirschman, 'the importance of loyalty...is that it can neutralize within certain limits the tendency of the most quality-conscious customers or members to be the first to exit' ( $\mathrm{p}$. 79). Thus, loyalty constitutes to the loyalist a psychological barrier to exit, thereby strengthening the propensity to voice. At the same time, however, Hirschman made clear that this barrier is not of infinite height and that loyalty also has to be regarded as a form of reasoned action, because it is the hope or expectation that the situation can be improved that keeps loyalty alive. In the organizational literature, loyalty was defined by Rusbult and colleagues as passively but optimistically waiting for conditions to improve, by giving public and private support to the organization, waiting and hoping for improvement, or practicing good citizenship (Rusbult et al., 1988). Withey and Cooper (1989) came to the conclusion that, due to the use of the items 'wait patiently and hope any problems will solve themselves', and 'say nothing to others and assume things will work out', taken from Farrell's (1983) scale, the loyalty they found did not fit with what lay people mean by loyalty (p. 537). They argued that something was seriously amiss with the concept of loyalty and that it should be operationalized as active support for the organization. Leck and Saunders (1992) made a distinction between loyalty as attitude and loyalty as behavior. They adopted the term patience for behavioral loyalty, based on previous operationalizations of the loyalty construct. This somewhat lethargic form of loyal behavior has prevailed in the literature. For instance, Hagedoorn et al. (1999) used items such as 'assume that in the end everything will work out' and 'optimistically wait for better times' to operationalize their patience construct.

In the context of responses to dissatisfaction in romantic relationships, neglect was identified as a distinct response, described as the kind of behavior shown by partners who passively allow their relationship to atrophy. Typically, they would ignore their partner, spend less time together, refuse to discuss problems, treat the partner badly emotionally or physically, or criticize the partner for things unrelated to the problem (Rusbult et al., 1982; Rusbult et al., 1986). As organizations and employees had already been conceived of as partners in exchange relationships long before the work of Rusbult and her 
colleagues (Levinson, 1965), it appeared to be a logical step to assume that neglect behavior would also occur in the work environment. Here, neglect was described as lax and disregardful behavior, exemplified by lateness, absenteeism, elevated error rates and using company time for personal business (Farrell, 1983; Rusbult et al., 1988). This conceptualization of neglect has prevailed in the literature, as it was unanimously adopted by all researchers who used the EVLN model in their studies.

In conclusion, despite the conceptual intricacies mentioned above, the model has proven a useful tool for research into various important aspects of organizational behavior.

\subsection{Expanding the EVLN model with organizational cynicism}

Discussing the conclusions of their study, Rusbult and colleagues (1988) suggest that the EVLN model may serve as a common framework, into which researchers may incorporate additional responses to dissatisfaction. In this chapter, we propose to extend the model with organizational cynicism (OC), a response defined as 'a negative attitude toward one's employing organization, comprising three dimensions: (1) a belief that the organization lacks integrity; (2) negative affect toward the organization; and (3) tendencies to disparaging and critical behavior toward the organization that are consistent with these beliefs and affect' (Dean et al., 1998). OC serves as a form of selfdefense, protecting employees from unpleasant thoughts and feelings of disappointment about actions taken by the organization and its management (Abraham, 2000a; Reichers et al., 1997). Cynicism is an important response that may have profound implications for both the individual and the organization, as it appears to be associated with a host of negative outcomes, such as apathy, resignation, alienation, hopelessness, distrust of others, suspicion, contempt, disillusionment, and scorn, as well as poor performance, interpersonal conflict, absenteeism, job turnover, and burnout (Abraham, 2000a; Andersson, 1996; Andersson \& Bateman, 1997; Dean et al., 1998). On the other hand, it is argued that 'in their particular manner, cynics may act as the voice of conscience for the organization' (Dean et al., 1998, p. 347) and that 'cynics care deeply about their organization and make careful and systematic recommendations of organizational problems' (Bommer et al., 2005, p. 748). Hence, although at first sight organizational cynicism seems to be associated with unfavorable reactions to adverse circumstances in the workplace, cynical people are at the same time motivated to care about the well-being of their organization. It seems that the nature of cynicism is not readily captured by exit, voice, loyalty, or neglect, and 
that cynicism can be conceptualized as a distinct response to adverse circumstances in the workplace.

A second reason why we believe cynicism should be considered for inclusion in the model is its prevalence. Kanter and Mirvis (1989) categorized 43 per cent of American workers as cynical, and Bommer et al. (2005) suggest that, given the recent series of corporate scandals in the United States, it is likely that worker's cynicism toward the organization has only increased. As Europe has also had its share of corporate scandals, e.g. Parmalat and Ahold, we have no reason to believe that cynicism is confined to the United States only. In our view, this combination of consequences and prevalence provides a compelling argument why cynicism should be considered for inclusion in the EVLN model.

In summary, we propose that there are five, not four, ways in which employees may respond to adverse organizational circumstances. We will set out to demonstrate by means of confirmatory factor analysis that organizational cynicism is a distinct response that can be differentiated from exit, voice, loyalty and neglect.

\section{Predicting exit, voice, loyalty, neglect, and cynicism}

Prior research on the EVLN model has not only dealt with the identification of different types of employee responses, but also with their prediction. In the studies mentioned earlier, exchange theory has been the dominant theoretical perspective. On the whole, these studies have shown mixed support for the general hypothesis that rational exchange arguments drive and, accordingly, predict employees' choices between exit, voice, loyalty, or neglect responses. For example, the level of employee investment in the relationship with the employing organization was found to be moderately related to exit $(r=-.29, p<.01)$, loyalty $(r=.15, p<.01)$, and neglect $(r=-.14$, $p<.01)$, and not significantly ( $r=.08$, n.s.) to voice (Rusbult et al., 1988). In another study (Withey \& Cooper, 1989), sunk costs and investment in the relationship significantly predicted exit $(r=-.21, p<.001$, and $r=-.14, p<.05)$ and loyalty $(r=.08, p<.05$, and $r=-.14, p<.01)$, neglect was only predicted by investment $(r=-.13, p<.05)$ and voice was unrelated to both in a sample of graduates, whereas in an accounting-firm sample neither significantly predicted voice and loyalty, sunk costs only predicted exit $(r=-.20, p<.05)$, and investment only predicted neglect $(r=-.26, p<.01)$. Despite these results, the rational exchange perspective seems to offer a promising framework for understanding and predicting responses, because the results obtained by Rusbult 
et al. (1988) were generally consistent with predictions based on exchange theory. However, new perspectives may also be fruitfully developed.

A limitation of previous research aiming to predict employee responses in the EVLN model has been that the adverse conditions to which the employees were supposed to respond were not explicitly included in the research design. They are typically addressed in the introduction to the questionnaire measuring employee responses. Thus, they constitute an unmeasured background variable that implicitly contributes to the prediction of the responses. In order to overcome this limitation, and to include the perceived seriousness of the adverse conditions, some studies have incorporated a predictor variable that serves as a proxy for adverse conditions in the workplace. In most studies this predictor was job satisfaction. However, the use of job satisfaction has two major disadvantages. First, satisfaction is as much a reaction to good or bad circumstances as an indicator of it. The risk of confounding satisfaction with the employee's reaction to adverse circumstances makes it unsuited as a proxy for those circumstances, just like subjective measures of stressors are inadequate as they are confounded by the strain produced (Spector, Chen, \& O'Connell, 2000). Second, job satisfaction has been found to be, at least in part, dispositionally based (Judge, 2001; Judge, Locke, Durham, \& Kluger, 1998) and related to negative affectivity (Spector, 1994; Spector, Chen et al., 2000; Spector \& O'Connell, 1994; Spector, Zapf, Chen, \& Frese, 2000), which could produce spurious relationships with responses to adverse circumstances. For these reasons, we prefer to use role conflict as a proxy for adverse circumstances, because it is less biased by negative affectivity than job satisfaction.

\subsection{Hypotheses}

In the present study we build on research which has shown that people's reactions to stressful conditions depend to some extent on the control they have over their work situation, and also to some extent on their personality. Thus, we focus on two situational job characteristics, i.e. role conflict and job autonomy, and two personality traits, i.e. assertiveness and rigidity, as factors that may predict employees' reactions to adverse organizational circumstances.

Role conflict, our proxy of adverse circumstances, was defined by Katz \& Kahn (1978) as the simultaneous occurrence of two or more role expectations in such a way, that compliance with one would make compliance with the other more difficult. Katz \& Kahn stated that the experience of role conflict in the work situation was widespread, and they described it as a stressful experience 
for the employees involved (p. 204). In their meta-analysis of research on role conflict and role ambiguity in work settings, Jackson \& Schuler (1985) report negative correlations between role conflict and general satisfaction (-.48), satisfaction with work itself (-.49), and satisfaction with supervision (-.53). Because job satisfaction was found to promote favorable responses and discourage unfavorable responses (Rusbult et al., 1988), we expect role conflict to be negatively associated with loyalty, and positively with exit, neglect, and cynicism. Voice is expected to be differentially related to role conflict, because in prior research voice was found to be at best moderately, and sometimes insignificantly, related to job satisfaction (Rusbult et al., 1988; Withey \& Cooper, 1989). Given the strong correlations between role conflict and job satisfaction, we also expect role conflict not to have an immediate impact on voice.

Job autonomy has been defined as the degree to which the job provides substantial freedom, independence, and discretion to the individual in scheduling the work and determining the procedures to be used in carrying it out (Hackman \& Oldham, 1976). There is a large body of research showing that job autonomy is related to positive work outcomes and that it constitutes an effective buffer against negative impacts from the work situation. At the individual level employees who have more job autonomy show more positive affect, internal motivation, and self-confidence (Hackman \& Oldham, 1976; Oldham, Hackman, \& Pearce, 1976), more creativity (Oldham \& Cummings, 1996), less mental strain (Karasek, 1979), more satisfaction with various aspects of the work context (Oldham \& Hackman, 1981), and less emotional dissonance (Abraham, 2000b), compared with those who have little job autonomy. Also, autonomy will likely be associated with greater opportunities for employees to influence their environment and to withdraw from unpleasant circumstances. For these reasons, we propose job autonomy as a factor predicting employees' reactions to adverse circumstances, both independently and in interaction with role conflict. We expect that autonomy will be positively associated with voice and loyalty, and negatively with exit, neglect and cynicism.

As personality factors that might play a role in predicting the responses in the extended EVLNC model we propose assertiveness and rigidity. Both of these variables can influence the choice for a particular type of behavior, independently as well as in interaction with the situation. A common definition of assertiveness is standing up for one's legitimate personal rights (Wilson \& Gallois, 1993). Therefore, one would expect assertive employees to somehow express their concern over unfavorable circumstances. They are likely to speak 
up, that is opt for voice. At the same time they are less likely to resort to exit, or express discontent by neglectful behavior. It is also argued that, as a subtrait of the 'Big Five' intraversion / extraversion dimension, assertiveness is associated with being sociable and gregarious (Barrick \& Mount, 1991), which might make the assertive employees more inclined to stay loyal to the employing organization. As the definition of organizational cynicism specifically refers to critically speaking up, we expect assertiveness to be positively related to cynicism.

Rigidity is a personality trait associated with tendencies toward behavioral consistency, to follow routines, to be inflexible and set in one's ways, and a general tendency to be skeptical of change in any form (Mudrack, 2004; Oreg, 2003). Employees scoring high on rigidity may be expected to be less adaptive, and hence not to show acquiescent loyalty. Also, they are not expected to voice suggestions for constructive solutions. Rather, they may express themselves through exit, cynicism, or neglect. On the basis of the foregoing, the following direct associations between predictors and responses are hypothesized:

Hypothesis 1: Exit will be positively associated with rigidity and role conflict, and negatively associated with assertiveness and autonomy.

Hypothesis 2: Voice will be positively associated with assertiveness and autonomy, and negatively associated with rigidity.

Hypothesis 3: Loyalty will be positively associated with assertiveness and autonomy, and negatively associated with rigidity and role conflict.

Hypothesis 4: Neglect will be positively associated with rigidity and role conflict, and negatively associated with assertiveness and autonomy.

Hypothesis 5: Cynicism will be positively associated with assertiveness, rigidity and role conflict, and negatively associated with autonomy.

As already mentioned above, the predictors may also interact in predicting the different responses. With 4 predicting variables, 6 two-way interactions may be hypothesized. As the literature provided no compelling reasons to expect interactions among the situational variables or among the personality variables, we confine ourselves to the four different person-situation interactions. Our expectation is that role conflict and rigidity, and autonomy and assertiveness, will reinforce each other, with opposite effects on employee responses. The employee who is subject to the stressful experience of not being able to meet conflicting demands, while lacking the psychological resilience to 
resolve the conflict, will most likely not respond with pro-social voice or loyalty, or with critical yet caring cynicism, but rather with the urge to escape the situation, i.e. exit or neglect. On the other hand, the assertive and (relatively) autonomous employee can be expected to respond to adverse circumstances with voice, loyalty, or cynicism, instead of exit or neglect. The other personsituation interactions are between role conflict and assertiveness, and between autonomy and rigidity. The assertive person experiencing role conflict can be expected to take a pragmatic stand, that is to somehow find a way to cope with the situation. This can be accomplished either through voice, making suggestions for alternative solutions or urging the organization to consider an alternative course of action, through psychological withdrawal from the situation by keeping a cynical distance, or by exit in case a solution cannot be found. In this case, patient loyalty or neglect behavior are unlikely options. Finally, the rigid person who has considerable autonomy to cling to privately held ideas will most likely not respond with voice or loyalty to unpleasant circumstances, but rather with distant cynicism ('you have your way, I have mine'), neglect or exit. Based on these expectations, we offer the following hypotheses:

Hypothesis 6: Exit will be positively associated with the interactions between role conflict and rigidity, between role conflict and assertiveness, and between autonomy and rigidity, and will be negatively associated with the interaction between autonomy and assertiveness.

Hypothesis 7: Voice will be positively associated with the interactions between autonomy and assertiveness, and between role conflict and assertiveness, and will be negatively associated with the interactions between role conflict and rigidity, and between autonomy and rigidity.

Hypothesis 8: Loyalty will be positively associated with the interaction between autonomy and assertiveness, and will be negatively associated with the interactions between role conflict and rigidity, between role conflict and assertiveness, and between autonomy and rigidity.

Hypothesis 9: Neglect will be positively associated with the interactions between role conflict and rigidity, and between autonomy and rigidity, and will be negatively associated with the interactions between autonomy and assertiveness, and between role conflict and assertiveness.

Hypothesis 10: Cynicism will be positively associated with the interactions between autonomy and assertiveness, between role conflict and assertiveness, 
and between autonomy and rigidity, and will be negatively associated with the interaction between role conflict and rigidity.

All hypothesized relationships are summarized in Table 1.

Table 1. Hypothesized relationships between four predictors and five EVLNC responses

EXIT VOICE LOYALTY NEGLECT CYNICISM

\begin{tabular}{lccccc} 
RC & + & 0 & - & + & + \\
AUT & - & + & + & - & - \\
RIGID & + & - & - & + & + \\
ASS & - & + & + & - & + \\
RC*AUT & 0 & 0 & 0 & 0 & 0 \\
RC*ASS & + & + & - & - & + \\
RC*RIGID & + & - & - & + & - \\
AUT*ASS & - & + & + & - & + \\
AUT*RIGID & + & - & - & + & + \\
ASS*RIGID & 0 & 0 & 0 & 0 & 0 \\
\hline
\end{tabular}

Note. $\mathrm{RC}=$ Role Conflict. AUT $=$ Autonomy. RIGID $=$ Rigidity. ASS $=$ Assertiveness. $+=$ Positive relationship hypothesized. $-=$ Negative relationship hypothesized. $0=$ No relationship hypothesized.

\section{Method}

\subsection{Sample and procedure}

Participants in this study were employees from a large Dutch trade union. In 2003 this organization announced a major restructuring to combat the financial worries resulting from a decline in membership. The measures taken included cutting costs and the prospective loss of jobs. In many organizations such measures have come to be part of everyday organizational life, but in this case they are of particular interest to assess the nature of our sample. Whereas the usual core business of trade unions is to critically evaluate the necessity of reorganisations elsewhere, and to act in the interest of their membership by making every possible effort to prevent the loss of jobs, in this case the union itself was the subject of reorganisation. At the time of our research, the restructuring project was still in operation. Hence, while the sample comprises ordinary employees doing regular office work, this particular aspect gives our 
sample an unusual, albeit interesting, extra. Conceivably, under these circumstances the employees' belief in the integrity of the employing organization was put to a serious test. The employees were approached through an internal email from the public relations department, encouraging them to participate in the study. The email message contained a link to an online questionnaire. In the questionnaire instructions, the topic of the study was explained as an investigation into work experiences, and anonimity and confidentiality were guaranteed. Completed questionnaires were received from 159 employees, for a response rate of about $30 \%{ }^{2}$. Respondents' ages ranged from 17 to 62 , with an average of 38.5 years $(S D=10.1$ years $)$, and tenure in the present job ranged from 0 to 32 years, with an average of 7.1 years $(S D=$ 7.6 years). The sample consisted of 58 men and 101 women, 89 participants held full-time jobs and 70 held part-time jobs.

\subsection{Measures: dependent variables}

It is important to note that the dependent variables in this study represent employee behaviors, rather than attitudes, beliefs, or affects. The behavioral manifestations of exit, voice, loyalty, and neglect were measured with self-descriptive items used by Hagedoorn and colleagues (1999). Through personal communication with the first author of their study, we obtained a slightly abbreviated version of the exit, voice (named 'considerate voice'), loyalty (named 'patience'), and neglect scales used in their study. Prior to being presented with the items measuring EVLN, respondents were asked to read a brief introduction, containing a few examples of adverse organizational circumstances and asking them how they would most likely respond to these sources of potential dissatisfaction.

The exit and neglect constructs were conceptualized alike in all studies working with the EVLN model and this conceptualization was adopted in the present study. The voice construct resembles what was earlier termed pro-social voice, i.e. the items are reflective of cooperative and constructive behavior that will likely be perceived as such by those who represent the organization. Loyalty, renamed patience by Hagedoorn and colleagues, may not actually measure what laypeople mean by loyalty (Withey \& Cooper, 1989), but this conceptualization of loyalty has prevailed in the literature to date and was

\footnotetext{
${ }^{2}$ It is unclear whether non-response is distributed evenly across the employees. Accordingly, the representativeness of the achieved sample and the generalizability of the findings may be subject to non-response bias and have to be assessed with due caution.
} 
therefore also adopted in this study. To measure cynicism, six items were written to reflect behavioral expressions of cynicism in the workplace, such as lack of trust, frustration, hopelessness, disillusionment, contempt, or scorn (Abraham, 2000a; Andersson, 1996). Examples of cynicism items are 'I shrug my shoulders at what management requires me to do' (contempt), and 'I hold back suggestions for improvements, because nothing is going to change anyway' (hopelessness / frustration). All items were measured on a 7-point scale with endpoints definitely not (1) and definitely (7). The introduction and the full list of items are provided in the appendix. Their reliability coefficients will be given in the analysis section of this chapter.

\subsection{Measures: independent variables}

Role conflict was measured with 6 items from House, Schuler and Levanoni (1983) on a 5-point scale with endpoints never (1) and very often (5). With a Cronbach's alpha coefficient of .87 the items demonstrated good internal consistency.

Job autonomy was measured with two items from a scale developed by Bacharach, Bamberger \& Conley (1990) to measure job formalization and three items from a scale by Karasek (1979) to measure decision latitude. Together, they measure the degree to which the employee has discretion to make workrelated decisions on the job. Job autonomy was measured on a 5-point scale with endpoints does not apply at all (1) and applies completely (5). With a Cronbach's alpha of .71 the scale demonstrated acceptable internal consistency.

Assertiveness is a personality trait that is associated with standing up for one's rights, freely expressing opinions and feelings, being sure of oneself, and being a leader (Twenge, 2001), and being sociable, gregarious, talkative and active (Barrick \& Mount, 1991). It seems that the assertive person approaches others with an open mind and does not hesitate to 'take a stand.' Six items were written to measure this personality trait. Representative items were 'I often say yes, when I should have said no' (reverse coded), and 'expressing disagreement with something makes me feel uncomfortable' (reverse coded). Items were measured on a 7-point scale with endpoints definitely disagree (1) and definitely agree (7). All items loaded on the same underlying factor, that accounted for $63.8 \%$ of the variance, and with a Cronbach's alpha of .85 these items made for an internally consistent scale.

Rigidity. Rigidity is a personality trait, associated with strong tendencies toward behavioral consistency, to follow routines, to be inflexible and set in one's ways, and a general tendency to be skeptical of change in any form 
(Mudrack, 2004). Five items were written to measure this trait. Items were measured on a 7-point scale with endpoints definitely disagree (1) and definitely agree (7). Two representative items were 'when people frequently change their mind, they apparently have no principles', and 'sometimes it is better to change one's mind than to stick to one's opinion' (reverse coded). Dropping one item resulted in a uni-dimensional solution, with the underlying factor accounting for $48.4 \%$ of the variance in the resulting items. With a Cronbach's alpha of .63 the internal consistency of the rigidity scale was relatively low, yet exceeded the threshold of .60 suggested for exploratory research (Hair, Anderson, Tatham, \& Black, 1998).

\section{Results}

\subsection{Factor analysis of exit, voice, loyalty, neglect, and cynicism items}

Our suggestion that the EVLN model should be extended with cynicism calls for an analysis, capable of demonstrating that cynicism indeed stands out as a complementary, yet distinct, construct. To this end, we replicated the procedure earlier applied by Rusbult et al. (1988). First, we examined the convergent validity of the response items by calculating average inter-item correlations for the items within the scales. For the exit, voice, loyalty, and neglect scales, all average inter-item correlations were in excess of .60. As such, these scales demonstrated satisfactory convergent validity. With .34, the cynicism items performed less satisfactory. One cynicism-item (Cynicism1, see appendix) showed below average correlations with the remaining five items, ranging from .035 to .324 , and was therefore dropped. As a result, the average correlation between the five remaining items within the cynicism scale increased to .41. We find this acceptable, given the fact that the average correlation for items within scales, as reported by Rusbult et al. (1988), was .42.

The discriminant validity of the items was assessed by calculating average inter-item correlations for items between the scales. For instance, the five remaining items comprising the cynicism scale were correlated with the five loyalty items, to form a matrix of 25 correlations, which we then averaged. With five (EVLNC) scales, we obtained the following 10 averaged betweenscales correlations: $\mathrm{EV}=-.147 ; \mathrm{EL}=-.342 ; \mathrm{EN}=.300 ; \mathrm{EC}=.276 ; \mathrm{VL}=.111$; $\mathrm{VN}=-.098 ; \mathrm{VC}=-.041 ; \mathrm{LN}=-.222 ; \mathrm{LC}=-.196 ; \mathrm{NC}=.286$. Given our earlier discussion of loyalty as a barrier to exit, it is interesting to see that the strongest (negative) association is between these constructs. Furthermore, associations between voice and the other responses are relatively weak, which is in line with 
prior research, and cynicism is strongest associated with exit. These associations exceeded the range of -.24 to .18, reported by Rusbult and colleagues, but they are low enough for the constructs to be regarded as distinct. On the whole, we judged these results to be indicative of acceptable convergent and discriminant validity of the items used in this study.

Next, we used Lisrel 8.72 to test the degree to which the sample covariance matrix was accurately represented by the covariance matrix implied by the hypothesized 5-factor model. In the first step, and in a strictly confirmatory mode, the most restrictive version of the full first-order measurement model was tested, comprising 25 (after Cynicism1 had been omitted) observed indicators, measuring 5 latent constructs. Each of these indicators was allowed to load on its corresponding latent construct only, and errors were posited to be uncorrelated. Hence, out of a total of 125 possible factor loadings, 100 loadings were fixed at zero and the remaining 25 were freely estimated parameters. For scaling purposes, the loading of the first indicator of each latent construct was fixed at 1. Maximum likelihood was used for parameter estimation, because most of the items showed skewness and kurtosis between -1 and +1 while none of them showed values exceeding -2 or +2 , and with a mean skewness of .20 and a mean kurtosis of -.58 the data did not strongly violate multivariate normality assumptions.

The analysis revealed no offending estimates, such as correlations $>1$, negative variances, or not-positive-definite matrices, and it took only 18 iterations for the model to converge to a proper solution. All factor loadings exceeded the .45 threshold, also applied by Hagedoorn et al. (1999), and they were highly significant with reasonable standard errors. The goodness-of-fit statistics for the baseline model (Model 1A) are presented in Table 2. With $d f>$ $N$, the GFI and AGFI are biased downward quite substantially (Ed Rigdon, message to SEMNET, October 28, 2003). We therefore applied Steiger's correction to the GFI and AGFI (Steiger \& Fouladi, 1997). Adjusted GFI and AGFI values are in parentheses. In the SEM literature, several 'rules of thumb' cutoff criteria have been suggested to evaluate model fit. None of these criteria has been universally accepted, due to the lack of a compelling theoretical rationale and empirical evidence (Hu \& Bentler, 1999; Marsh \& Hocevar, 1985). Addressing these issues, $\mathrm{Hu} \&$ Bentler (1999) have suggested several alternatives for cutoff criteria. They argue that cutoff values close to .95 for TLI and CFI, close to .06 for RMSEA and close to .08 for RSMR, would justify the conclusion of a relatively good fit between the hypothesized model and the data. 


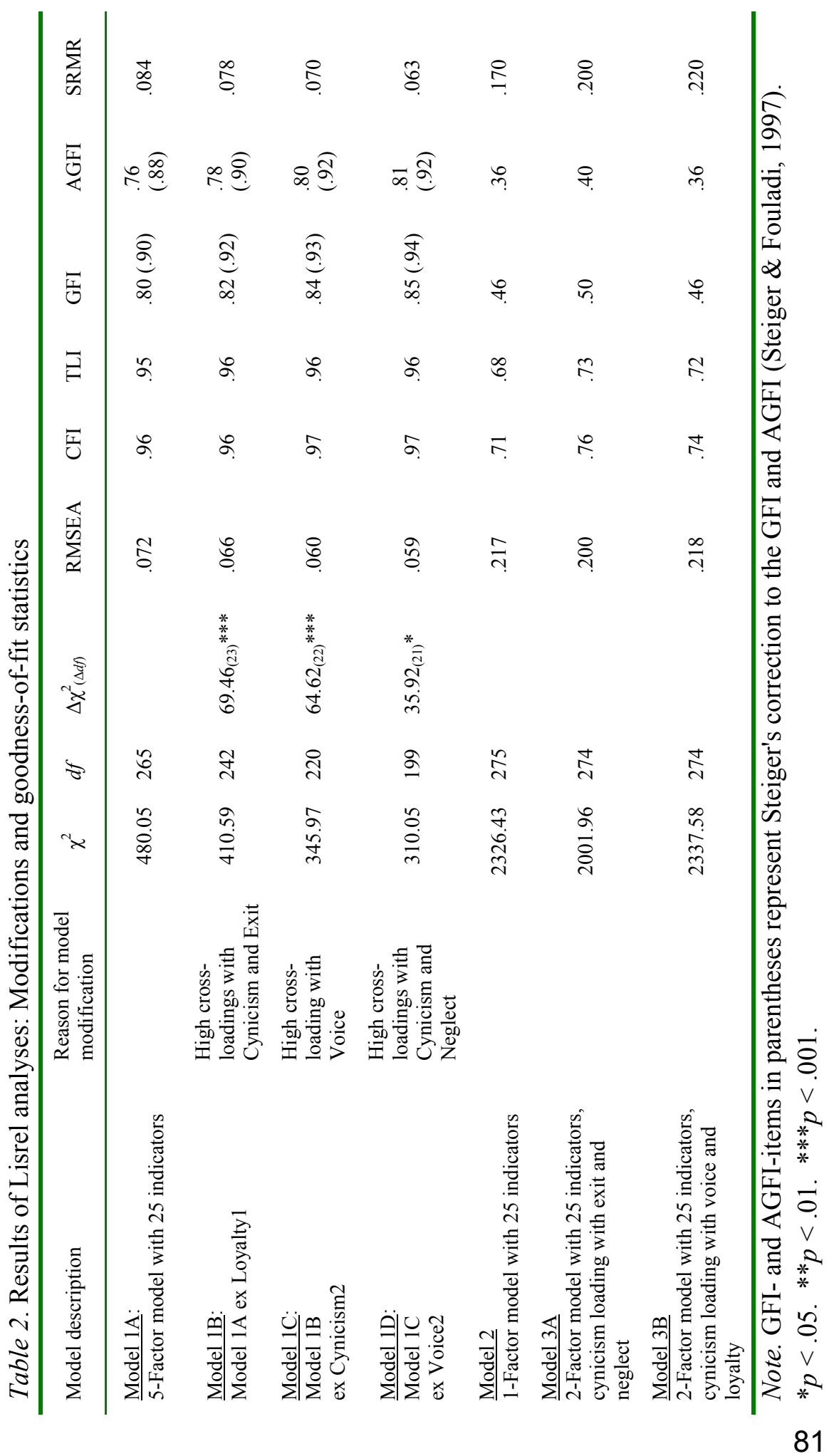


Given these recommendations and the results presented in Table 2, the baseline model (model 1A) is reasonably good, but it seems possible to find a better representation of the covariance structure in the data.

Leaving the confirmatory mode of analysis, we set out on an exploratory specification search, seeking empirical clues to improve the measuring instrument. Especially items with high cross-loadings would require closer scrutiny, as they confound the unidimensionality of the scales. Furthermore, in each step only one modification at a time was addressed, because modification index values are calculated univariately and thus they can fluctuate from one estimation to another (Byrne, 1998). After each modification, the model's fit with the data was re-assessed, until no more additional modifications could be justified. In this particular case, we believe that consulting the diagnostics to improve the model's fit with the data is a legitimate course of action, because the scales used to measure the responses have not been validated extensively in prior research. For each intermediate solution the fit statistics are provided in Table 2. The final version of the firstorder model (Model 1D) appears to provide an acceptable description of the covariance structure in the sample. In addition to the 5-factor model, we also estimated two alternative models: the 1-factor model, and two 2-factor models, one with cynicism loading on the same factor as exit and neglect, the other with cynicism loading on the same factor as voice and loyalty. Table 2 shows that by far the best fitting model is the 5-factor model. Table 3 presents the standardized factor loadings and the individual scales' composite reliabilities for the final model (Model 1D). Taken together, the reliabilities, fit statistics and factor intercorrelations (see Table 4) show that cynicism has been established as a response mode that can be distinguished from the exit, voice, loyalty, and neglect responses. 
Table 3. Standardized factor loadings for final EVLNC model (Table 2: Model 1D).

\begin{tabular}{|c|c|c|c|c|c|}
\hline Item & Exit (.90) & Voice $(.86)$ & Loyalty (.87) & Neglect (.90) & Cynicism (.75) \\
\hline Exit1 & .98 & & & & \\
\hline Exit2 & .95 & & & & \\
\hline Exit3 & .46 & & & & \\
\hline Exit4 & .81 & & & & \\
\hline Exit5 & .80 & & & & \\
\hline Voice1 & & .75 & & & \\
\hline Voice3 & & .82 & & & \\
\hline Voice4 & & .79 & & & \\
\hline Voice5 & & .80 & & & \\
\hline Loyalty2 & & & .84 & & \\
\hline Loyalty 3 & & & .90 & & \\
\hline Loyalty 4 & & & .82 & & \\
\hline Loyalty 5 & & & .65 & & \\
\hline Neglect1 & & & & .78 & \\
\hline Neglect2 & & & & .79 & \\
\hline Neglect3 & & & & .94 & \\
\hline Neglect4 & & & & .81 & \\
\hline Neglect5 & & & & .73 & \\
\hline Cynicism3 & & & & & .45 \\
\hline Cynicism4 & & & & & .71 \\
\hline Cynicism5 & & & & & .70 \\
\hline Cynicism6 & & & & & .78 \\
\hline
\end{tabular}

Note. Composite reliabilities (Hair et al., 1998) are given in parentheses. Factor loadings not shown in this table were posited equal to zero. 


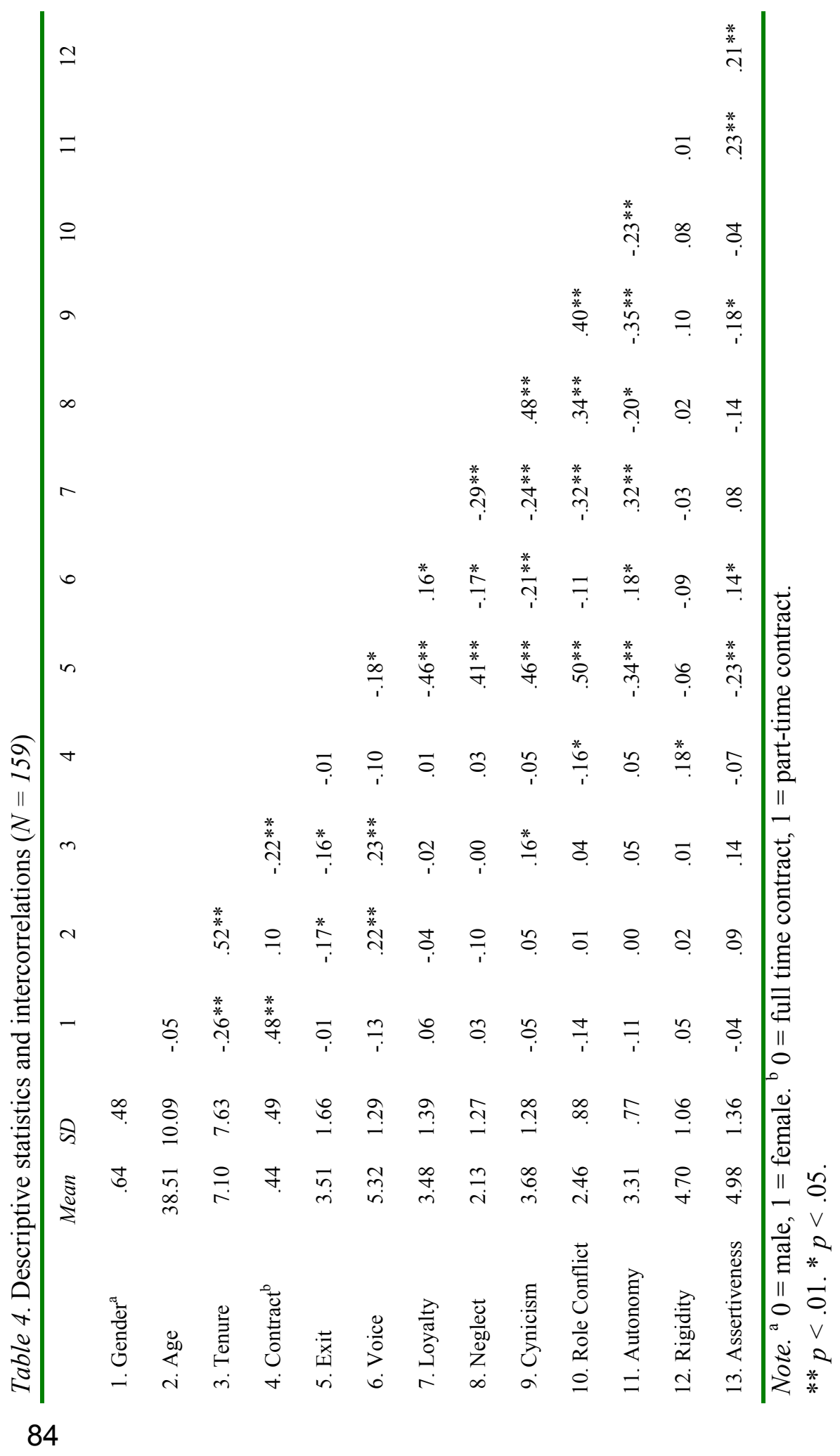


Table 5. Moderated hierarchical regression results for exit, voice, loyalty, neglect, and cynicism

\begin{tabular}{|c|c|c|c|c|c|}
\hline & EXIT & VOICE & LOYALTY & NEGLECT & CYNICISM \\
\hline $\mathrm{RC}$ & $.392 * * *$ & -.104 & $-.249 * * *$ & $.3211^{* * *}$ & $.347^{* * *}$ \\
\hline AUT & $-.219 * *$ & .112 & $.253 * * *$ & -.095 & $-.221 * *$ \\
\hline RIGID & -.035 & -.069 & .032 & .010 & .091 \\
\hline ASS & $-.183 * *$ & $.151^{*}$ & .007 & -.115 & $-.150 *$ \\
\hline Multiple $R$ & .56 & .22 & .40 & .38 & .48 \\
\hline RC*AUT & -.038 & .076 & $.133 *$ & -.115 & -.026 \\
\hline RC*ASS & -.102 & -.157 & .001 & .117 & $.167 *$ \\
\hline RC*RIGID & $.184 *$ & $.232 *$ & -.057 & .041 & -.002 \\
\hline AUT*ASS & -.071 & .036 & $-.150^{*}$ & $.148 *$ & .035 \\
\hline AUT*RIGID & .094 & .090 & $.156^{*}$ & -.004 & -.012 \\
\hline ASS*RIGID & .060 & -.131 & -.036 & .047 & -.041 \\
\hline$\Delta$ Multiple $R$ & .21 & .05 & .09 & .08 & .16 \\
\hline$R^{2}$ for total equation & .363 & .113 & .217 & .188 & .277 \\
\hline$F$ for total equation & $8.422 * * *$ & $1.866^{\dagger}$ & $4.095 * * *$ & $3.452 * *$ & $5.659^{* * *}$ \\
\hline
\end{tabular}

Note. Values for RC, AUT, RIGID, ASS, and their interaction terms are $\beta$ coefficients, with all variables and interaction terms included in the regression equation. Underlined coefficients indicate relationships in the hypothesized direction. Multiple $R$ and $\Delta$ multiple $R$ are composed of hypothesized relationships only.

$\mathrm{RC}=$ Role Conflict. AUT $=$ Autonomy. RIGID $=$ Rigidity. ASS $=$ Assertiveness. $N=159$.

${ }^{* * *} p<.001 .{ }^{* *} p<.01 .{ }^{*} p<.05 .{ }^{\dagger} p<.06$.

\subsection{Regression results}

The second aim of this study was to predict each response as a function of the job characteristics autonomy and role conflict, and the personality variables assertiveness and rigidity, as well as their interactions. To this end, summated scales of predictors and responses were constructed. Descriptive statistics and intercorrelations are given in Table 4. As they were not measured on the same scales, and to avoid multicollinearity between predictors and their interaction terms, the independent variables were standardized. Gender, age, tenure and type of contract (fulltime, parttime) were specified as control variables. Table 4 shows moderate correlations between some of the control variables and outcomes, especially between age and exit, and tenure and voice/cynicism. These effects were partialled out, prior to conducting regression analyses. 
The hypotheses were tested using hierarchical regression analysis. Main effects were entered at the first level, and all interaction effects at the second level. Regression results are presented in Table 5. In this table the coefficients of the full model are presented, i.e. with all variables in the equation. It is important to note that for the interpretation of statistically significant coefficients, a significant overall $F$-value is not a prerequisite (Bedeian \& Mossholder, 1994).

Hypotheses 1-5 predict exit, voice, loyalty, neglect, and cynicism as a function of the direct effects of the situational variables autonomy and role conflict, and the personality variables assertiveness and rigidity. As expected, exit was positively related to role conflict and negatively to autonomy. Also, assertiveness was associated with a lower propensity to exit. It seems that being able to speak up prevents employees from leaving the organization. We found no significant relationship between rigidity and exit. On the whole, with a multiple correlation of .56 hypothesis 1 was supported. Consistent with prior research findings, voice could not be predicted from workplace characteristics. In our study, however, there was a link with assertiveness. With a multiple correlation of .22, support for hypothesis 2 was moderate. As expected, loyalty was negatively associated with role conflict and positively with autonomy. Although the expected associations with personality variables were insignificant, these results lend moderate support to hypothesis 3, with a multiple correlation of .40. Support for hypothesis 4 was somewhat weaker, showing a significant relation between neglect and role conflict only, and a multiple correlation of .38. Finally, cynicism was associated with both situational variables in the expected direction. Contrary to what we expected, assertiveness was inversely related to cynicism. Apparently, cynical behavior is expressed by employees with little autonomy, who experience role conflict, but who generally feel inhibited to express their grievances by speaking up freely. With a multiple correlation of .48 , these results nevertheless provide good support for hypothesis 5. In conclusion, the matrix of direct associations between predictors and responses shows that situational predictors clearly outperform personality predictors, that rigidity was not directly related to any of the responses, and that exit and cynicism have very similar antecedents.

As for the hypothesized interactive effects of predictors on responses, it is argued that 'robust main effects are much easier to find than are replicable two-way (not to mention higher order) interactions' (Funder, 2006, p. 29). Also, interaction effects tend to be weak and generally require large sample sizes for detection. Nevertheless, we were able to detect a number of significant 
interaction effects. Perhaps the most interesting finding is that on the basis of direct effects we could not distinguish between exit and cynicism, whereas the interaction effects enable us to make this distinction. The interaction between role conflict and rigidity is positively related to exit, indicating that employees experiencing role conflict and who are unwilling or unable to give up on fixed ideas about right and wrong, are inclined to leave the organization. On the other hand, the interaction between role conflict and assertiveness is positively related to cynicism. While the direct effect suggests that assertiveness helps avoid cynicism, in combination with role conflict assertiveness seems to take the form of cynically speaking up. Thus, it appears that, conditional on role conflict, rigidity accounts for exit and assertiveness accounts for cynicism. Both interactive effects were in line with expectations, formulated in hypotheses 6 and 10. No support was found for the remaining interactions, which all had unexpected signs.

\section{Discussion}

The study reported in this chapter revolved around two central issues. First, we aimed to extend the exit, voice, loyalty, and neglect model of responses to adverse organizational circumstances with cynicism toward the employing organization. Second, we aimed to predict how employees would 'choose' among these alternatives, given varying degrees of role conflict, autonomy, assertiveness, and rigidity.

The factor analysis results indicated that the final version of the 5-factor measurement model constituted a reasonably adequate representation of the covariance structure in the data, with cynicism standing out as a distinct response. Thus, the first aim of this study was largely accomplished and we conclude that cynicism constitutes a feasible and meaningful extension to the EVLN model .

In predicting exit, voice, loyalty, neglect, and cynicism, the situational workplace characteristics appeared to have considerably more direct impact on responses than personality characteristics. Although the latter facilitated more accurate predictions in interaction with the situation, we were not able to identify a unique and complete set of predictors for each response. Cynicism appeared to be promoted by high role conflict, low autonomy, and low assertiveness. All in all, our results compare well against predictions made by others, such as Rusbult et al. (1988; see Table 4 on p. 610). In their study, multiple $R$ for the prediction of exit and voice was somewhat higher than in the present study (.58 and .29 respectively vs .56 and .22 in the present study), 
whereas for the prediction of loyalty it was somewhat lower (.35 vs .40$)$ and for the prediction of neglect it was considerably lower (.17 vs .38). In addition, we were able to predict cynicism fairly well, and the additional predictions made on the basis of interaction effects offer a promising perspective to achieve even better results in future research, given that these effects were found with only a moderate sample size.

Our findings may have important implications for management. For organizations, there is a lot at stake to predict how their employees would likely respond to intended or unintended unpleasant events. We consider the main strength of this study the advancement of a new research design to make such predictions. In addition, incorporating organizational cynicism into the EVLN framework makes it a more comprehensive typology of responses. Thus, an extension of the typology would allow for generating and testing more accurate hypotheses about relationships between antecedent conditions and resulting outcomes. Surely, cynicism is not a desirable response. It is potentially noxious for the individual as appears from the repeatedly found association with burnout, and widespread cynicism can intoxicate the working atmosphere in organizational units or even entire organizations. The belief that the organization falls short of integrity undermines trust in the organization and its management and can eventually corrode the foundation of the relationship between employee and employing organization. This may likely have a detrimental impact on organizational effectiveness. Organizations are therefore well-advised to take organizational cynicism seriously as a warning sign, and to make every possible effort to understand, contain and prevent cynicism where possible before it develops into something beyond repair. The insights gained from the present study may help organizations to do so.

The main limitation of this study was its cross-sectional design with self-reported data, implying the complete absence of any causal inferences. In structural equation modeling the assumption is made that the latent variable 'causes' the observed indicators. However, no matter how intuitively appealing as it might be to, for instance, regard role conflict as the underlying cause for employees to become cynical, the inverse relationship, i.e. being cynical for whatever reason and thereby experiencing more role conflict than non-cynical colleagues, cannot be ruled out. Only longitudinal research can resolve this issue of the direction of causality. Also, employees do not respond in an either or fashion. Rather, they will demonstrate signs of all responses, but in varying degrees. It would be interesting to see how individuals dynamically develop their own personal way of responding. Again, this issue can only be addressed 
in longitudinal or experimental research. Also, factor analysis results should be interpreted with caution, because they may reflect structural characteristics idiosyncratic to the sample, rather than a general phenomenon. It is therefore imperative that factor analysis results be replicated in future research. Yet another limitation of this study is its relatively small sample size. As interaction effects tend to be weak, detecting such effects requires the statistical power provided by large samples. Hence, the fact that we did find a number of statistically significant interaction effects was indeed very encouraging, indicating that our research design has potential to detect even more interactions with larger samples. Future research should replicate both the factor analysis and the regression results in this study to substantiate the reliability and generalizability of our results and possibly help develop a complete set of unique predictors for each response. 


\section{References}

Abraham, R. (2000a). Organizational cynicism: Bases and consequences. Genetic, Social, and General Psychology Monographs, 126(3), 269-292.

Abraham, R. (2000b). The role of job control as a moderator of emotional dissonance and emotional intelligence-outcome relationships. The Journal of Psychology, 134, 169-184.

Andersson, L. M. (1996). Employee cynicism: An examination using a contract violation framework. Human Relations, 49(11), 1395-1418.

Andersson, L. M., \& Bateman, T. S. (1997). Cynicism in the workplace: some causes and effects. Journal of Organizational Behavior, 18(5), 449-469.

Bacharach, S. B., Bamberger, P., \& Conley, S. C. (1990). Work processes, role conflict, and role overload. Work \& Occupations, 17(2), 199-228.

Barrick, M. R., \& Mount, M. K. (1991). The big five personality dimensions and job performance: A meta-analysis. Personnel Psychology, 44(1), 1-26.

Bedeian, A. G., \& Mossholder, K. W. (1994). Simple question, not so simple answer: Interpreting interaction terms in moderated multiple regression. Journal of Management, 20(1), 159-165.

Bommer, W. H., Rich, G. A., \& Rubin, R. S. (2005). Changing attitudes about change: Longitudinal effects of transformational leader behavior on employee cynicism about organizational change. Journal of Organizational Behavior, 26(7), 733-753.

Byrne, B. M. (1998). Structural equation modeling with Lisrel, Prelis, and Simplis: Basic concepts, applications, and programming. Mahwah, New Jersey: Lawrence Erlbaum Associates.

Dean, J. W., Brandes, P., \& Dharwadkar, R. (1998). Organizational cynicism. Academy of Management Review, 23(2), 341-352.

Dowding, K., John, P., Mergoupis, T., \& van Vugt, M. (2000). Exit, voice and loyalty: Analytic and empirical developments. European Journal of Political Research, 37, 469-495. 
Farrell, D. (1983). Exit, voice, loyalty, and neglect as responses to job dissatisfaction: A multidimensional scaling study. Academy of Management Journal, 26(4), 596-607.

Funder, D. C. (2006). Towards a resolution of the personality triad: Persons, situations and behaviors. Journal of Research in Personality, 40, 21-34.

Hackman, J. R., \& Oldham, G. R. (1976). Motivation through the design of work: Test of a theory. Organizational Behavior \& Human Performance, 16(2), 250-279.

Hagedoorn, M., van Yperen, N. W., van de Vliert, E., \& Buunk, B. P. (1999). Employees' reactions to problematic events: A circumflex structure of five categories of responses, and the role of job satisfaction. Journal of Organizational Behavior, 20(3), 309-321.

Hair, J. F., Anderson, R. E., Tatham, R. L., \& Black, W. C. (1998). Multivariate data analysis (fifth ed.). Upper Saddle River (NJ): Prentice-Hall International, Inc.

Hirschman, A. O. (1970). Exit, voice and loyalty. Responses to decline in firms, organizations, and states. Cambridge, Massachusetts: Harvard University Press.

House, R. J., Schuler, R. S., \& Levanoni, E. (1983). Role conflict and ambiguity scales: Reality or artifacts? Journal of Applied Psychology, 68(2), 334-337.

Hu, L., \& Bentler, P. M. (1999). Cutoff criteria for fit indexes in covariance structure analysis: Conventional criteria versus new alternatives. Structural Equation Modeling, 6(1), 1-55.

Jackson, S. E., \& Schuler, R. S. (1985). A meta-analysis and conceptual critique of research on role ambiguity and role conflict in work settings. Organizational Behavior \& Human Decision Processes, 36(1), 16-78.

Judge, T. A. (2001). Dispositional affect and job satisfaction: A review and theoretical extension. Organizational Behavior \& Human Decision Processes, 86(1), 67-98. 
Judge, T. A., Locke, E. A., Durham, C. C., \& Kluger, A. N. (1998). Dispositional effects on job and life satisfaction: The role of core evaluations. Journal of Applied Psychology, 83(1), 17-34.

Kanter, D. L., \& Mirvis, P. H. (1989). The cynical Americans: Living and working in an age of discontent and disillusionment. San Francisco: JosseyBass.

Karasek, R. A. (1979). Job demands, job decision latitude, and mental strain: Implications for job redesign. Administrative Science Quarterly, 24(2), 285308.

Katz, D., \& Kahn, R. L. (1978). The social psychology of organizations. New York: John Wiley \& Sons.

Leck, J. D., \& Saunders, D. M. (1992). Hirschman's loyalty: Attitude or behavior? Employee Responsibilities and Rights Journal, 5(3), 219-230.

Levinson, H. (1965). Reciprocation: The relationship between man and organization. Administrative Science Quarterly, 9(4), 370-390.

Marsh, H. W., \& Hocevar, D. (1985). Application of confirmatory factor analysis to the study of self-concept : First- and higher order factor models and their invariance across groups. Psychological Bulletin, 97(3), 562-582.

Mudrack, P. E. (2004). Job involvement, obsessive - compulsive personality traits, and workaholic behavioral tendencies. Journal of Organizational Change Management, 17(5), 490-508.

Oldham, G. R., \& Cummings, A. (1996). Employee creativity: Personal and contextual factors at work. Academy of Management Journal, 39(3), 607634.

Oldham, G. R., \& Hackman, J. R. (1981). Relationships between organizational structure and employee reactions: Comparing alternative frameworks. Administrative Science Quarterly, 26(1), 66-83.

Oldham, G. R., Hackman, J. R., \& Pearce, J. L. (1976). Conditions under which employees respond positively to enriched work. Journal of Applied Psychology, 61(4), 395-403. 
Oreg, S. (2003). Resistance to change: Developing an individual differences measure. Journal of Applied Psychology, 88(4), 680-693.

Reichers, A. E., Wanous, J. P., \& Austin, J. T. (1997). Understanding and managing cynicism about organizational change. Academy of Management Executive, 11(1), 48-59.

Rusbult, C. E., Farrell, D., Rogers, G., \& Mainous III, A. G. (1988). Impact of exchange variables on exit, voice, loyalty, and neglect: An integrative model of responses to declining job satisfaction. Academy of Management Journal, 31(3), 599-627.

Rusbult, C. E., Johnson, D. J., \& Morrow, G. D. (1986). Determinants and consequences of exit, voice, loyalty, and neglect: Responses to dissatisfaction in adult romantic involvements. Human Relations, 39(1), 4564.

Rusbult, C. E., \& Zembrodt, I. M. (1983). Responses to dissatisfaction in romantic involvements: A multidimensional scaling analysis. Journal of Experimental Social Psychology, 19, 274-293.

Rusbult, C. E., Zembrodt, I. M., \& Gunn, L. K. (1982). Exit, voice, loyalty, and neglect: Responses to dissatisfaction in romantic involvements. Journal of Personality and Social Psychology, 43(6), 1230-1242.

Spector, P. E. (1994). Using self-report questionnaires in OB research: A comment on the use of a controversial method. Journal of Organizational Behavior, 15(5), 385-392.

Spector, P. E., Chen, P. Y., \& O'Connell, B. J. (2000). A longitudinal study of relations between job stressors and job strains while controlling for prior negative affectivity and strains. Journal of Applied Psychology, 85(2), 211218.

Spector, P. E., \& O'Connell, B. J. (1994). The contribution of personality traits, negative affectivity, locus of control and Type A to the subsequent reports of job stressors and job strains. Journal of Occupational \& Organizational Psychology, 67(1), 1-12. 
Spector, P. E., Zapf, D., Chen, P. Y., \& Frese, M. (2000). Why negative affectivity should not be controlled in job stress research: Don't throw out the baby with the bath water. Journal of Organizational Behavior, 21(1), 79-95.

Steiger, J. H., \& Fouladi, R. T. (1997). Noncentrality interval estimation and the evaluation of statistical models. In L. L. Harlow, S. A. Mulaik \& J. H. Steiger (Eds.), What if there were no significance tests? Mahwah, NJ: Lawrence Erlbaum Associates.

Turnley, W. H., \& Feldman, D. C. (1999). The impact of psychological contract violations on exit, voice, loyalty, and neglect. Human Relations, 52(7), 895922.

Twenge, J. M. (2001). Changes in women's assertiveness in response to status and roles: A cross-temporal meta-analysis, 1931-1993. Journal of Personality and Social Psychology, 81(1), 133-145.

Van Dyne, L., Ang, S., \& Botero, I. C. (2003). Conceptualizing employee silence and employee voice as multidimensional constructs. Journal of Management Studies, 40(6), 1359-1392.

Wilson, K., \& Gallois, C. (1993). Assertion and its social context. New York: Pergamon Press.

Withey, M. J., \& Cooper, W. H. (1989). Predicting exit, voice, loyalty, and neglect. Administrative Science Quarterly, 34(4), 521-539. 


\section{Appendix}

In the questionnaire, the items used to measure exit, voice, loyalty, neglect, and cynicism, were introduced as follows:

Work has many positive sides, such as income or social contacts, but work may also have less favorable sides. At times, you may feel annoyed at certain things, experience stress or a lack of support, or you may be required to meet contradictory demands. People tend to respond differently to aspects of work experienced as less favorable. Would you please indicate how likely you would respond in the following manner:

Items measuring Exit:

Exit $1=$ Consider the possibility to change jobs

Exit2 $=$ Intend to change employers

Exit3 = Actively look for a job elsewhere within the same industry

Exit4 $=$ Look for job advertisements in the newspapers to which you could apply

Exit5 = Intend to change your field of work

Items measuring Voice:

Voice $1=$ Try to work out solutions the organization might benefit from

Voice2 $=$ Come up with suggestions how to prevent these circumstances

Voice3 = Try to work out a solution to the benefit of everyone

Voice4 $=$ Discuss the problem with your superior and try to work out a solution together

Voice5 = In, for instance, work meetings express your point of view to suggest improvements

Items measuring Loyalty:

Loyalty $1=$ Trust the decision-making process of the organization without your interference

Loyalty $2=$ Trust the organization to solve the problem without your help

Loyalty 3 = Remain confident that the situation will be taken care of, without you actively contributing to the decision-making process

Loyalty $4=$ Assume that in the end everything will work out fine

Loyalty $5=$ Optimistically wait for better times 
Items measuring Neglect:

Neglect $1=$ Report sick because you do not feel like working

Neglect $2=$ Come in late because you do not feel like working

Neglect3 $=$ Put less effort into your work than may be expected of you

Neglect $4=$ Every now and then do not put enough effort into your work

Neglect5 $=$ Miss out on meetings because you do not feel like attending them

Items measuring Cynicism:

Cynicism 1 = Express your confidence in the sincerity of your organization (R)

Cynicism2 $=$ Express the feeling that you are not taken seriously by the organization

Cynicism3 = Use cynical humor to 'let off steam'

Cynicism4 = Withhold suggestions for improvements, because you think nothing is going to change anyway

Cynicism5 $=$ Talk to your colleagues about your management's incompetence

Cynicism6 = Shrug your shoulders at what management requires you to do 


\title{
CHAPTER 5
}

\section{Effects on work outcomes of employees' exit, voice, loyalty, neglect, and cynicism responses to adverse circumstances in the workplace}

\begin{abstract}
The present study has two aims. First, to find empirical support for the inclusion of organizational cynicism in the exit, voice, loyalty, and neglect model of employee responses to adverse circumstances in the workplace. Second, to investigate relationships between these responses and resultant affective organizational commitment, helping behavior, and in-role behavior related to the organization, service orientation and job involvement related to the job, and organization-based self-esteem and stress related to the individual employee. We used structural equation modeling to fit the data, provided by 576 hospital employees, to the response model. The fit statistics showed good support for the 5-factor model. Cynicism was shown to be most similar to exit, and both were positively associated with stress, and negatively associated with the other outcomes. Whereas exit was indicative of disengagement from the organization and from work, cynicism was indicative of disengagement from the organization but not from work. Adding cynicism to the exit, voice, loyalty, and neglect model made a significant contribution to the enhanced prediction of affective commitment and organization-based self-esteem.
\end{abstract}




\section{Introduction}

The nature of the employment relationship is changing fundamentally. Organizations and employees have to find ways to respond to the new realities in the workplace such, that work continues to provide meaning and organizational success. Whereas the workplace of twenty years ago was a place where employees offered loyalty, trust, and commitment in exchange for job security, training, promotion, and support from their employer, in the contemporary workplace they are expected to work longer hours, accept greater responsibility, be more flexible and to tolerate continual change and ambiguity (Cartwright \& Holmes, 2006). Moreover, organizational strategies seem to almost invariably work against the interests of employees by bringing job insecurity through outsourcing, downsizing, and firings (Hodson \& Roscigno, 2004). The way employees respond to such unfavorable circumstances may have a significant impact on organizational effectiveness. In the present study we seek to investigate the relationships between employees' responses and work outcomes in relation to the organization, the job, and the employee him- or herself.

In the extant literature, the exit, voice, loyalty, and neglect (EVLN) model is offered as a typology of employees' behavioral reactions to adverse circumstances in the work environment (Farrell, 1983; Hirschman, 1970; Rusbult et al., 1988; Rusbult et al., 1986; Rusbult \& Zembrodt, 1983; Rusbult et al., 1982). Factor analyses have supported the 4-factor structure of the model, while efforts to predict the responses on the basis of employees' rational tradeoffs between the anticipated cost of the response, its efficacy, the attractiveness of the setting in which the action occurs, and the availability and quality of alternatives, have yielded promising, albeit inconclusive, results (Hagedoorn et al., 1999; Rusbult et al., 1988; Rusbult et al., 1986; Turnley \& Feldman, 1999; Withey \& Cooper, 1989). In the previous chapter, an extension of the model with organizational cynicism was proposed, and factor analysis identified cynicism as a distinct response. Moreover, this study explored a new perspective to predict the responses, with mixed success. In the present study we pursue two main objectives. First, the study reported in the previous chapter will be replicated to seek additional support for the 5-factor structure of the exit, voice, loyalty, neglect, and cynicism (EVLNC) model. Second, extending previous research, hypotheses will be formulated and tested regarding associations between the responses and a number of key outcome variables related to the organization, the job, and the individual employee, to substantiate 
the claim that these responses are not only distinct in a statistical sense, but also in terms of their relationships with outcomes.

\section{Exit, voice, loyalty, neglect, cynicism, and work outcomes}

A groundbreaking model of employee responses to adverse organizational circumstances was conceived by Albert Hirschman (1970). In Hirschman's view, customers and employees may respond to organizational 'lapses from efficient, rational, law-abiding, virtuous, or otherwise functional behavior' (1970, p. 1), either by discontinuing the relationship with the organization (exit), by pro-actively voicing complaints and/or suggestions for improvements (voice), or by patiently and confidently waiting for conditions to improve (loyalty). Building on Hirschman's work, it was suggested to extend the model with the neglect response, described as lax and disregardful behavior (Farrell, 1983; Rusbult \& Zembrodt, 1983; Rusbult et al., 1982). Rusbult and colleagues also suggested to expand the exit option with a psychological component, that is besides employees actually leaving the organization they could also think of quitting. Efforts have been made to predict the exit, voice, loyalty, and neglect responses, with predictors primarily derived from social exchange theory (Blau, 1964; Homans, 1958; Lawler, 2001; Settoon et al., 1996). In the previous chapter it was argued that organizational cynicism should be included in the model, because cynicism is an important response with potentially profound implications for the person and the organization, and with features not readily captured by exit, voice, loyalty, or neglect. Organizational cynicism is the belief that the organization lacks sincerity and integrity, and it is expressed as negative affect and disparaging behavior toward the organization consistent with this belief (Dean et al., 1998). Cynicism appears to be widespread in modern business organizations (Kanter \& Mirvis, 1989, 1991; Reichers et al., 1997), and still on the rise (Bommer et al., 2005). Despite the fact that relationships have been suggested, with some of these actually found, between cynicism and various unfavorable behavioral tendencies and outcomes, such as apathy, resignation, alienation, hopelessness, distrust of others, suspicion, contempt, scorn, absenteism, conflict, burnout (Abraham, 2000a; Andersson, 1996; Andersson \& Bateman, 1997), it has also been argued that cynics care deeply for their organization and make careful recommendations (Bommer et al., 2005). In the previous study, the situational variables role conflict and autonomy, the personality variables assertiveness and rigidity, and 
selected person-situation interactions were used to predict responses. As in earlier research, these efforts were not completely successful.

In the present study the focus will be on relationships between responses and work outcomes instead of antecedents, because the literature shows a paucity of studies systematically investigating these relationships. The differential effects of responses were investigated by Rusbult, Johnson and Morrow (1986), in a study on responses to dissatisfaction in romantic relationships. They found that 'the consequences of exit responding were consistently negative...the consequences of neglect were fairly consistently negative...voice reactions fairly consistently yielded favorable consequences...and there was some evidence that loyalty results in favorable outcomes' (Rusbult et al., 1986, p. 60). Hence, although it may be intuitively appealing to categorize exit and neglect as 'destructive' responses associated with negative outcomes, and voice and loyalty as 'constructive' responses associated with positive outcomes (Farrell, 1983; Rusbult et al., 1988; Rusbult et al., 1986; Rusbult \& Zembrodt, 1983), relationships between responses and outcomes are imperfectly understood. The same holds for the associations between cynicism and work outcomes, because on the one hand cynicism is associated with negative effects while on the other hand cynics are believed to have good intentions, i.e. they prefer the organization to act with greater integrity.

The employee maintains relationships with the organization at large, management, the department, and the job. Satisfaction with these relationships adds up to overall job satisfaction, but the variables comprising the equation may show quite some variability. In other words, the employee may be satisfied with certain aspects of work, while not being satisfied with other aspects of work. To assess and understand the impact of responses on outcomes, it is imperative that outcomes be differentiated according to the type of relationship to which they pertain. Therefore, associations between responses and work outcomes will be investigated in relation to the organization, the job and the person, whereas the measurement of the constructs took place at the level of the individual employee. With regard to the organization we will look into affective organizational commitment, helping behavior, and in-role behavior, with regard to the job we will look into job involvement and service orientation, and at the individual level organization-based self-esteem and stress are considered.

It has to be noted that the term 'outcomes' can be somewhat deceptive, because in the dynamics of ongoing processes, outcomes may become antecedents and vice versa. For example, in the previous chapter a model was 
postulated with organization-based self-esteem (OBSE) as a precursor of cynicism, suggesting that cynicism operates as a form of 'damage control' to prevent further erosion of self-esteem. In other words, cynicism is a function of antecedent 'threatened' OBSE, while at the same time 'protected' OBSE can be seen as an outcome of cynicism. Nevertheless, we will adopt the term outcomes, because it is commonly used in the literature. The research model is presented in Figure 1.

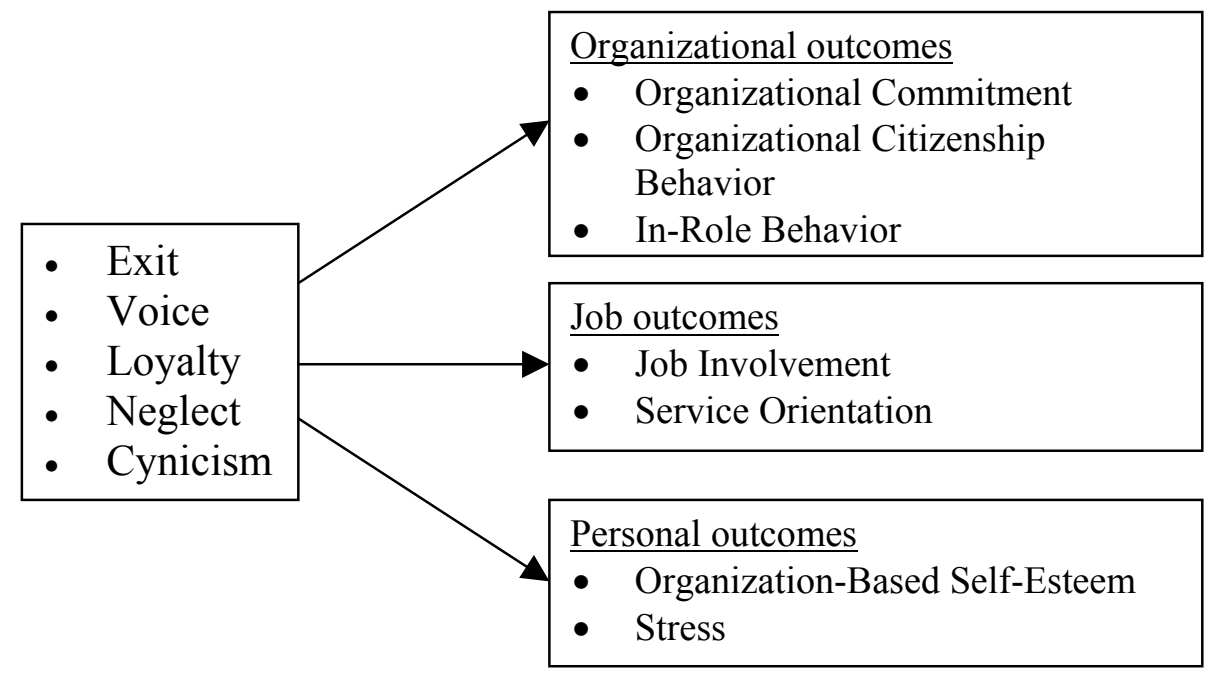

Figure 1. Research model

\subsection{Associations between responses and outcomes: hypotheses}

The factor analysis from the previous study provided support for the distinctiveness of the exit, voice, loyalty, neglect, and cynicism responses. The general hypothesis in the present study is that these distinct responses will be differentially associated with outcomes related to the organization, the job, and the person. Organizational outcomes are: affective organizational commitment (AOC), referred to as an employee's emotional attachment to, identification with, and involvement in the organization (Meyer \& Allen, 1991), organizational citizenship behavior directed at individuals (OCBI), described as a form of altruistic behavior primarily expressed by helping individuals in the work environment (Williams \& Anderson, 1991), and in-role behaviors (IRB), referred to as those behaviors that are formally expected and required to perform a certain job, and that are recognized and evaluated by the formal reward systems (Williams \& Anderson, 1991). Job outcomes are: job 
involvement (JI), which refers to the employee's psychological identification with the job (Brown, 1996), and service orientation (SERV), which typically refers to being patient and accommodating with people, especially with clients (Hogan, Hogan, \& Busch, 1984). Personal outcomes are: organization-based self-esteem (OBSE), which reflects the self-perceived value employees have of themselves as organization members and acting within an organizational context (Pierce et al., 1989), and (psychological) stress which refers to 'a relationship between the person and the environment that is appraised by the person as taxing or exceeding his or her resources and endangering his or her well-being' (Lazarus \& Folkman, 1984, p. 19). The prolonged experience of stress is generally believed to cause physical and mental disorders (Ganster \& Schaubroeck, 1991). A literature search was conducted to formulate hypotheses regarding the associations between responses and outcomes.

Exit. In the literature, the exit option also appears under various other labels, such as turnover intent, intent to leave, or intent to quit. This option refers to the employee's actual determination, or psychological desire, to terminate the relationship with the organization. It is important to note that in this study the exit option is conceptualized as a response to unfavorable circumstances. Hence, exit is not prompted by, for instance, a better career opportunity elsewhere, or moving with the spouse who has accepted another job, but there is something undesirable in the work environment causing employees to entertain this option. In the literature high negative correlations, ranging from -.45 to -.65 , between exit and affective organizational commitment have been reported (Cropanzano, Howes, Grandey, \& Toth, 1997; Jaros, Jermier, Koehler, \& Sincich, 1993; Withey \& Cooper, 1989). The relationship between exit and helping behavior seems much less pronounced. Cropanzano et al. (1997) report insignificant associations between turnover intent and altruism (.09) and between turnover intent and positive work behavior (.06). It seems that the exit option is more directed toward the organization, than toward the person's social environment. For that reason, a negative relationship between exit and in-role behavior might be expected, because meeting formal job requirements is more associated with the organization and organizational rules, regulations, and directives, than with colleagues. Although people who leave as a consequence of adverse circumstances will not likely identify themselves any longer with the employing organization, this is expected to pertain less to identification with the job. For the relationship with service orientation, we expected null relationships, because the employee's service orientation largely reflects personal values and develops 
more within the service provider-client interface, than in the employee's relationship with the employing organization. Negative associations ranging between -.24 and -.49 between turnover intent and organization-based selfesteem have been reported by Pierce and Gardner (2004), and a positive correlation of .18 between turnover intent and job tension is reported by Cropanzano et al. (1997). This leads to the following hypothesis:

Hypothesis 1: Exit will be negatively related to affective organizational commitment, in-role behavior, and OBSE, and positively related to stress. Exit will not be related to helping behavior, job involvement, and service orientation.

Voice. In the present study voice is conceptualized as pro-social voice, i.e. the expression of work-related ideas, information, or opinions, based on cooperative motives, intending to improve the situation (Van Dyne et al., 2003). Withey and Cooper (1989) report positive correlations of .20 and .08 (n.s.) between voice and affective commitment. Substantial positive correlations ( $>$ .50) with helping behavior and in-role behavior are reported by Van Dyne and LePine (1998). These correlations were found across time and regardless of whether voice, helping behavior, and in-role behavior were measured as selfreported, peer-reported, or supervisor-reported constructs. Pierce \& Gardner (2004) suggest a positive association between voice and identification, indicating that a positive relationship between voice and job involvement can be expected. Because the suggestions for improvements implied by voice can be expected to also aim at providing better services to clients, it stands to reason to expect a positive relationship between voice and service orientation. Regarding the relationship between voice and OBSE, it can be argued that making suggestions for improvements will add to OBSE, especially when employees notice that suggestions are considered carefully by the organization and maybe even lead to practical results. In the same vein it can be argued that voice may attenuate the experience of stress. In summary, the following associations are hypothesized:

Hypothesis 2: Voice will be positively related to affective organizational commitment, helping behavior, in-role behavior, job involvement, service orientation, and OBSE, and negatively related to stress.

Loyalty. Loyalty is described as passively but optimistically waiting for conditions to improve, giving public and private support to the organization, 
waiting and hoping for improvement, or practicing good citizenship (Rusbult et al., 1988). Loyalty appears to be grounded in trust and faith in the organization. Although correlational evidence regarding the relationship between loyalty and outcomes is lacking, the foregoing description suggests positive associations with affective organizational commitment, helping behavior, and in-role behavior. Less obvious are the associations with outcomes at the level of the job. As it seems, loyalty implies putting one's faith in the hands of the organization. We therefore had no compelling reasons to expect loyalty to be associated with job involvement and service orientation. Because loyalty may also be indicative of identification with the organization, providing the employee a sense of belongingness and being a valued member of the organization, we expected a positive relationship with OBSE. The relationship between loyalty and stress can be seen from a person-organization (P-O) fit perspective. Kristof (1996, p. 26) reports that strong support has been found for the positive effects of $\mathrm{P}-\mathrm{O}$ fit on a range of individual work attitudes and prosocial behaviors, such as job satisfaction, organizational commitment, motivation, and organizational citizenship behaviors. It can be expected that P$\mathrm{O}$ fit also has a positive effect on loyalty. On the other hand, a negative relationship between P-O fit and work-related stress has been found across a number of studies (Cropanzano et al., 1997; Kristof, 1996). Given these associations, it stands to reason to expect a negative relationship between loyalty and stress. Accordingly, we offer the following hypothesis:

Hypothesis 3: Loyalty will be positively related to affective organizational commitment, helping behavior, in-role behavior, and OBSE, and negatively related to stress. Loyalty will not be related to job involvement and service orientation.

Neglect. The neglect response is associated with negative expressions of discontent primarily targeted at the organization, such as putting in less effort than one should, chronic lateness or absenteeism, or using company time for personal business. The concept is akin to psychological withdrawal (Jaros et al., 1993). For the relationship between neglect and affective organizational commitment, Kidwell and Bennett (2001) report a negative correlation of -.15, Withey and Cooper (1989) found negative correlations of -.19 and -.26, and Cropanzano et al. (1997) found a negative correlation of -.27. For the association between neglect and organizational citizenship behaviors, a negative correlation of -.45 is reported by Turnley and Feldman (2000). Although the 
withdrawal process primarily pertains to the employee's relationship with the employing organization, we also expected a negative association with job involvement and service orientation. The association with OBSE is expected to be negative, because employees who receive positive feedback from the environment and who, accordingly, have reason to perceive themselves as valuable members of the organization will most likely not engage in lax and disregardful behaviors. The relationship between neglect and stress can again be seen from a P-O fit perspective. Because the aforementioned forms of neglect behavior can be seen as the antithesis of pro-social behavior, we expected a positive relationship between neglect and stress. Thus, the following hypothesis is offered:

Hypothesis 4: Neglect will be negatively related to affective organizational commitment, helping behavior, in-role behavior, job involvement, service orientation, and OBSE, and will be positively related to stress.

Organizational cynicism. Cynicism toward the organization reflects the belief that the organization lacks integrity, and that official motives for actions and decisions cannot be trusted. Johnson and O'Leary-Kelly (2003) have found strong negative associations of -.50 and -.57 between organizational cynicism and self-rated organizational commitment, and insignificant associations with peer-rated helping behavior. Moreover, the association between cognitive cynicism and supervisor-rated in-role behavior was insignificant, and for the relationship between affective cynicism and in-role behavior a significant and moderately negative correlation of -.21 was found. Because distrusting the organization cannot conceivably be reconciled with affective commitment toward the organization, a negative relationship is expected. Johnson and O'Leary-Kelly (2003) found non-significant associations between cynicism and helping behavior. As it is argued that, despite their criticisms targeted at the organization and its management, cynics care deeply for their organization and make careful recommendations (Bommer et al., 2005), we also did not expect cynicism to be related to in-role behavior, job involvement, or service orientation. In the previous study, a negative correlation of -.55 between cynicism and OBSE was found, and the burnout literature strongly suggests that stress will likely be positively associated with cynicism (Maslach \& Leiter, 1997; Maslach et al., 2001). This leads to the following hypothesis: 
Hypothesis 5: Organizational cynicism will be negatively related to affective organizational commitment and OBSE, and will be positively related to stress. Organizational cynicism will not be related to helping behavior, in-role behavior, job involvement, and service orientation.

All hypothesized relationships are summarized in Table 1.

Table 1. Hypothesized relationships between responses and outcomes

\begin{tabular}{lccccccc}
\hline & $\begin{array}{l}\text { Affective } \\
\text { organizational } \\
\text { commitment }\end{array}$ & $\begin{array}{l}\text { Helping } \\
\text { behavior }\end{array}$ & $\begin{array}{l}\text { In-role } \\
\text { behavior }\end{array}$ & $\begin{array}{l}\text { Job } \\
\text { involvement }\end{array}$ & $\begin{array}{l}\text { Service } \\
\text { orientation }\end{array}$ & OBSE & Stress \\
\hline Exit & - & 0 & - & 0 & 0 & - & + \\
Voice & + & + & + & + & + & + & - \\
Loyalty & + & + & + & 0 & 0 & + & - \\
Neglect & - & - & - & - & - & - & + \\
Cynicism & - & 0 & 0 & 0 & 0 & - & + \\
\hline
\end{tabular}

Note. OBSE = Organization-Based Self-Esteem. - = Negative relationship hypothesized. $+=$ Positive relationship hypothesized. $0=$ No relationship hypothesized.

\section{Method}

\subsection{Sample and procedure}

Participants in this study were employees of a mid-sized hospital in the Netherlands. The hospital has two units, a large one and a smaller one located in the same part of the country. During the past five years, important activities and assets were centralized in the larger unit as part of an ongoing restructuring program. The organization structure is primarily based on groupings of medical specialisms, but also contains staff-services.

All employees received a questionnaire, a cover letter, and a postagepaid return envelope, addressed to the first author of this study. The questionnaire was printed on university paper, but mailed in a hospital envelope, and the return envelope again had the logo of the university. In the accompanying letter, it was explained that the hospital had taken care of sending the mail, to avoid an address exchange between hospital and university, which would be highly undesirable for reasons of confidentiality. It was also emphasized that management was not the client of the study, and that the research would not go at the expense of the health care budget, as the university would bear the total cost. The aim of the research was explained in general terms as gaining a better understanding of how employees experience their work and employing organization, why people have such different experiences 
and what the consequences of these differences might be. Finally, confidentiality and anonymity were guaranteed, and it was assured that the data would exclusively be available to the authors of this study and that they would be used for scientific purposes only. In total 773 usable questionnaires were returned, for a response rate of $28,1 \%{ }^{3}$.

Prior to measuring the exit, voice, loyalty, neglect, and cynicism items, and in agreement with the procedure in earlier research (Hagedoorn et al., 1999), participants were asked to first read a brief introduction, containing a few examples of adverse organizational circumstances, and then to separately indicate how they would usually respond to such circumstances and events, and how they would most likely respond now. Respondents were assured that, in case they were unable or unwilling to make this distinction, a single answer would also be highly appreciated. In total 576 participants did not make a distinction between usual and now on any of the 25 items measuring the responses. The data provided by these respondents will be used in the present study to evaluate the distinctiveness of exit, voice, loyalty, neglect, and cynicism, as well as their associations with outcomes. In an effort to alleviate common method variance, the order in which the response-items and the outcome-items were presented was randomized (Podsakoff et al., 2003).

\subsection{Measures: work outcomes}

Affective organizational commitment (AOC) was measured with 5 items taken from Meyer, Allen and Smith (1993). All items loaded on the same factor, accounting for $53,27 \%$ of the variance. Helping behavior was measured by using all 7 items comprising the OCBI-scale, measuring organizational citizenship behaviors directed at individuals (Williams \& Anderson, 1991). The item 'Assists supervisor with his/her work (when not asked)' was dropped because this item constituted a second factor. Dropping this item resulted in a uni-dimensional scale, the underlying factor accounting for $56,35 \%$ of the variance. In-role behavior was measured with 5 items from Williams' and Anderson's (1991) IRB-scale. The item 'Engages in activities, such as reading or self-study, that will directly affect his or her performance' was dropped because it constituted a second factor. The 4 remaining items made for a unidimensional solution that captured $49,43 \%$ of the variance. Job involvement

\footnotetext{
${ }^{3}$ It is unclear whether non-response is distributed evenly across the employees. Accordingly, the representativeness of the achieved sample and the generalizability of the findings may be subject to non-response bias and have to be assessed with due caution.
} 
was measured with 4 items from Roe, Ten Horn, Dienes and Zinovieva (1997) and service-orientation was measured by using 4 items from Roe et al. (1997). For both constructs, uni-dimensional solutions were obtained, accounting for $38,24 \%$ and $49,07 \%$ of the variance respectively. Organization-based selfesteem was measured by using 6 items developed by Pierce, Gardner and Cummings (1989), and stress was measured with 3 items from Roe et al. (1997). Again, both measures resulted in uni-dimensional solutions, accounting for $54,32 \%$ and $73,31 \%$ of the variance respectively. Stress was measured on a $7-$ point Likert-type scale with endpoints never and (nearly) always. All other outcomes were measured on a 7-point Likert-type scale with endpoints strongly disagree and strongly agree. Composite reliabilities for the responses and Cronbach's alpha reliabilities for outcomes are provided in Table 4.

\section{Results}

\subsection{Factor analysis of the exit, voice, loyalty, neglect, and cynicism items}

The first aim of this study is to replicate the results from the previous study, to gain additional support for the 5-factor exit, voice, loyalty, neglect, and cynicism model of employee responses to adverse organizational circumstances. Except for one item, we used the same items that we used in the previous study, with the same indexes, to measure responses. An exception was made for the exit3 item ('Actively look for a job elsewhere within the same industry'), because this item was judged to have too much overlap with the other items comprising the exit-scale. Lisrel 8.72 was used to test the fit between the actual sample covariance matrix and the covariance matrix implied by the hypothesized model. In the first step, the most restrictive version of the full measurement model was tested, comprising all 25 indicators, measuring 5 latent constructs. Each of these indicators was allowed to load on its corresponding latent construct only, that is cross-loadings were not allowed, and errors were posited to be uncorrelated. For scaling purposes, the loading of the first indicator of each latent construct was fixed at 1 . Skewness and kurtosis values justified the use of maximum likelihood for parameter estimation. Twenty-three items showed skewness and kurtoses between -1 and +1 . The remaining two items (Neglect3 and Neglect4) showed elevated skewness and kurtosis values that would classify their distributions as moderately non-normal (Curran, West, \& Finch, 1996). The goodness-of-fit statistics for the baseline model (Model A) are presented in Table 2. 
Table 2. Results of Lisrel analyses: Goodness-of-fit statistics

\begin{tabular}{lllllll}
\hline Model & $\chi^{2}$ & $d f$ & $\Delta \chi_{(\Delta d)}^{2}$ & RMSEA & SRMR & NNFI \\
\hline Model A & 818.33 & 265 & & .060 & .075 & .88 \\
Model B & 649.06 & 242 & $169.27_{(23)} * * *$ & .054 & .066 & .90 \\
\hline
\end{tabular}

Note. Model A $=$ Full model with 25 indicators. Model B = Model A without omitted cynicism item.

$* * * p<.001$.

Because it is widely recognized that the traditional chi-square test of model fit can yield questionable results, due to its susceptibility to sample size, we followed Vandenberg and Lance (2000), who recommend supplementing the chi-square with the nonnormed-fit index (NNFI), the root mean square error of approximation (RMSEA), and the standardized root mean square residual (SRMR). For these supplementing indices, norms for cutoff values have been established in the literature. For NNFI, the authors state that, although in one study (Hu \& Bentler, 1999) it is argued that values should exceed the .95 threshold, 'it may be premature to throw out the .90 critical value' (p. 44). For RMSEA and SRMR, values $<.06$ and $<.08$ respectively are suggested (Hu \& Bentler, 1999). Table 2 shows that for the baseline model all fit statistics indicate some degree of misfit. Switching from a strictly confirmatory into an exploratory mode of analysis, an inspection of the modification indices provided in the Lisrel output revealed a high cross-loading of the cynicism item 'Not commit yourself because you think nothing is going to change anyway' on the voice construct. Because cross-loadings compromise the uni-dimensionality of the scales, it was decided to drop this single item. The resulting model being nested in the original model, the difference in chi-square, in combination with degrees of freedom gained, can be taken as evidence for the significance of model fit improvement. Table 2 shows for Model B a significantly better fit as indicated by chi-square. In addition, after this modification the model meets the RMSEA and SRMR criteria for good fit, suggested by Hu \& Bentler (1999). The value for NNFI meets the conservative cutoff value, but not the stricter cutoff value suggested by the same authors. In conclusion, given these fit statistics and the strong restrictions imposed upon the model, i.e. no crossloadings and no correlated errors were allowed, these results support the tenability of the 5 -factor structure of employees' responses. Table 3 presents the standardized factor loadings and composite reliabilities. All factor loadings were statistically significant, and although some of the items are not very strong indicators of the underlying construct, thereby having a negative effect on the 
reliability, more research is needed to assess their psychometric properties. It was therefore decided not to drop these items.

Table 3. Standardized factor loadings for final EVLNC model (Model B, Table 2)

\begin{tabular}{lccccc}
\hline & Exit (.79) & Voice (.74) & Loyalty (.62) & Neglect (.58) & Cynicism (.68) \\
\hline Exit1 & .56 & & & & \\
Exit2 & .82 & & & & \\
Exit4 & .74 & & & & \\
Exit5 & .67 & & & & \\
Voice1 & & .61 & & & \\
Voice2 & & .69 & & & \\
Voice3 & & .57 & & & \\
Voice4 & & .44 & & & \\
Voice5 & & .67 & & & \\
Loyalty1 & & & .27 & & \\
Loyalty2 & & & .79 & & \\
Loyalty3 & & & .37 & & \\
Loyalty4 & & & .63 & & \\
Loyalty5 & & & .38 & .37 & \\
Neglect1 & & & & .47 & \\
Neglect2 & & & & .63 & \\
Neglect3 & & & & .58 & \\
Neglect4 & & & & .24 & \\
Neglect5 & & & & & \\
Cynicism1 & & & & & \\
Cynicism2 & & & & & \\
Cynicism3 & & & & & \\
Cynicism5 & & & & & \\
Cynicism6 & & & & & \\
\hline
\end{tabular}

Note. Composite reliabilities (Hair et al., 1998) are given in parentheses. Factor loadings not shown in this table were posited equal to zero. EVLNC $=$ Exit, Voice, Loyalty, Neglect, Cynicism.

\subsection{Descriptive statistics and correlational analyses}

Prior to the further analyses, summated scales were created for all the variables using all items that passed the factor analysis. Means, standard deviations, reliabilities and zero-order correlations are presented in Table 4. Most reliabilities are acceptable, but the reliability of job involvement is clearly below par. Table 4 shows that age is significantly related to all outcomes except OBSE, and also to exit and voice. Contrary to age, tenure shows less significant relationships with outcomes and responses, but it is positively related to cynicism. 


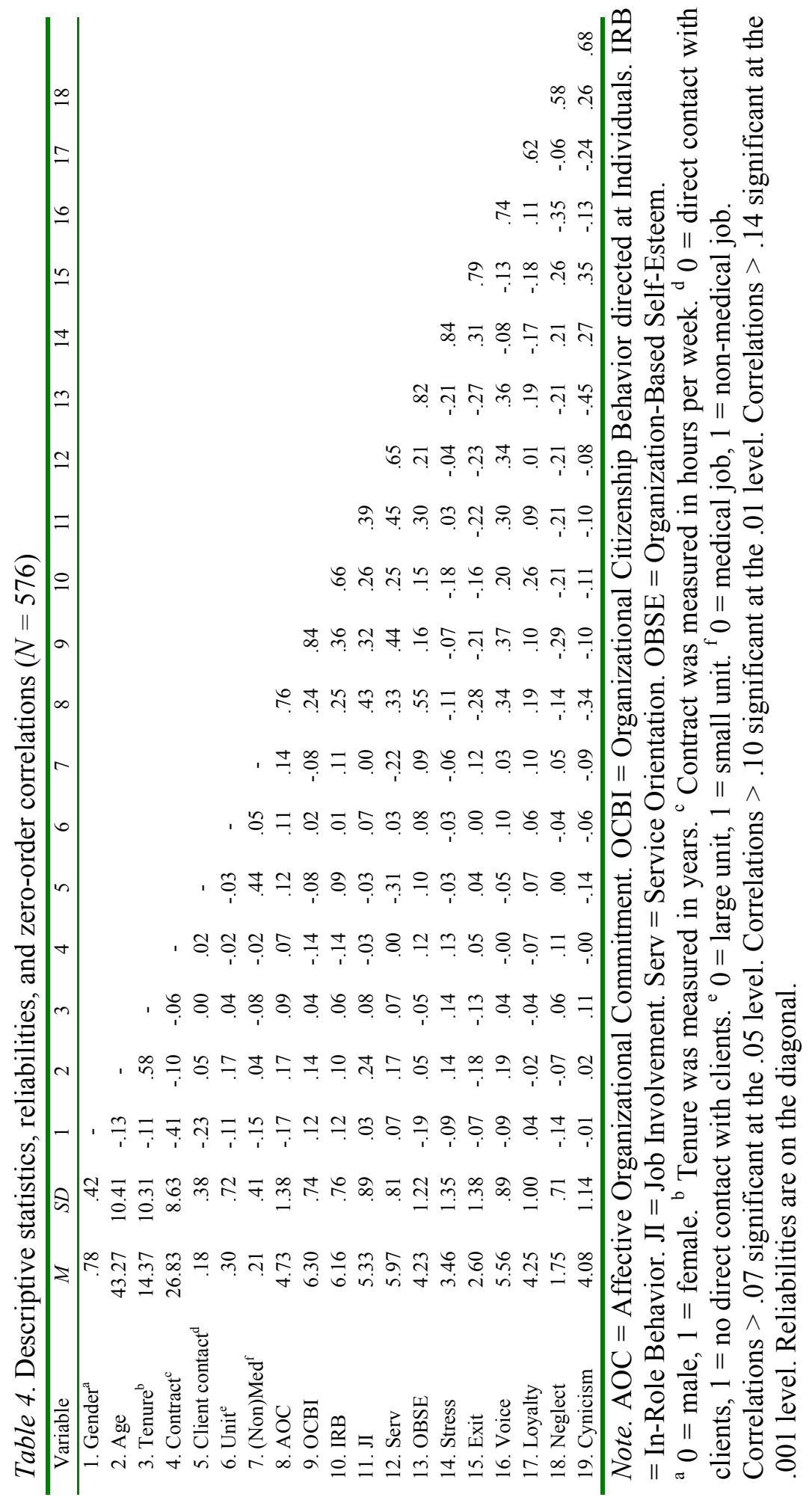


To assess the impact of control variables on responses and outcomes, we first conducted ANOVAs with gender, presence vs. absence of direct client contact, large unit vs. small unit, and medical vs. non-medical jobs as factors. Table 5 shows a number of statistically significant differences in means. Respondents in non-medical jobs showed a higher propensity to exit while, surprisingly, at the same time they reported more loyalty than medical personnel. Voice was higher among men and among those who worked in the small unit, men were more inclined to neglect behavior than women, and respondents who directly interacted with clients reported more cynicism toward the organization than those who had no direct contacts with clients. Respondents in medical jobs also reported higher cynicism, although there will conceivably be overlap with the previous category.

Men scored considerably higher on organizational commitment than women, and higher commitment toward the organization was also reported by respondents who had no direct contacts with clients, who worked in nonmedical jobs, and by those who worked in the small unit. Women, on the other hand, were more helping oriented, as were those respondents who worked in the small unit and who worked in medical jobs. Women scored somewhat higher on in-role behavior, as did respondents who had no direct contact with clients, who worked in the small unit, and who held non-medical jobs.

Job involvement was consistent across all categories. Self-reported service orientation was considerably higher among respondents with direct client contacts, and those working in medical jobs. Organization-based selfesteem was higher for men, for respondents who had no direct contacts with clients, and for respondents in non-medical jobs. Finally, men reported somewhat more stress, and respondents in the large unit experienced considerably more stress than those in the small unit. 


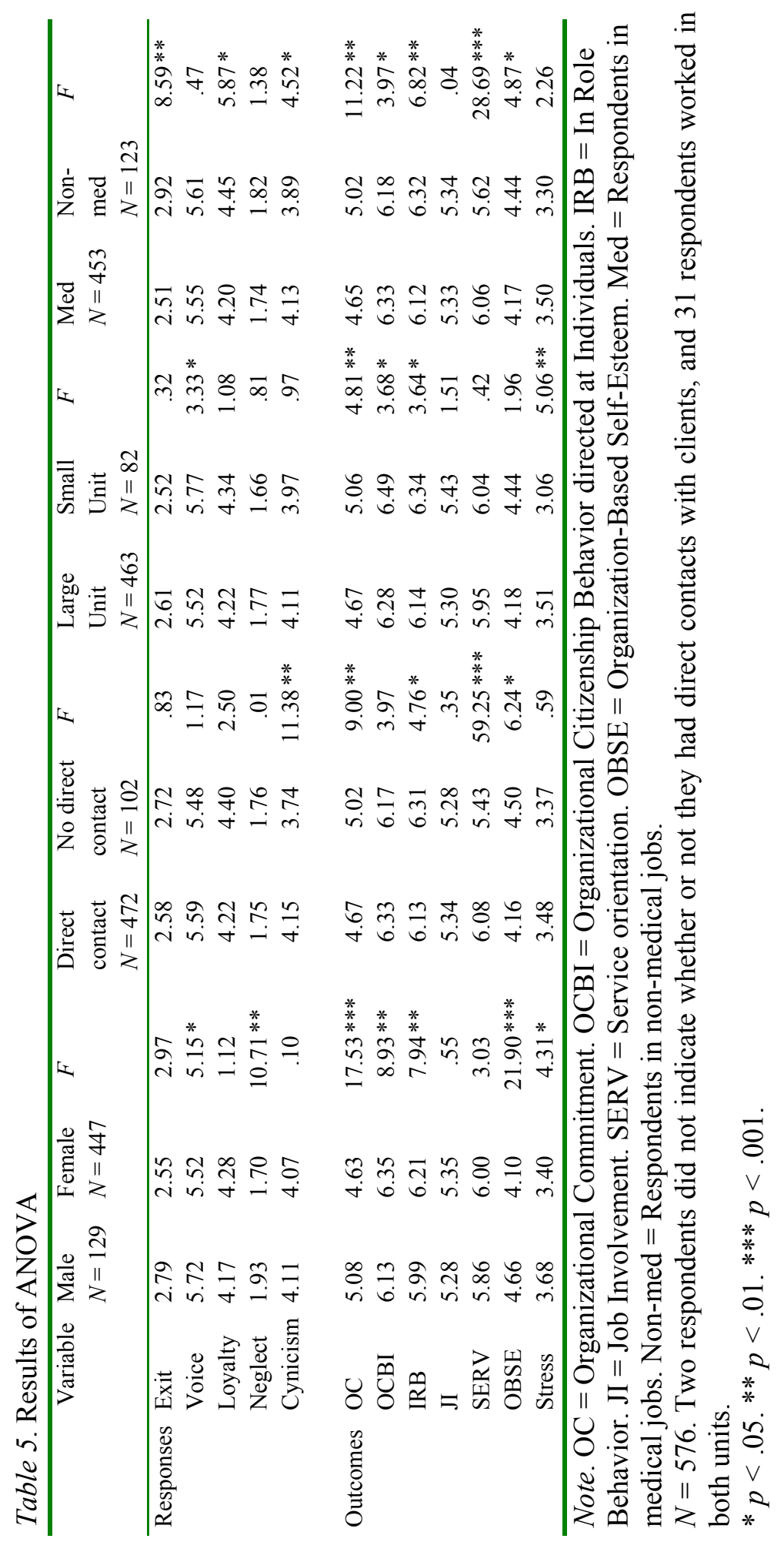


The zero-order correlations between responses and outcomes reported in Table 4 were used to test the hypothesized relationships presented in Table 1. Because hypotheses 1-5 are composite hypotheses, each consisting of 7 singular subhypotheses, Bonferroni adjustment was applied to protect against the probability of making Type I errors. The required minimum significance level of .05 was divided by 35 (the total number of associations involved in testing the hypotheses), and thus all significance-tests were conducted at the conservative .001 level.

As hypothesized, exit was negatively associated with affective commitment toward the organization, in-role behaviors, and OBSE, and positively related with stress. However, exit was expected not to be associated with organizational citizenship behavior, job involvement and service orientation, but these relationships were all significant and negative. Together, these results lend moderate support to hypothesis 1. As expected, voice was positively associated with affective organizational commitment, organizational cititenship behavior, in-role behavior, job involvement, service orientation, and OBSE. The relationship between voice and stress did not reach the .001 signifance level. Overall, these results are in support of hypothesis 2. Loyalty was, as hypothesized, positively associated with affective organizational commitment, in-role behavior and OBSE, and negatively associated with stress, but the relationship with organizational citizenship behavior was not significant. The hypothesized null- relationships with job involvement and service orientation indeed did not reach the .001 significance level. Together, these results lend strong support to hypothesis 3 . Hypothesis 4 was fully supported, because all hypothesized relationships between neglect and work outcomes were confirmed by the data. As expected in hypothesis 5, organizational cynicism was negatively associated with affective organizational commitment and OBSE, and positively associated with stress. Cynicism was hypothesized not to be associated with organizational citizenship behavior, in-role behavior and service orientation, and these associations were indeed non-significant at the .001 level. These results lend excellent support to hypothesis 5. Taken together, these results provide moderate to good support for the hypothesized relationships between responses and outcomes. Also, the aforementioned results from the study by Rusbult et al. (1986), now pertaining to relationships between employees and their employing organization instead of romantic relationships, were confirmed in our study. 


\subsection{Using outcome patterns to differentiate EVLNC}

In the factor analyses conducted in chapter 4 and the present chapter we have shown that exit, voice, loyalty, neglect, and cynicism are different constructs because they have different measurement characteristics. For instance, the item 'shrug your shoulders at what management requires you to do' is indicative of cynicism, but not of exit, voice, loyalty, or neglect. This measurement information is sufficient to construct a typology of distinct responses. Surely, such a typology is important from a theoretical point of view, but the fact that the responses have different characteristics is of limited practical relevance, unless it can be shown that responses are differentially associated with predictor variables and/or outcome variables. In that case responses would be predicted by particular antecedent variables, such as personality traits or job characteristics, and in turn they would predict particular outcomes, such as commitment to the organization or to the job.

In the previous chapter we have attempted to predict responses using personality variables, situational variables, and their interactions as predictors. In all events, results were promising, opening up new areas for future research, yet they were inconclusive in that no set of predictors could be found that would perfectly distinguish between responses. In the present study we aimed to investigate whether the responses are differentially related to various work outcomes. In the previous section of this chapter it was demonstrated that indeed differential associations between responses and work outcomes exist. However, hypothesis testing was conducted at the level of separate associations, each between a single response and various individual outcomes. In this section we seek to extend the analysis by testing whether responses are also differentially related to patterns of outcomes. This test has a number of advantages over the previous tests. Its main advantage is that inferences made about responses are less susceptible to coincidence and based on a joint evaluation of multiple outcomes.

An example will help clarify this. If two responses are compared on the basis of their associations with a single outcome, a difference in association with that outcome would likely lead to the conclusion that the responses have different effects. For instance, voice is strongly and positively related to service orientation, and the relationship between loyalty and service orientation is insignificant, hence voice and loyalty have different effects. However, if voice and loyalty would be equally associated with the remaining 6 outcomes, it can be argued that they are really quite similar in their effects. Hence, comparing responses on the basis of single associations may lead to erroneous conclusions. 
To get a good impression of true associations, unconfounded by the effects of age, tenure, and the aforementioned categorical variables, these effects were partialled out prior to analyzing the associations between responses and patterns of outcomes. Then a structural equation model was defined, using multiple indicators, to make paired comparisons between models comprising sets of two responses and their associations with all seven outcomes. For each set of responses, the null hypothesis that both responses are similar was tested against the alternative hypothesis that both responses are dissimilar. With 5 responses, 10 such comparisons were made: exit-voice, exit-loyalty, exitneglect, exit-cynicism, voice-loyalty, voice-neglect, voice-cynicism, loyaltyneglect, loyalty-cynicism, and neglect-cynicism. Again, Bonferroni adjustment was applied by setting the required significance level for each individual test at .005 (i.e. .05 divided by 10). This model is presented in Figure 2. For the sake of simplicity, only the structural model is displayed, not the measurement model.

A comparison was made between the model with all 14 paths (all $\gamma$ 's in Figure 2) between the 2 responses and 7 outcomes estimated freely, and the same model in which the corresponding paths between the 2 responses and all 7 outcomes were constrained to equality:

$\gamma_{1,1}=\gamma_{1,2}$ and $\gamma_{2,1}=\gamma_{2,2}$ and $\gamma_{3,1}=\gamma_{3,2}$ and $\gamma_{4,1}=\gamma_{4,2}$ and $\gamma_{5,1}=\gamma_{5,2}$ and $\gamma_{6,1}=\gamma_{6,2}$ and $\gamma_{7,1}=\gamma_{7,2}$.

The drop in fit when moving from the model without equality constraints to the more constrained model, as indicated by $\Delta \chi^{2}$ with $d f=7$, was taken as a measure of dissimilarity between both responses across all outcomes. The results of these analyses are presented in Table 6 . All increases in chi-square were significant at the .001 level. Table 6 shows that cynicism can be distinguished from the other responses, and appears to be most dissimilar to voice. By imposing the equality constraints one by one, instead of imposing them all simultaneously, we were also able to identify the outcomes that differentiated most between responses. Results indicated that differences between responses were primarily due to their associations with OBSE, affective organizational commitment, and organizational citizenship (helping) behavior, that is with outcomes at the level of the person and the organization, and only marginally to job-related outcomes. 
Figure 2. Structural Equation Model to test (dis)similarity of responses.

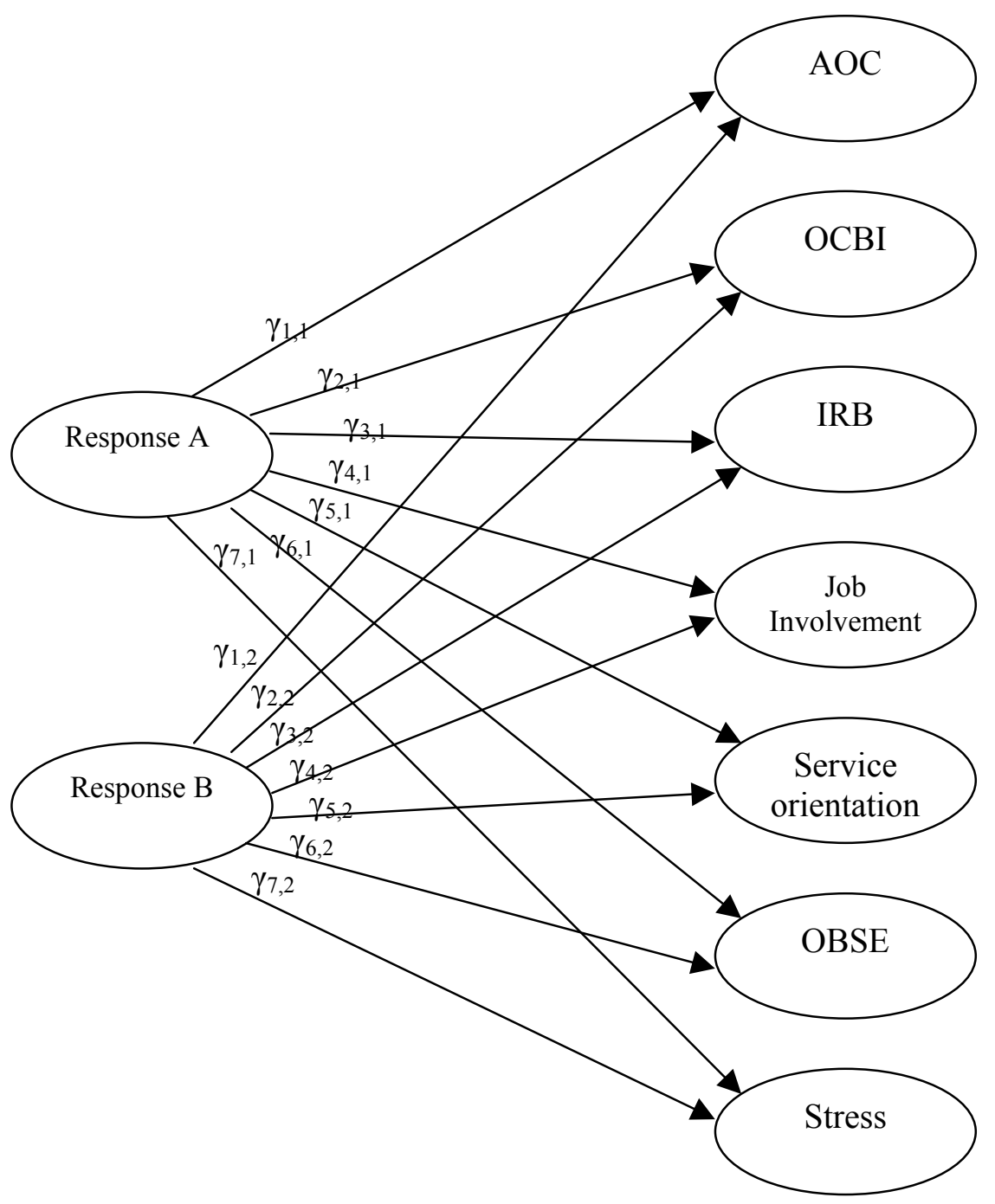

Note. AOC $=$ Affective Organizational Commitment. OCBI $=$ Organizational Citizenship Behavior directed at Individuals. IRB $=$ In-Role Behavior. OBSE $=$ Organization-Based Self-Esteem. 
Table 6. Response comparisons

\begin{tabular}{lrrrr}
\hline & Exit & Voice & Loyalty & Neglect \\
\hline Exit & - & & & \\
Voice & 200.18 & - & & \\
Loyalty & 86.89 & 72.13 & - & \\
Neglect & 100.77 & 85.38 & 158.05 & - \\
Cynicism & 50.75 & 234.18 & 63.32 & 133.26 \\
\hline
\end{tabular}

Note. Values are chi-square differences, representing misfit between model with paths between responses and outcomes freely estimated, and model with corresponding paths between responses and outcomes constrained to equality. All differences are significant at the $p<.001$ level $(d f=7)$.

\subsection{The added value of cynicism to the EVLN model}

Given that organizational cynicism has been identified as a distinct employee response to adverse organizational circumstances, both on the basis of factor analysis results as well as correlational patterns with outcomes, we finally address the question whether cynicism is capable of accounting for unique variance in outcomes, over and above the variance already accounted for by exit, voice, loyalty, and neglect. In linear regression, with 1 dependent variable and multiple predictors, the answer to this question can be found by simply looking at $\Delta R^{2}$ when an additional predictor is added to the regression equation. The great benefit of structural equation modeling (SEM) is that it captures the complexity of relationships in a wide variety of phenomena and processes, by allowing for the simultaneous regression of multiple dependent variables on multiple predictors. Unfortunately, there is no such thing as an overall $R^{2}$, which can be interpreted as a percentage of explained variance, for the structural model as a whole. A proxy for this overall measure is the set of squared multiple correlations for all individual outcome variables, provided in the Lisrel output. The difference between these measures in the 4-factor factor model and those in the the 5-factor model provides information on the added value of cynicism in the response model. Table 7 shows that adding cynicism to the exit, voice, loyalty, and neglect model makes a significant contribution to the enhanced prediction of AOC and OBSE. In addition to the factor analyses in chapter 4 and the present chapter, and the regression results indicating that cynicism is differentially associated with individual work outcomes as well as patterns of work outcomes, this is another justification for including cynicism in the EVLN typology. 
Table 7. Squared multiple correlations for regressions of multiple outcomes on responses

\begin{tabular}{lcrrrrrc}
\hline & AOC & OCBI & IRB & JI & SERV & OBSE & STRESS \\
\hline 4-Factor model & .33 & .26 & .31 & .38 & .31 & .33 & .25 \\
5-Factor model & .44 & .27 & .33 & .38 & .31 & .52 & .25 \\
$F_{(569,570)}$ & $1.33 * * *$ & 1.04 & 1.06 & .00 & .00 & $1.58 * * *$ & .00 \\
\hline
\end{tabular}

Note. AOC $=$ Affective Organizational Commitment. OCBI $=$ Organizational Citizenship Behavior directed at Individuals. IRB $=$ In-Role Behavior. JI $=$ Job Involvement. SERV $=$ Service Orientation. OBSE = Organization-Based SelfEsteem. 4-Factor Model = exit, voice, loyalty, and neglect $($ EVLN) Model. 5Factor Model = exit, voice, loyalty, neglect, and cynicism (EVLNC) Model. $* * * p<.001$.

\section{Discussion}

This study has two major goals. First, to find additional support for including cynicism in the exit, voice, loyalty, and neglect (EVLN) model of employee responses to adverse organizational circumstances. Second, to distinguish between responses on the basis of their differential associations with outcomes.

In the previous chapter it was suggested that organizational cynicism be included in the EVLN model. Factor analysis identified cynicism as a distinct response. To reduce the likelihood of these results being indicative of idiosyncratic features of a particular sample, rather than representing a structure that generalizes across various populations, the present study replicated the study reported in the previous chapter, now using a larger sample. Factor analysis again provided clear support for the 5-factor exit, voice, loyalty, neglect, and cynicism model.

The second aim of this study was to investigate the associations between responses and a set of outcomes related to the organization, the job, and the person, to explore the distinctiveness of the responses in terms of their effects on outcomes. In particular, we aimed to learn more about the effects of organizational cynicism. With regard to exit, voice, loyalty, and neglect, our results largely confirmed earlier findings by Rusbult, Johnson and Morrow (1986), that voice and loyalty are primarily associated with positive consequences and exit and neglect primarily with negative consequences. As for cynicism, the present study found that helping behavior, in-role behavior, job involvement, and service orientation all 'suffer' less from employees' cynical reactions, than from employees' desire to terminate the relationship with the organization (exit), or the inclination to withhold effort from the job (neglect). 
The associations between cynicism and these outcomes, although statistically significant, were not of practical significance, with cynicism explaining about one per cent of the variance in outcomes. In short, the detrimental effect of cynicism on job-related behavior and social behavior toward colleagues has been found to be limited. This is consonant with Johnson and O'Leary-Kelly who found that 'employees' cynical attitudes toward the employer did not influence their work performance, their organizational citizenship behaviors, or their absence levels' (Johnson \& O'Leary-Kelly, 2003, p. 641). On the other hand, cynicism is weakly associated with longer tenure, moderately associated with low organizational commitment and even stronger related to low organization-based self-esteem. This suggests that cynicism not only works as a form of disengagement from the organization, but also as a form of self-defense. The categorical variables gender, presence or absence of direct contact with clients, large or small unit, and medical or non-medical jobs showed a number of significant differences in the means of responses and outcomes. Because these effects were partialled out, the findings of this study should generalize across the organization.

Given that cynicism has been identified as a distinct response in factor analysis, and on the basis of its correlational patterns with a number of important work outcomes, and cynicism adding significantly to the prediction of two important outcomes, i.e. affective commitment toward the organization and the self-perceived value employees have of themselves as organization members, there is sufficient reason to extend the exit, voice, loyalty, and neglect model with the cynicism response.

As any other study, this study has limitations that may attenuate the validity and generalizability of the findings. First, all outcomes and responses are self-reported measures. Hence, relationships may have been artificially inflated or deflated as a result of common method bias, even though we scrambled the order in which the items were presented. Second, the reliability of some of the measures was questionable. Especially the reliability of job involvement was unacceptably low. It is unclear whether this was due to the psychometric properties of the items, or to sample specific factors. Third, although hospitals are in many respects 'ordinary' organizations, in some important respects they are not, which may have implications for the generalizability of our findings. For instance, more than in many other industries or organizations, medical professionals tend to identify strongly with their jobs. This may explain why responses to adverse conditions could not be differentiated on the basis of helping behavior and job-related outcomes. Also, 
social relationships and work attitudes are more controlled by professional and personal values and less by organizational values. In other words, the associations between responses and outcomes may be significantly moderated by the professional values of the participants.

Our findings have some important implications for management. The crave for efficiency in contemporary organizations is frequently perceived as an impediment for doing a proper job, especially by professionals with strongly developed vocational and personal standards. It has even been suggested that the excessive control measures in the contemporary workplace, aiming to discipline the workers and in effect limiting their autonomy, can be regarded as the instruments used to colonize their affect and subjectivity (Gabriel, 1999), a perspective reminiscent of Gareth Morgan's image of the organization as an instrument of domination (Morgan, 1998). It may not come as a surprise, then, that many employees in our study seem to have lost their affective commitment toward the organization. These are also the employees expressing cynicism toward the organization. In the organization participating in this study, the mean for cynicism (4.08) was above the midpoint of the scale and the cynicism variable followed an almost perfect normal distribution, indicating that more than half of the employees score relatively high on cynicism toward their organization. Again, given the special characteristics of health care organizations, this need not be representative for other industries, although it is in line with the incidence figures presented in chapter 2.

Moreover, this study puts the image of cynical employees as 'bad apples' in a more informed perspective. One of the main findings of this study is that cynical employees show relatively low emotional attachment to, identification with, and involvement in the organization, whereas the way in which they do their work is not negatively affected by this lack of organizational commitment. However, cynicism is by no means as harmless as this finding might suggest. Organizations are systems of coordinated and controlled activities, and the viability of any organization depends on the effectiveness of its coordination and control mechanisms and systems. The cynicism of employees who psychologically turn their backs on the organization in large numbers may introduce a sense of self-control that potentially undermines the authority of management and the acceptance of managerial decisions. It may also be a source of resistance to change that jeopardizes the success of managers' efforts to bring about organizational change.

From the perspective of the interaction between employee and organization, another important finding with profound managerial implications 
is the strong negative relationship between cynicism and organization-based self-esteem. More than any other response, cynicism reflects the attitude and behavior of employees who do not believe that the organization values their contribution and that the organization sees them as important organizational members. There is a strong relationship between the perceived lack of integrity of the employing organization, and the feedback received from the organization that makes employees feel like insignificant members. In the short run, these employees may sustain their work morale, but in the long run the consequences for organizational and personal effectiveness can be expected to be severe. In the next chapter, we will summarize the findings of the literature review and the empirical studies reported in this dissertation, and we will elaborate on their wider implications. 


\section{References}

Abraham, R. (2000). Organizational cynicism: Bases and consequences. Genetic, Social, and General Psychology Monographs, 126(3), 269-292.

Andersson, L. M. (1996). Employee cynicism: An examination using a contract violation framework. Human Relations, 49(11), 1395-1418.

Andersson, L. M., \& Bateman, T. S. (1997). Cynicism in the workplace: some causes and effects. Journal of Organizational Behavior, 18(5), 449-469.

Blau, P. (1964). Exchange and power in social life. New York: Wiley.

Bommer, W. H., Rich, G. A., \& Rubin, R. S. (2005). Changing attitudes about change: Longitudinal effects of transformational leader behavior on employee cynicism about organizational change. Journal of Organizational Behavior, 26(7), 733-753.

Brown, S. P. (1996). A meta-analysis and review of organizational research on job involvement. Psychological Bulletin, 120(2), 235-255.

Cartwright, S., \& Holmes, N. (2006). The meaning of work: The challenge of regaining employee engagement and reducing cynicism. Human Resource Management Review, 16, 199-208.

Cropanzano, R., Howes, J. C., Grandey, A. A., \& Toth, P. (1997). The relationship of organizational politics and support to work behaviors, attitudes, and stress. Journal of Organizational Behavior, 18(2), 159-180.

Curran, P. J., West, S. G., \& Finch, J. F. (1996). The robustness of test statistics to nonnormality and specification error in confirmatory factor analysis. Psychological Methods, 1(1), 16-29.

Dean, J. W., Brandes, P., \& Dharwadkar, R. (1998). Organizational cynicism. Academy of Management Review, 23(2), 341-352.

Farrell, D. (1983). Exit, voice, loyalty, and neglect as responses to job dissatisfaction: A multidimensional scaling study. Academy of Management Journal, 26(4), 596-607. 
Gabriel, Y. (1999). Beyond happy families: A critical reevaluation of the control-resistance-identity triangle. Human Relations, 52(2), 179-203.

Ganster, D. C., \& Schaubroeck, J. (1991). Work stress and employee health. Journal of Management, 17(2), 235-271.

Hagedoorn, M., van Yperen, N. W., van de Vliert, E., \& Buunk, B. P. (1999). Employees' reactions to problematic events: A circumflex structure of five categories of responses, and the role of job satisfaction. Journal of Organizational Behavior, 20(3), 309-321.

Hair, J. F., Anderson, R. E., Tatham, R. L., \& Black, W. C. (1998). Multivariate data analysis (fifth ed.). Upper Saddle River (NJ): Prentice-Hall International, Inc.

Hirschman, A. O. (1970). Exit, voice and loyalty. Responses to decline in firms, organizations, and states. Cambridge, Massachusetts: Harvard University Press.

Hodson, R., \& Roscigno, V. J. (2004). Organizational success and worker dignity: Complementary or contradictory? American Journal of Sociology, 110(3), 672-708.

Hogan, J., Hogan, R., \& Busch, C. M. (1984). How to measure service orientation? Journal of Applied Psychology, 69(1), 167-173.

Homans, G. C. (1958). Social behavior as exchange. American Journal of Sociology, 63(6), 597-606.

Hu, L., \& Bentler, P. M. (1999). Cutoff criteria for fit indexes in covariance structure analysis: Conventional criteria versus new alternatives. Structural Equation Modeling, 6(1), 1-55.

Jaros, S. J., Jermier, J. M., Koehler, J. W., \& Sincich, T. (1993). Effects of continuance, affective, and moral commitment on the withdrawal process: An evaluation of eight structural equation models. Academy of Management Journal, 36(5), 951-996.

Johnson, J. L., \& O'Leary-Kelly, A. M. (2003). The effects of psychological contract breach and organizational cynicism: Not all social exchange 
violations are created equal. Journal of Organizational Behavior, 24(5), 627-647.

Kanter, D. L., \& Mirvis, P. H. (1989). The cynical Americans: Living and working in an age of discontent and disillusionment. San Francisco: JosseyBass.

Kanter, D. L., \& Mirvis, P. H. (1991). Cynicism: The new American malaise. Business \& Society Review, Spring 91(77), 57-61.

Kidwell, R. E., \& Bennett, N. (2001). Perceived work context and employee job neglect. American Business Review, 19(2), 64-75.

Kristof, A. L. (1996). Person-organization fit: An integrative review of its conceptualizations, measurement, and Personnel Psychology, 49(1), 1-49.

Lawler, E. J. (2001). An affect theory of social exchange. American Journal of Sociology, 107(2), 321-352.

Lazarus, R. S., \& Folkman, S. (1984). Stress, appraisal, and coping. New York: Springer Publishing Company.

Maslach, C., \& Leiter, M. P. (1997). The truth about burnout. San Francisco: Jossey-Bass.

Maslach, C., Schaufeli, W. B., \& Leiter, M. P. (2001). Job burnout. Annual Review of Psychology, 52(1), 397-422.

Meyer, J. P., \& Allen, N. J. (1991). A three-component conceptualization of organizational commitment. Human Resource Management Review, 1(1), 61-89.

Meyer, J. P., Allen, N. J., \& Smith, C. A. (1993). Commitment to organizations and occupations: Extension and test of a three-component conceptualization. Journal of Applied Psychology, 78(4), 538-551.

Morgan, G. (1998). Images of organization. Thousand Oaks: Sage Publications. 
Pierce, J. L., \& Gardner, D. G. (2004). Self-esteem within the work and organizational context: A review of the organization-based self-esteem literature. Journal of Management, 30(5), 591-622.

Pierce, J. L., Gardner, D. G., Cummings, L. L., \& Dunham, R. B. (1989). Organization-based self-esteem: Construct definition, measurement, and validation. Academy of Management Journal, 32(3), 622-648.

Podsakoff, P. M., MacKenzie, S. B., Lee, J.-Y., \& Podsakoff, N. P. (2003). Common method biases in behavioral research: A critical review of the literature and recommended remedies. Journal of Applied Psychology, 88(5), 879-903.

Reichers, A. E., Wanous, J. P., \& Austin, J. T. (1997). Understanding and managing cynicism about organizational change. Academy of Management Executive, 11(1), 48-59.

Roe, R. A., Ten Horn, L. A., Dienes, E., \& Zinovieva, I. L. (1997). Extended Delft Measurement Kit - Technical Guideline. European Research Programme on Work Motivation and Quality of Working Life (No. WMQDocument 010-97-EXT-EN). Delft, Netherlands: Delft Technical University.

Rusbult, C. E., Farrell, D., Rogers, G., \& Mainous III, A. G. (1988). Impact of exchange variables on exit, voice, loyalty, and neglect: An integrative model of responses to declining job satisfaction. Academy of Management Journal, 31(3), 599-627.

Rusbult, C. E., Johnson, D. J., \& Morrow, G. D. (1986). Determinants and consequences of exit, voice, loyalty, and neglect: Responses to dissatisfaction in adult romantic involvements. Human Relations, 39(1), 4564.

Rusbult, C. E., \& Zembrodt, I. M. (1983). Responses to dissatisfaction in romantic involvements: A multidimensional scaling analysis. Journal of Experimental Social Psychology, 19, 274-293.

Rusbult, C. E., Zembrodt, I. M., \& Gunn, L. K. (1982). Exit, voice, loyalty, and neglect: Responses to dissatisfaction in romantic involvements. Journal of Personality and Social Psychology, 43(6), 1230-1242. 
Settoon, R. P., Bennett, N., \& Liden, R. C. (1996). Social exchange in organizations: Perceived organizational support, leader-member exchange, and employee reciprocity. Journal of Applied Psychology, 81(3), 219-227.

Turnley, W. H., \& Feldman, D. C. (1999). The impact of psychological contract violations on exit, voice, loyalty, and neglect. Human Relations, 52(7), 895922.

Turnley, W. H., \& Feldman, D. C. (2000). Re-examining the effects of psychological contract violations: Unmet expectations and job dissatisfaction as mediators. Journal of Organizational Behavior, 21(1), 2542 .

Van Dyne, L., Ang, S., \& Botero, I. C. (2003). Conceptualizing employee silence and employee voice as multidimensional constructs. Journal of Management Studies, 40(6), 1359-1392.

Van Dyne, L., \& LePine, J. A. (1998). Helping and voice extra-role behaviors: Evidence of construct and predictive validity. Academy of Management Journal, 41(1), 108-119.

Vandenberg, R. J., \& Lance, C. E. (2000). A review and synthesis of the measurement invariance literature: Suggestions, practices, and recommendations for organizational research. Organizational Research Methods, 3(1), 4-70.

Williams, L. J., \& Anderson, S. E. (1991). Job satisfaction and organizational commitment as predictors of organizational citizenship and in-role behaviors. Journal of Management, 17(3), 601-617.

Withey, M. J., \& Cooper, W. H. (1989). Predicting exit, voice, loyalty, and neglect. Administrative Science Quarterly, 34(4), 521-539. 


\section{CHAPTER 6}

\section{Discussion}

\section{Introduction}

Employee cynicism toward the employing organization (organizational cynicism: OC) is an intriguing two-faced phenomenon. On the one hand it has been argued that cynicism has a bad connotation and that it is generally regarded as a socially undesirable attitude or emotion, on the other hand it is also considered an adaptive, and sometimes even positive, response (Andersson, 1996). The fact that cynicism is widespread among organization members in the United States, Europe, and Asia (Dean, Brandes, \& Dharwadkar, 1998) makes it an important phenomenon. This dissertation aims to make a contribution to the accumulating body of knowledge about organizational cynicism by looking into its nature, antecedents, and consequences.

\section{Research questions and answers}

This dissertation addressed the following research questions:

Question 1: What is organizational cynicism?

Question 2: What are the antecedents of organizational cynicism?

Question 3: What are the consequences of organizational cynicism?

These questions were dealt with in two ways. First, we embarked on a review of the extant literature on $\mathrm{OC}$, resulting in an overview of conceptualizations, antecedents and consequences. Next, building on the findings from the literature review, each research question was theoretically and empirically elaborated.

In chapter 2, we reviewed the extant OC literature. As regards the conceptualization of cynicism, an important perspective shared by most researchers is that cynicism is an attitude, rather than a stable disposition or a fixed personality trait. Whereas personality traits or dispositions can hardly be unlearned as a result of disconfirming experiences, the conceptualization of cynicism as an attitude allows for the possibility of change. This conceptualization also implies the adoption of a 3-dimensional belief-affect- 
behavior structure of the cynical attitude, with employees thinking and experiencing cynicism (belief), feeling cynicism (affect), and acting out cynicism (behavior). These components come together in the definition of organizational cynicism as 'the belief that the organization lacks integrity, and negative affect and disparaging behavior consistent with this belief' (Dean et al., 1998, p. 345). Integrity is described in terms of uprightness, honesty, and sincerity, and the belief that the organization falls short of integrity subsumes antecedents of cynicism which have been identified as unmet expectations or broken promises, self-serving behavior, managerial incompetence especially in combination with lofty salaries, not being treated with respect and dignity, meaningless work, no genuine support by management, no real participation in decision making, and so on. The consequences of cynicism reported in the literature all pertain to various forms of psychological disengagement and detachment, such as a decrease in organizational commitment, motivation and job satisfaction, or increased suspicion, distrust and contempt of the organization.

In chapter 3 we used self-consistency theory (Korman, 1970, 1976, 2001) to develop a proces model of organizational cynicism as a self-defensive mechanism. This theory holds that people will be strongly motivated to act and behave in self-consistent ways, i.e. in accordance with their most important values, traits, and competencies. To the extent that they are inhibited to do so, they will likely offer resistance. As primary antecedents of OC we postulated job autonomy as a facilitator of self-consistent behavior, and incongruence between personal key values of employees (achievement, helping and concern for others, fairness, honesty, and integrity) and their perceptions of the corresponding values of the organization, which is supposed to inhibit selfconsistent behavior. Furthermore, we expected that the relationships between these predictors and $\mathrm{OC}$ would be mediated by organization-based self-esteem (OBSE), defined as the self-perceived value employees have of themselves as members of the organization (Pierce, Gardner, Cummings, \& Dunham, 1989). When self-esteem is threatened by a lack of job autonomy or by being forced to comply with organizational values incongruent with personal values, cynicism as psychological disengagement or detachment from the organization is a form of self-defense or 'damage control' to cope with the situation in an effort to maintain a positive self-image (Pierce \& Gardner, 2004). The model was tested on a sample of 174 workers from various Dutch organizations. The results were largely in support of the hypothesized model, with a strong negative relationship 
between OBSE and cynicism $(r=-.55)$, and OBSE partially mediating both relationships.

In Chapter 4 cynicism was regarded as a response to adverse circumstances in the work environment. However, cynicism is by no means the only option for employees to respond to such circumstances. We therefore proposed to include cynicism in the existing exit, voice, loyalty, and neglect (EVLN) model of employee responses. Factor analysis of the data provided by 159 employees of a large Dutch trade union, who were in the midst of an organizational change process, provided clear support for the 5-factor structure of the exit, voice, loyalty, neglect, and cynicism (EVLNC) model. Thus, it was shown that cynicism can be conceptually distinguished from exit, voice, loyalty, and neglect. In other words, cynicism is a response with unique characteristics, not shared by the other responses. Furthermore, building on earlier efforts to predict responses, we used two personality variables (assertiveness and rigidity), two situational variables (role conflict and job autonomy) and a selection of person-situation interactions between these variables to predict responses. As in earlier studies, we were unable to perfectly distinguish between the responses on the basis of these predictors. Cynicism and exit were very much alike. Both were about equally predicted by high role conflict, low autonomy, and low assertiveness.

In Chapter 5 the factor analysis from the previous chapter was replicated. The data provided by 576 employees of a mid-sized hospital provided renewed support for the 5-factor EVLNC model of employee responses. Next, all responses were related to key work outcomes. In relation to the organization these were affective organizational commitment, helping behavior and in-role behavior, in relation to the job these were serviceorientation and job involvement, and in relation to the individual employee these were organization-based self-esteem and stress. We found that voice and loyalty were negatively related to stress and positively to the other responses, and exit, neglect and cynicism showed the opposite pattern of associations. Cynicism was rather strongly associated with low affective organizational commitment and even stronger associated with low organization-based selfesteem, but the relationships with helping behavior, in-role behavior, service orientation, and job involvement were not of practical significance. These insignificant relationships were also found in an earlier study by Johnson and O'Leary-Kelly (2003). 


\section{Theoretical and methodological strengths and limitations}

The empirical studies in this dissertation make some important theoretical and methodological contributions to the study of cynicism in the work environment. First, although it has been assumed that cynicism is a selfreferent attitude (e.g., Kanter \& Mirvis, 1989; Meyerson, 1990), this proposition was never tested by relating cynicism to a self-referent construct. The model that we postulated and tested in chapter 3 is based on this assumption, and the empirical results indicate that organization-based self-esteem indeed intervenes in the relationships between value incongruence and cynicism and between autonomy and cynicism. Second, cynicism has been identified twice as a response to adverse circumstances at work that can be distinguished from alternative responses. Thus, we have shown that cynicism adds to the comprehensiveness of the exit, voice, loyalty, and neglect typology of employee responses. Including cynicism in the model will facilitate more accurate hypotheses about the relationships between antecedents and effects of responses, thereby contributing to a better understanding of important aspects of organizational life. Third, we have shown that structural equation modeling can be fruitfully employed to develop what can be regarded as a spatial map of responses. Importantly, this map was not based on associations between responses and single outcomes, but on patterns of associations with multiple outcomes. Thus, we were able to make robust comparisons between responses. The use of this technique provided additional support for including cynicism in the response model. Finally, we have shown that cynicism indeed makes a contribution to the enhanced prediction of important work outcomes.

The empirical studies reported in this dissertation all show limitations that may confound the validity and generalizability of the findings. The most important limitation is that all studies were designed as cross-sectional point-intime studies. This precludes the inference of causality and the developmental trajectory of cynicism. A second limitation is that all data used in our studies were collected as self-reports. The use of self-reports is a controversial area in organizational research. Some researchers claim that associations between measures obtained through self-reports suffer from problems such as common method variance and the consistency motif, to the extent that research findings become invalidated (Podsakoff, MacKenzie, Lee, \& Podsakoff, 2003; Podsakoff \& Organ, 1986), while others claim that the effects of self-report methods on research cannot be considered self-evident (Crampton \& Wagner III., 1994) and that common methods bias is indeed cause for concern, but it does not 
invalidate many research findings (Doty \& Glick, 1998). A third limitation is the reliability of some measures. Especially the reliability of the measure for job involvement used in the third empirical study is unacceptably low. It is unclear whether this is an unfortunate coincidence, or whether it is due to the scale's properties. Finally, the generalizability of findings is always an issue of concern, although we made an effort to draw diverse samples of employees. Each of the three samples used in this dissertation may be subject to certain biases yielding results that may apply more to these micro-populations, than being representative of relationships in larger populations.

\section{Practical implications and considerations}

Understanding cynicism requires an understanding of developments in the relationship between employees and their employing organization. We have argued that the nature of the employment relationship is changing fundamentally, with organizations and employees struggling to find ways to respond to the new realities in the workplace such, that work continues to provide meaning and organizational success. Some researchers argue that organizations expect their employees to work longer hours, accept greater responsibility, be more flexible and to tolerate continual change and ambiguity, while providing little in return, other than simply a job or employability (Cartwright \& Holmes, 2006). Others go even further, claiming that the excessive control measures aiming to discipline the workers can be regarded as the instruments used to colonize their affect and subjectivity (Gabriel, 1999), a perspective reminiscent of Gareth Morgan's image of the organization as an instrument of domination (Morgan, 1998). When the relationship between employees and the employing organization gets out of balance, employees may be hard-pressed to preserve a sense of dignity, described by Hodson as 'the ability to establish a sense of self-worth and self-respect and to appreciate the respect of others' (Hodson, 2001, p. 3). For employees, cynicism may very well be an alternative sense-making way to adapt to the changing terms of the employment relationship and to preserve their self-worth and self-respect.

In this dissertation we have shown that the impact of cynicism on work performance and social behavior is limited. However, using these results to play down the consequences of cynicism would be a mistake, because cynicism was also found to be associated with low affective commitment toward the organization and low organization-based self-esteem (OBSE). Although affective commitment appears not to predict job performance (see e.g. Keller, 1997), it does predict withdrawal behaviors of turnover and absenteeism 
(Mathieu \& Zajac, 1990), and a decrease in identification with and emotional attachment to the organization. When employees turn their backs on the organization and its management, the psychological tissue of the organization dissolves. In the end, management is heard but not listened to, and employees may start setting their own private goals, and work according to their own rules. When systems of authority and coordination are no longer taken seriously, their effectiveness fades away and forms of organizational anarchy set in. Perhaps even more worrisome is the fact that high levels of cynicism were found to be associated with low OBSE. In their review of the OBSE literature, Pierce and Gardner (2004) state that OBSE is positively related to intrinsic work motivation, job and career attitudes (e.g., satisfaction, commitment and identification), behavioral intentions (e.g., turnover), and constructive workrelated behaviors (e.g., in- and extra-role performance, and adaptation to change). Through low work-related self-esteem, cynicism is potentially related to a much wider range of consequences than a loss of commitment only.

The question how cynicism can be prevented or contained has no easy answer. Referring to the 'rotten apples' metaphor that we discussed in chapter 1, a heavy responsibility rests with management to find ways to ensure organizational effectiveness without 'spoiling the fruit.' Adherence in words to principles of truth and fair dealing, uprightness, honesty, and sincerity is not enough. Alignment between words and deeds is indispensable to create an atmosphere in which cynicism is unlikely to prosper. Management has an important function as a role model, to set the standards for the rest of the organization by walking its talk. Having a mandate to manage depends on establishing managerial competence and organizational coherence, and on the inclusion of employees in decision making and recognition of their skills and contribution to the organization (Hodson \& Roscigno, 2004, p. 675). The difficult task of satisfying multiple stakeholders who frequently have contradictory demands raises the crucial question if and how organizational success and worker dignity and engagement can be combined at all. Hodson and Roscigno state that 'workers want to work effectively and to be productive. When they are allowed the opportunity to do so by coherent organizational practices and by the sollicitation of employee involvement, organizations prosper and dignity at work is maximized' (Hodson \& Roscigno, 2004, p. 701).

\section{Future research directions}

In the previous chapters we have already discussed a number of potential areas for future research. In this section we will briefly list what we 
see as the most fruitful research opportunities, but this list is by no means intended to be exhaustive. First, longitudinal research is needed to identify causal relationships in order to understand the emergence and decline of cynicism. Even though it is questionable whether in real life causality in, for instance, the model presented in chapter 3 will only run from OBSE to cynicism or vice versa, if relationships are found to be uni-directional this will contribute significantly to the understanding of the cynicism process. Longitudinal research is perhaps even more needed to study the development of cynicism over time. How long after the employee's entry in the organization does cynicism start to develop and for what reason(s), and what is the shape of the developmental trajectory? Of particular importance is the question why some manage to reach the stage of 'informed idealism' through cynicism, while others get carried away by it, ending up with burnout. Apparently, for some cynicism helps to preserve self-esteem and self-worth, but for others it makes things even worse. Could it be that certain personality traits, such as conscientiousness, play a key role in this bifurcation? Especially in the light of the high incidence figures discussed earlier, another important issue refers to the dissemination of cynicism. Does cynicism disseminate through processes of social contagion or does it develop on an individual basis only? A third area would be research into behavioral manifestations of cynicism. From psychology we know that consistency between beliefs, affect and behavior is frequently absent. In that case, how do we recognize cynicism? How can we tap into people's beliefs and affect, in the absence of a clear relationship with behavior? And if disparaging behavior is not expressed overtly, what may be the alternatives for employees to act out their cynicism? For instance, could forms of employee silence (Milliken, 2003; Milliken \& Morrison, 2003; Milliken, Morrison, \& Hewlin, 2003; Morrison, 2000; Morrison \& Milliken, 2003; Pinder \& Harlos, 2001; Van Dyne, Ang, \& Botero, 2003) be indicative of cynicism? Finally, are common workers and managers equally susceptible to cynicism? In what respects do they hold similar cynical attitudes and in what respects do their attitudes differ and why?

Wrapping it all up, we believe that, due to its prevalence and implications, organizational cynicism should occupy a prominent place on the agenda of organizational research. To further the continued effectiveness of organizations, this dissertation aims to make a positive contribution to our knowledge and understanding of this important phenomenon, 


\section{References}

Andersson, L. M. (1996). Employee cynicism: An examination using a contract violation framework. Human Relations, 49(11), 1395-1418.

Cartwright, S. \& Holmes, N. (2006). The meaning of work: The challenge of regaining employee engagement and reducing cynicism. Human Resource Management Review, 16, 199-208.

Crampton, S. M. \& Wagner III., J. A. (1994). Percept-percept inflation in microorganizational research: An investigation of prevalence and effect. Journal of Applied Psychology, 79(1), 67-76.

Dean, J. W., Brandes, P. \& Dharwadkar, R. (1998). Organizational cynicism. Academy of Management Review, 23(2), 341-352.

Doty, D. H. \& Glick, W. H. (1998). Common methods bias: Does common methods variance really bias results? Organizational Research Methods, 1, 374-406.

Gabriel, Y. (1999). Beyond happy families: A critical reevaluation of the control-resistance-identity triangle. Human Relations, 52(2), 179-203.

Hodson, R. (2001). Dignity at work. Cambridge, UK: Cambridge University Press.

Hodson, R. \& Roscigno, V. J. (2004). Organizational success and worker dignity: Complementary or contradictory? American Journal of Sociology, 110(3), 672-708.

Johnson, J. L. \& O'Leary-Kelly, A. M. (2003). The effects of psychological contract breach and organizational cynicism: Not all social exchange violations are created equal. Journal of Organizational Behavior, 24(5), 627-647.

Kanter, D. L. \& Mirvis, P. H. (1989). The cynical Americans: Living and working in an age of discontent and disillusionment. San Francisco: JosseyBass. 
Keller, R. T. (1997). Job involvement and organizational commitment as longitudinal predictors of job performance : A study of scientists and engineers. Journal of Applied Psychology, 82(4), 539-545.

Korman, A. K. (1970). Toward an hypothesis of work behavior. Journal of Applied Psychology, 54(1), 31-41.

Korman, A. K. (1976). Hypothesis of work behavior revisited and an extension. Academy of Management Review, 1(1), 50-63.

Korman, A. K. (2001). Self-enhancement and self-protection: Toward a theory of work motivation. In M. Erez, U. Kleinbeck \& H. Thierry (Eds.), Work motivation in the context of a globalizing economy. Mahwah, NJ: Lawrence Erlbaum Associates, Inc.

Mathieu, J. E. \& Zajac, D. M. (1990). A review and meta-analysis of the antecedents, correlates, and consequences of organizational commitment. Psychological Bulletin, 108, 171-194.

Meyerson, D. E. (1990). Uncovering socially undesirable emotions. American Behavioral Scientist, 33(3), 296-307.

Milliken, F. J. (2003). Speaking up, remaining silent: The dynamics of voice and silence in organizations. Journal of Management Studies, 40(6), 13531358 .

Milliken, F. J. \& Morrison, E. W. (2003). Shades of silence: Emerging themes and future directions for research on silence in organizations. Journal of Management Studies, 40(6), 1563-1568.

Milliken, F. J., Morrison, E. W. \& Hewlin, P. F. (2003). An exploratory study of employee silence: Issues that employees don't communicate upward and why. Journal of Management Studies, 40(6), 1453-1476.

Morgan, G. (1998). Images of organization. Thousand Oaks: Sage Publications.

Morrison, E. W. (2000). Organizational silence: A barrier to change and development in a pluralistic world. Academy of Management Review, 25(4), 706-725. 
Morrison, E. W. \& Milliken, F. J. (2003). Speaking up, remaining silent: The dynamics of voice and silence in organizations. Journal of Management Studies, 40(6), 1353-1358.

Pierce, J. L. \& Gardner, D. G. (2004). Self-esteem within the work and organizational context: A review of the organization-based self-esteem literature. Journal of Management, 30(5), 591-622.

Pierce, J. L., Gardner, D. G., Cummings, L. L. \& Dunham, R. B. (1989). Organization-based self-esteem: Construct definition, measurement, and validation. Academy of Management Journal, 32(3), 622-648.

Pinder, C. C. \& Harlos, K. P. (2001). Employee silence: Quiescence and acquiescence as responses to perceived injustices. Research in Personnel and Human Resources Management, 20, 331-369.

Podsakoff, P. M., MacKenzie, S. B., Lee, J.-Y. \& Podsakoff, N. P. (2003). Common method biases in behavioral research: A critical review of the literature and recommended remedies. Journal of Applied Psychology, 88(5), 879-903.

Podsakoff, P. M. \& Organ, D. W. (1986). Self-reports in organizational research: Problems and prospects. Journal of Management, 12(4), 531-544.

Van Dyne, L., Ang, S. \& Botero, I. C. (2003). Conceptualizing employee silence and employee voice as multidimensional constructs. Journal of Management Studies, 40(6), 1359-1392. 


\section{Summary}

Organizational cynicism (OC) is defined as the employee's belief that the organization lacks integrity, and negative affect and disparaging behavior consistent with this belief. This dissertation aims to make a contribution to the accumulating body of scientific knowledge about organizational cynicism by looking into its nature, antecedents, and consequences.

A review of the literature in chapter 2 revealed that most researchers agree that cynicism is an attitude, rather than a stable disposition or a fixed personality trait. Whereas personality traits or dispositions can hardly be unlearned as a result of disconfirming experiences, the conceptualization of cynicism as an attitude allows for the possibility of change. Key to OC is the belief that the organization falls short of integrity, which is described in terms of uprightness, honesty, and sincerity. This may lead to various forms of psychological disengagement and detachment, such as disappointment, disillusionment, anger, frustration, and distrust.

In chapter 3 self-consistency theory was used to advance a model of organizational cynicism as a self-defensive mechanism. The theory postulates that individuals will be motivated to act and behave in accordance with their most important values, traits, and competencies, in order to maintain a positive self-image. As primary antecedents of $\mathrm{OC}$ we postulated job autonomy as a facilitator of self-consistent behavior, and incongruence between personal key values of employees (achievement, helping and concern for others, fairness, honesty, and integrity) and their perceptions of the corresponding values of the organization, which is supposed to inhibit self-consistent behavior. Furthermore, we expected that the relationships between these predictors and OC would be mediated by organization-based self-esteem (OBSE), defined as the self-perceived value employees have of themselves as members of the organization. The model was tested on a sample of 174 Dutch workers from various organizations and the results were largely in support of the hypothesized model.

In chapter 4 we proposed to include cynicism in the existing exit, voice, loyalty, and neglect (EVLN) model of employee responses to adverse circumstances in the work environment. Factor analysis of the data provided by 159 employees of a large Dutch trade union, who were in the midst of an organizational change process, provided clear support for the 5-factor structure of the exit, voice, loyalty, neglect, and cynicism (EVLNC) model. Furthermore, we used two personality variables (assertiveness and rigidity), two situational 
variables (role conflict and job autonomy) and a selection of person-situation interactions between these variables to predict responses. As in earlier studies, we were unable to perfectly distinguish between the responses on the basis of these predictors. Cynicism and exit were very much alike. Both were about equally predicted by high role conflict, low autonomy, and low assertiveness.

In chapter 5 the factor analysis from the previous chapter was replicated. The data provided by 576 employees of a mid-sized hospital provided renewed support for the 5-factor EVLNC model of employee responses. Next, all responses were related to key work outcomes: In relation to the organization these were affective organizational commitment, helping behavior and in-role behavior, in relation to the job these were serviceorientation and job involvement, and in relation to the individual employee these were organization-based self-esteem and stress. We found that voice and loyalty were negatively related to stress and positively to the other outcomes, and exit, neglect and cynicism showed the opposite pattern of associations. Cynicism was rather strongly associated with low affective organizational commitment and even stronger associated with low organization-based selfesteem, but the relationships with helping behavior, in-role behavior, service orientation, and job involvement were not of practical significance.

In chapter 6 we discussed theoretical and methodological contributions and practical implications of our studies. An important theoretical contribution is that we were the first to actually test the proposition of cynicism as a selfreferent attitude, by relating it to personal values and to work-related selfesteem. Both explained significant amounts of variance in cynicism. Another theoretical contribution is that cynicism was shown, not once but twice, to be distinct from alternative employee responses to adverse circumstances at work. Accordingly, there is ample reason for cynicism to be included in the exit, voice, loyalty, and neglect model of responses. Discussing the practical implications of this research, we have argued that although cynicism is not significantly related to work outcomes, there is no reason to play down its importance for the well-being of employees and the organization. The fact that significant relationships with affective organizational commitment and workrelated self-esteem were found implies that the consequences of cynicism should not be underestimated. The prevention of cynicism is largely in the hands of management. Cynicism implies a decline in the legitimacy of management, as perceived by employees. Restoring this legitimacy requires the solicitation of employees' engagement, through honest and sincere participation in decision making and recognition of their talents and contributions. For a 
mandate to manage, integrity is indispensible. Finally, we have indicated some promising directions for future research into this important area of organizational behavior. 


\section{Samenvatting}

Organisatie cynisme (OC) is gedefinieerd als het geloof bij werknemers dat de organisatie niet integer is, en negatieve gevoelens en minachtend gedrag dat met dit geloof in overeenstemming is. Deze dissertatie heeft als doel een bijdrage te leveren aan de groeiende hoeveelheid wetenschappelijke kennis over OC door te kijken naar aard, oorzaken en gevolgen.

Een beschrijving van de bestaande literatuur in hoofdstuk 2 laat zien dat cynisme een attitude is, meer dan een stabiele dispositie of een persoonlijkheidskenmerk. Dit is erg belangrijk want persoonlijkheidskenmerken of disposities kunnen moeilijk door ervaringen worden afgeleerd, maar de conceptualisering van cynisme als attitude laat zien dat verandering mogelijk is. De kern van OC is het geschonden vertrouwen in de integriteit van de organisatie, waarbij integriteit wordt omschreven in termen van rechtschapenheid, eerlijkheid en oprechtheid. Dit kan leiden tot allerlei vormen van psychologische onthechting, zoals teleurstelling, woede, frustratie en wantrouwen.

In hoofdstuk 3 is self-consistency theorie gebruikt om een model te ontwikkelen van cynisme als een zelfbeschermingsmechanisme. Deze theorie houdt in dat mensen er naar zullen streven zich te gedragen in overeenstemming met hun belangrijkste eigenschappen, competenties en waarden, om zo een positief eigenbeeld te behouden. Als antecedenten (voorspellers) van OC veronderstelden we autonomie als facilitator van dergelijk consistent gedrag, en discongruentie tussen een aantal belangrijke persoonlijke waarden van medewerkers (waardering van prestaties, het helpen van en bekommernis om anderen, rechtvaardigheid, eerlijkheid en integriteit) en hun percepties van het belang dat door de organisatie aan deze waarden wordt gehecht, in de veronderstelling dat de spanning tussen persoonlijke en organisatiewaarden de mogelijkheid tot consistent gedrag juist vermindert. Bovendien veronderstelden we dat de relaties van beide voorspellers met OC zouden worden gemedieerd door werkgerelateerde zelfwaardering, dat is de mate waarin medewerkers zich een gewaardeerd lid van de organisatie voelen. Het model is getest onder 174 werknemers van verschillende organisaties en de resultaten ondersteunden het model grotendeels.

In hoofdstuk 4 stelden we voor cynisme op te nemen in een bestaand model van reacties van medewerkers op onplezierige omstandigheden op het werk: het exit, voice, loyalty, and neglect model (EVLN). Factor analyse van data verkregen van 159 medewerkers van een grote Nederlandse vakbond, die 
op dat moment een proces van organisatieverandering doormaakten, ondersteunde de 5-factor structuur van het exit, voice, loyalty, neglect, and cynicism (EVLNC) model. Vervolgens hebben we twee persoonlijkheidsvariabelen (assertiviteit en rigiditeit), twee omgevingsvariabelen (rolconflict en autonomie) en interacties tussen deze variabelen gebruikt om deze 5 reacties te voorspellen. Net als in andere studies is dat slechts ten dele gelukt. Cynisme en exit leken erg veel op elkaar. Beiden werden in ongeveer gelijke mate voorspeld door hoog rolconflict, lage autonomie en lage assertiviteit.

In hoofdstuk 5 is de factor analyse uit het vorige hoofdstuk herhaald. De antwoorden verkregen van 576 werknemers van een middelgroot ziekenhuis ondersteunden opnieuw de 5-factor structuur van het EVLNC model. Vervolgens zijn de reacties gerelateerd aan belangrijke gevolgen: in relatie tot de organisatie waren dat affectieve betrokkenheid bij de organisatie, het helpen van anderen en rolgedrag, in relatie tot het werk waren dat dienstbaarheid en betrokkenheid bij het werk en in relatie tot de individuele medewerker waren dat werkgerelateerde zelfwaardering en stress. Voice en loyalty waren negatief gerelateerd aan stress en positief aan de andere uitkomsten en bij exit, neglect en cynisme was dit andersom. Cynisme was tamelijk sterk gerelateerd aan lage affectieve betrokkenheid bij de organisatie en nog sterker aan lage werkgerelateerde zelfwaardering, maar de relatie met het helpen van anderen, rolgedrag, dienstbaarheid en betrokkenheid bij het werk was in praktische zin niet significant.

In hoofdstuk 6 zijn de uit de verschillende studies voortvloeiende theoretische en methodologische bijdragen besproken, alsmede de implicaties voor de praktijk. Een belangrijke theoretische bijdrage is dat wij met dit onderzoek de eersten waren die de veronderstelling hebben getest dat cynisme gerelateerd is aan het zelfbeeld van medewerkers door het te relateren aan persoonlijke waarden en aan werkgerelateerde zelfwaardering. Beiden verklaarden aanzienlijke porties variantie in cynisme. Een andere theoretische bijdrage is dat we niet een keer, maar twee keer hebben aangetoond dat cynisme kan worden onderscheiden van alternatieve reacties van medewerkers op onplezierige omstandigheden op het werk. We denken dan ook dat er op grond van deze uitkomsten voldoende reden is cynisme op te nemen in het exit, voice, loyalty en neglect model. Bij de bespreking van de praktische implicaties van het onderzoek hebben we gesteld dat, hoewel cynisme niet of nauwelijks gerelateerd is aan belangrijke werkgerelateerde uitkomsten, er geen enkele reden is het belang van cynisme voor het welbevinden van zowel medewerkers als organisatie te bagatelliseren. Het feit dat we significante verbanden hebben 
gevonden met affectieve betrokkenheid bij de organisatie en met werkgerelateerde zelfwaardering houdt in dat de gevolgen van cynisme niet mogen worden onderschat. Het voorkomen van cynisme ligt voor een groot deel in de handen van het management. Cynisme houdt in een vermindering van de door medewerkers ervaren legitimiteit van het management. Het herstel van deze legitimiteit vergt dat men de betrokkenheid van medewerkers zoekt, door ze op een oprechte manier te betrekken bij de besluitvorming en door hun talenten en bijdragen aan de organisatie te waarderen. Voor dit alles is integriteit onontbeerlijk. Tenslotte hebben we een aantal veelbelovende richtingen aangegeven voor toekomstig onderzoek in dit belangrijke deelgebied van organisatiegedrag. 


\section{Biography of Fons Naus}

Fons Naus (October 29, 1955) was born in Venray, the Netherlands. Between 1968 and 1974 he enjoyed his Gymnasium B high school education at the Boschveldcollege in Venray. Following high school he worked in the private and public sector for twenty years. Meanwhile, he graduated in Business Administration at the Open University of the Netherlands in 1995. Then he redirected his focus toward academia. First, he was employed as a lecturer at Tilburg University until the end of 2000. Then he moved to Maastricht University, where he was a lecturer for two years and on November 1, 2002, he started working on his $\mathrm{PhD}$. Currently, he is again employed at Tilburg University. 